NAA-SR-12118

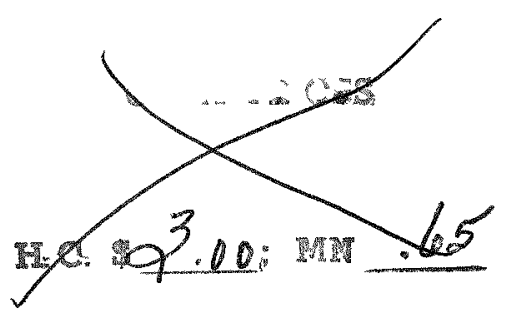

Instruments

\title{
Characteristics of Two Commercial High-Temperature Electric Resistance Strain Gages
}

\author{
By \\ M. M. Lemcoe
}

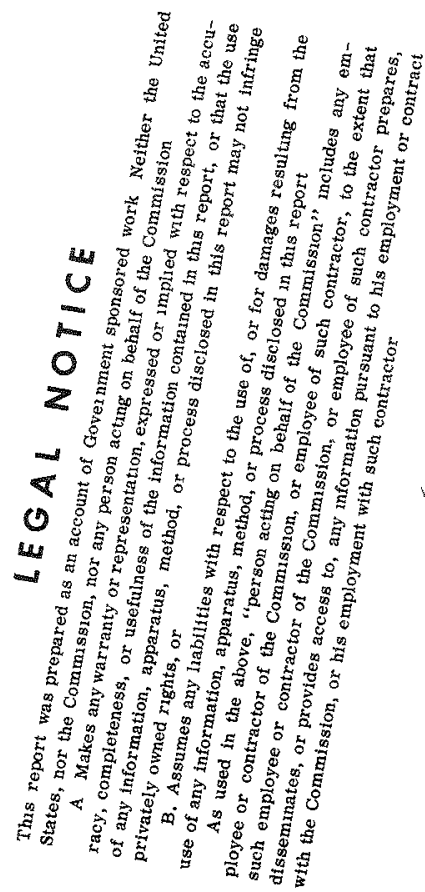

\section{Liquid Metal Engineering Center Operated for}

the U S Atomic Energy Commission by Atomics Internatıonal

A Drvision of North American Aviation inc

Contract: AT(04-3)-700

Issued: AUG 151967 


\section{DISCLAIMER}

This report was prepared as an account of work sponsored by an agency of the United States Government. Neither the United States Government nor any agency Thereof, nor any of their employees, makes any warranty, express or implied, or assumes any legal liability or responsibility for the accuracy, completeness, or usefulness of any information, apparatus, product, or process disclosed, or represents that its use would not infringe privately owned rights. Reference herein to any specific commercial product, process, or service by trade name, trademark, manufacturer, or otherwise does not necessarily constitute or imply its endorsement, recommendation, or favoring by the United States Government or any agency thereof. The views and opinions of authors expressed herein do not necessarily state or reflect those of the United States Government or any agency thereof. 


\section{DISCLAIMER}

Portions of this document may be illegible in electronic image products. Images are produced from the best available original document. 


\section{DISTRIBUTION}

This report has been distributed according to the category

"Instruments" as given in the Standard Distribution for Unclassified Scientific and Technical Reports, TID-4500.

\section{ACKNOWLEDGMENT}

This work could not have been accomplished without the guidance and valuable comments from many sources, and in particular the painstaking work of Messrs. G. J. Czechanski and M. Dudley, who performed the laboratory portion of the work, and Mmes. B. Dray and M. Reed, who were responsible for programming the data and checking the results from the digital computer. 
Abstract....................... 8

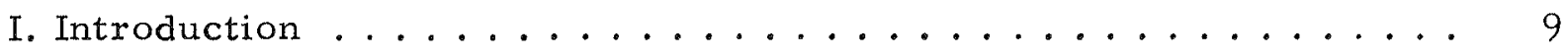

A. Performance Parameters ...................... 10

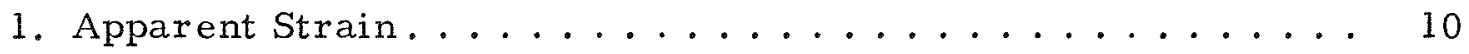

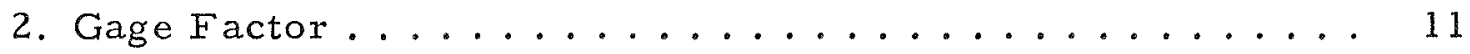

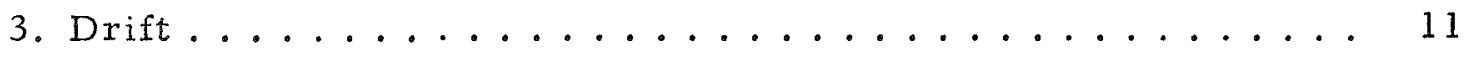

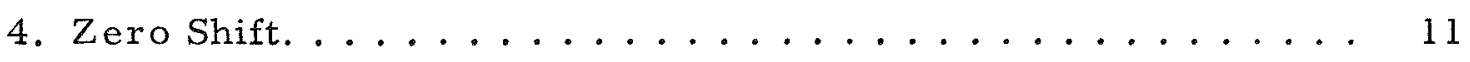

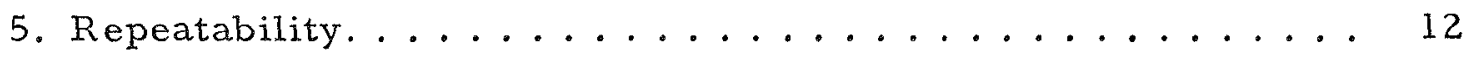

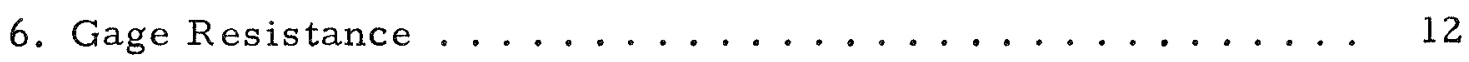

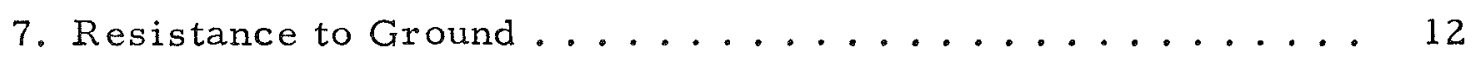

B. Performance Requirements ................... 13

C. Selection of Gages for Test ................... 16

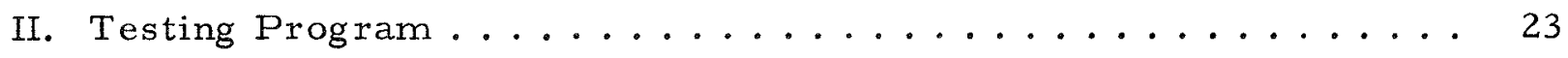

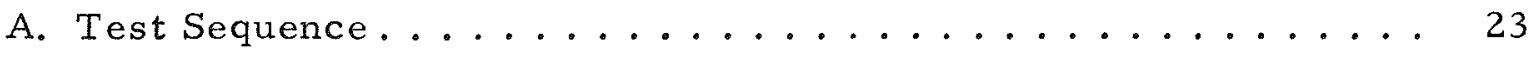

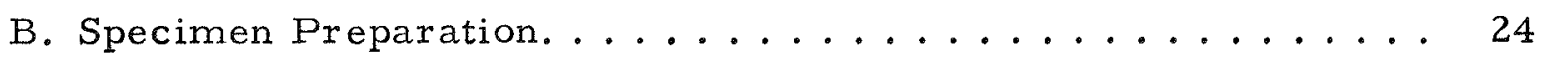

C. Test Apparatus and Procedures ................... 25

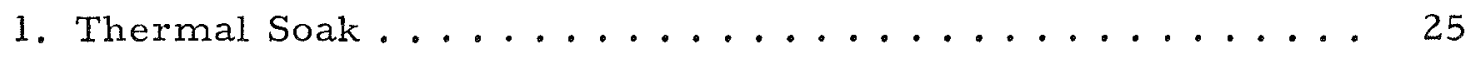

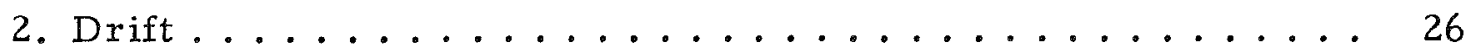

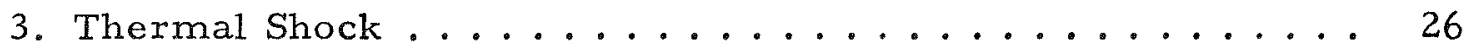

4. Gage Factor and Linearity. . . . . . . . . . . . 28

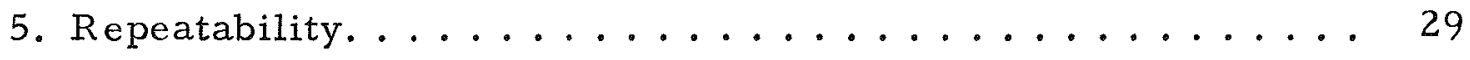

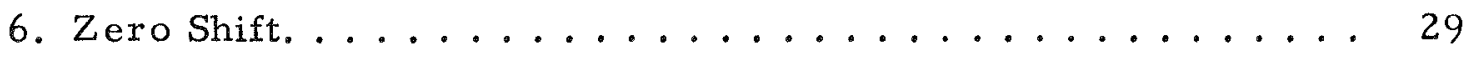

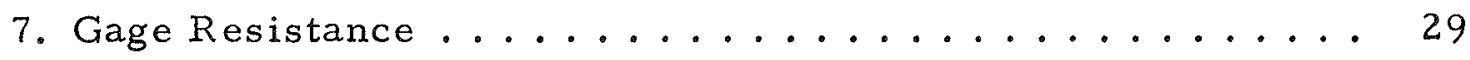

8. Resistance to Ground ..................... . . 29

9. Apparent Strain vs Temperature............... 29

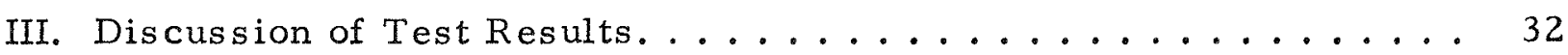

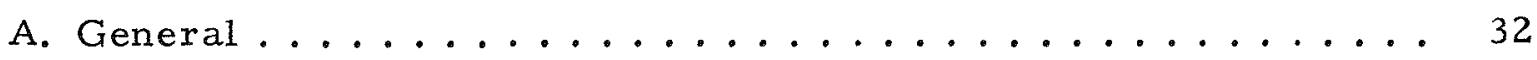

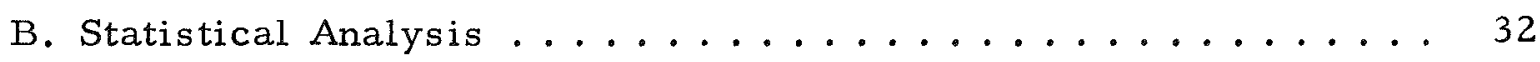

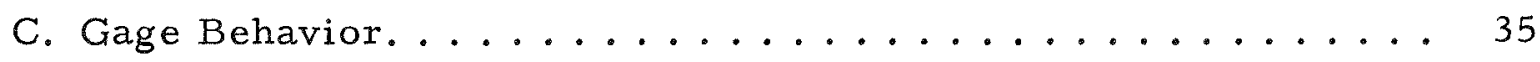

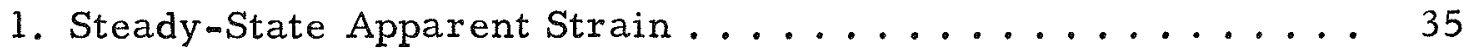

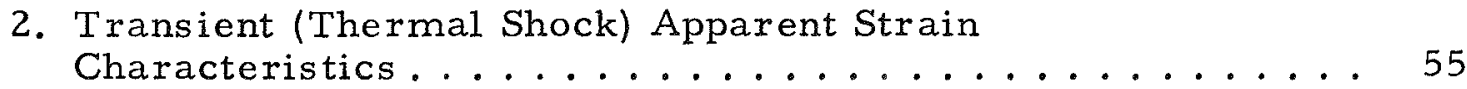


3. Gage Factor Characteristics ................. 69

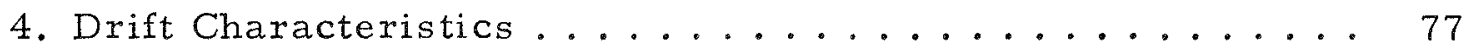

5. Linearity and Repeatability Under Mechanical Strain ..... 81

6. Resistance to Ground vs Temperature Characteristics . . . . 87

7. Variations in Gage Resistance .............. 87

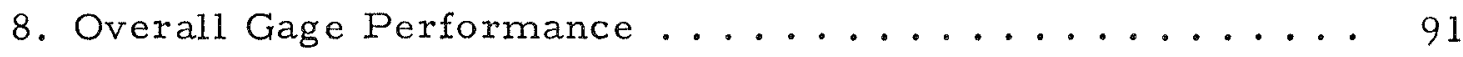

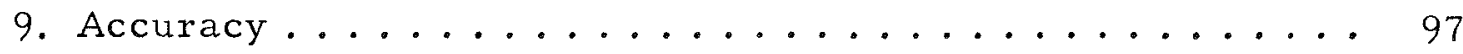

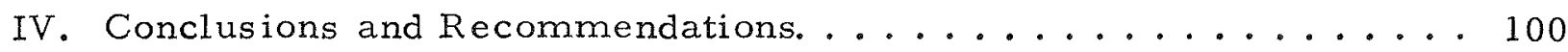

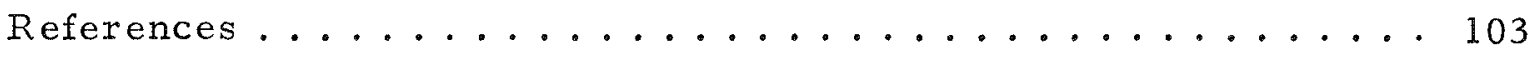

\section{TABLES}

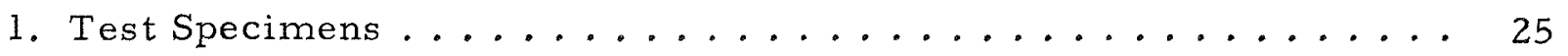

2. Variations in Initial Apparent Strain (Series 1) at

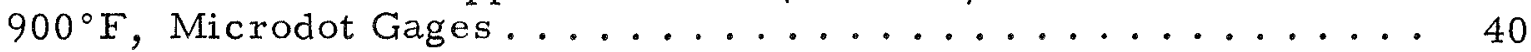

3. Series-to-Series Variations in Apparent Strain at $900^{\circ} \mathrm{F}$, Microdot Gages........................ 41

4. Microdot Gage Performance. . . . . . . . . . . . . 93

5. BLH Gage Performance. .......................... 96

\section{FIGURES}

1. Microdot Gage

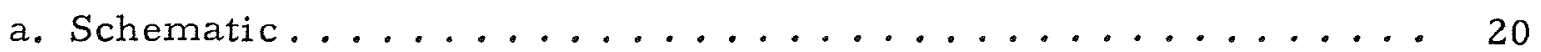

b. Photograph of Installation .................. 20

2. BLH Gage

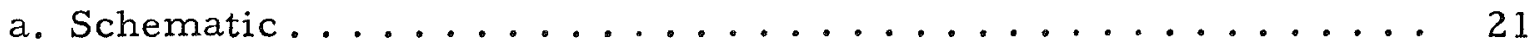

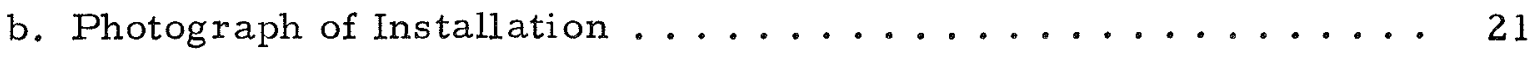

3. Gage Evaluation Sequence ....................... 22

4. Radiant Heating Thermal Shock Test Furnace . . . . . . . . . 27

5. Constant Moment Fixture. . . . . . . . . . . . . . . 27

6. Circuit for Microdot Gage With Temperature Compensation

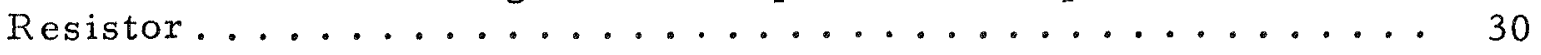

NAA-SR -12118 


\section{FIGURES}

Page

7. Average Initial Apparent Strain vs Temperature, Microdot Specimens $M-1$ Through $M-3$, series $1 \ldots \ldots \ldots$

8. Average Initial Apparent Strain vs Temperature, Microdot

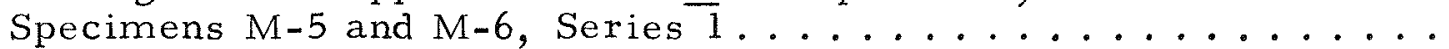

9. Average Apparent Strain vs Temperature, Microdot Specimens $M-1$ Through $\bar{M}-3$, Cycle 1 , Series 1 Through $6 \ldots$

10. Average Apparent Strain vs Temperature, Microdot Specimens M-5 and M-6, Cycle 1, Series 1 Through $4 \ldots . .$.

11. Apparent Strain vs Temperature, With Confidence and Tolerance Limits, Microdot Specimens $\mathrm{M}-1, \mathrm{M}-2$, and $\mathrm{M}-3$, Gages No. 1 and No. 2, Series 1, Cycle 1.............

12. Apparent Strain vs Temperature, With Confidence and Tolerance Limits, Microdot Specimens $\mathrm{M}-1, \mathrm{M}-2$, and $\mathrm{M}-3$, Gages No. 1 and No. 2, Series 2, Cycle 1.............

13. Apparent Strain vs Temperature, With Confidence and Tolerance Limits, Microdot Specimens $\mathrm{M}-1, \mathrm{M}-2$, and $\mathrm{M}-3$, Gages No. 1 and No. 2, Series 3, Cycle 1............

14. Apparent Strain vs Temperature, With Confidence and Tolerance Limits, Microdot Specimens $\mathrm{M}-1, \mathrm{M}-2$, and $\mathrm{M}-3$, Gages No. 1 and No. 2, Series 4, Cycle 1............

15. Apparent Strain vs Temperature, With Confidence and Tolerance Limits, Microdot Specimens $M-1, M-2$, and $M-3$, Gages No. 1 and No. 2, Series 5, Cycle 1............

16. Apparent Strain vs Temperature, With Confidence and Tolerance Limits, Microdot Specimens $M-1, M-2$, and $M-3$, Gages No. 1 and No. 2, Series 6, Cycle 1............

17. Apparent Strain vs Temperature, Microdot Specimens $M-1$, $\mathrm{M}-2$, and $\mathrm{M}-3$, With Optimum Temperature Compensation

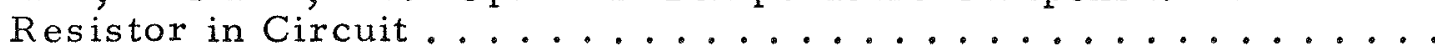

18. Apparent Strain vs Temperature, With Confidence and Tolerance Limits, Microdot Specimens $\mathrm{M}-1, \mathrm{M}-2$, and $\mathrm{M}-3$, Gages No. 1 and No. 2, With Optimum Temperature Compensation Resistor in Circuit ...............

19. Initial Apparent Strain vs Temperature, BLH Specimens B-1, and B-5 Through B-8, Gages No. 1 and No. 2, Series 1, Cycle 1.... 


\section{FIGURES}

Page

20. Initial Apparent Strain vs Temperature, BLH Specimens B-1, B-7, and B-8, Gages No. 1 and No. 2, Series 1, Cycle 2..... 54

21. Initial Apparent Strain vs Temperature, With Confidence and Tolerance Limits, BLH Specimens, Series 1, Cycle 2...... 56

22. Apparent Strain vs Temperature, With Confidence and Tolerance Limits, BLH Specimens B-1, and B-5 Through B-8,

Gages No. 1 and No. 2, Series 1, Cycle 2............

23. Transient (Thermal Shock) Apparent Strain vs Temperature, Microdot Specimen $M-1,10^{\circ} \mathrm{F} / \mathrm{sec}$, Series 1 Through $6 \ldots . .$.

24. Transient (Thermal Shock) Apparent Strain vs Temperature, Microdot Specimen M-1, $20^{\circ} \mathrm{F} / \mathrm{sec}$, Series 1 Through $6 \ldots$

25. Transient (Thermal Shock) Apparent Strain vs Temperature, Microdot Specimen M-1, 30 $\mathrm{F} / \mathrm{sec}$, Series 1 Through $6 \ldots . .$.

26. Apparent Strain vs Temperature for Different Heating Rates, Microdot Specimen $\mathrm{M}-1 \ldots \ldots \ldots \ldots \ldots$

27. Transient (Thermal Shock) Apparent Strain vs Temperature, Microdot Specimen M-5, $10^{\circ} \mathrm{F} / \mathrm{sec}$, Series 1 Through $4 \ldots \ldots$

28. Transient (Thermal Shock) Apparent Strain vs Temperature, Microdot Specimen $\mathrm{M}-7,10^{\circ} \mathrm{F} / \mathrm{sec}$, Series $1 \ldots \ldots$

29. Average Transient (Thermal Shock) Apparent Strain vs Temperature, BLH Specimens, $5^{\circ} \mathrm{F} / \mathrm{sec}$, Series 1........

30. Average Transient (Thermal Shock) Apparent Strain vs Temperature, BLH Specimens, $10^{\circ} \mathrm{F} / \mathrm{sec}$, Series 1.......

31. Average Transient (Thermal Shock) Apparent Strain Vs Temperature, BLH Specimens, $25^{\circ} \mathrm{F} / \mathrm{sec}$, Series 1.......

32. Gage Factor vs Temperature, With Confidence and Tolerance Limits, Microdot Specimens M-1 Through M-3, Series 1......

33. Gage Factor vs Temperature, With Confidence and Tolerance Limits, Microdot Specimens M-1 Through M-3, Series 3......

34. Gage Factor vs Temperature, With Confidence and Tolerance Limits, Microdot Specimens M-1 Through M-3, Series 6......

35. Gage Factor vs Temperature, With Confidence and Tolerance Limits, Microdot Specimens $M-5$ and $M-6$, Series 1....... 


\section{FIGURES}

36. Gage Factor vs Temperature, With Confidence and Tolerance Limits, Microdot Specimens $\mathrm{M}-5$ and $\mathrm{M}-6$, Series 2........

37. Gage Factor vs Temperature, With Confidence and Tolerance Limits, Microdot Specimens $M-5$ and $M-6$, Series 3.........

38. Gage Factor vs Temperature, With Confidence and Tolerance Limits, BLH Specimens B-1, B-2, and B-5 Through B-8,

Series $1 \ldots \ldots \ldots \ldots \ldots \ldots \ldots$

39. Drift vs Time, $900^{\circ} \mathrm{F}$, With Confidence and Tolerance Limits, Microdot Specimens $\mathrm{M}-1$ Through $\mathrm{M}-3 \ldots \ldots \ldots \ldots$

40. Drift vs Time, $900^{\circ} \mathrm{F}$, With Confidence and Tolerance Limits, Microdot Specimens $M-5$ and $M-6 \ldots \ldots \ldots \ldots$

41. Drift vs Time, $1200^{\circ} \mathrm{F}$, With Confidence and Tolerance Limits,

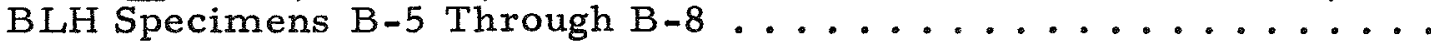

42. Measured Strain vs Calculated Strain, Microdot Specimens M-1 Through $\mathrm{M}-3 \ldots \ldots \ldots \ldots \ldots \ldots$

43. Measured Strain vs Calculated Strain, Microdot Specimens M-5 and $M-6 \ldots \ldots \ldots \ldots \ldots \ldots \ldots$

44. Measured Strain vs Calculated Strain, Microdot Specimen M-7...

45. Measured Strain vs Calculated Strain, BLH Specimens . . . . . .

46. Resistance to Ground vs Temperature, Microdot Gages. . . . . . 86

47. Resistance to Ground vs Temperature, BLH Gages. . . . . . . . 88

48. Variations in Gage Resistance, Microdot Specimens $M-1$ Through $\mathrm{M}-3 \ldots \ldots \ldots \ldots \ldots \ldots$

49. Variations in Gage Resistance, Microdot Specimens $M-5$

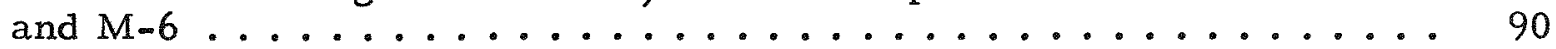

50. Variations in Gage Resistance, BLH Specimens . . . . . . . . 92 


\begin{abstract}
A technical evaluation of two types of commercially available high-temperature electric resistance strain gages is reported. These gages, the BLH Type HT 1212-5A and Microdot Type SG420, were selected for evaluation because of the need for more reliable electric resistance strain gages for high-temperature stress or strain measurements, and process instrumentation for use in the temperature range of 900 to $1200^{\circ} \mathrm{F}$. The BLH gage is rated by the manufacturer as a 1000 to $1200^{\circ} \mathrm{F}$ gage; the Microdot gage is rated as a $900^{\circ} \mathrm{F}$ gage. Instrumentation of this type is needed to determine or insure component structural integrity and overall system reliability of fast breeder reactors.

These two types of gages were considered to be the most promising of the commercial high-temperature gages for sodium component loop testing. Other types of commercial gages were ruled out because of their temperature limitations, their inability to be properly installed or cured in the field, and other factors which are discussed in this report.

The results of this evaluation indicate that the BLH gage is not suitable as a $1200^{\circ} \mathrm{F}$ gage for measurements on austenitic stainless steel components which are subjected to both steady-state and transient temperature conditions and heating rates in excess of $5^{\circ} \mathrm{F} / \mathrm{sec}$.

The Microdot gage, on the other hand, was found satisfactory for use on austenitic stainless steel components for temperatures up to $900^{\circ} \mathrm{F}$, under both steady-state and transient conditions, for heating rates up to at least $30^{\circ} \mathrm{F} / \mathrm{sec}$.

It was therefore concluded that, while there are electric resistance strain gages satisfactory for use up to $900^{\circ} \mathrm{F}$, there are no suitable commercial gages for use at $1200^{\circ} \mathrm{F}$. The results reported, which include a statistical analysis of the data, relate only to the evaluation of the previously mentioned commercial gages.
\end{abstract}

NAA-SR - 12118 


\section{INTRODUCTION}

The electric resistance strain gage has been accepted and used extensively by engineers and scientists to obtain solutions to stress, deformation, or instrumentation problems which would be otherwise unobtainable. These gages have been used to translate hydraulic and mechanical phenomena into electric signals which provide a reliable and relatively accurate measure of such parameters as load, pressure, torque, acceleration, flow, level, and strain. From the measured strains, stresses may be computed by means of Hooke's generalized stress-strain relations. There are literally hundreds of different sizes, shapes, and types of gages that are commercially available for use under a wide spectrum of environmental conditions, ranging from the cryogenic to the high-temperature regime.

Provided these gages are installed by competent and experienced technicians, and that proper technical judgement is exercised in the selection of the gage type (in terms of the anticipated environmental conditions), good accuracy can be expected at temperatures up to $900^{\circ} \mathrm{F}$, in most situations. However, above $900^{\circ} \mathrm{F}$, commercial gages have not been evaluated for applications involved in the testing of sodium or other liquid metal components. The program described in this report covers the evaluation of commercial gages for use in sodium loops, including gage requirements, gage selection, test procedures, and results. In general, no commercial gage was found suitable for use to $1200^{\circ} \mathrm{F}$, under the conditions of the test, but the Microdot SG420 was found suitable to $900^{\circ} \mathrm{F}$.

The broad objectives of this program are to:

1) Evaluate specific commercial gages for experimental stress or strain measurements on sodium components, or for use in process instrumentation; and, if suitable commercial gages are not available,

2) Develop suitable gages for such applications.

Included within the scope of this program is the development of encapsulated high-temperature gages for measurement of strain in sodium environments. Subsequent reports will cover the other objectives of the program.

NAA-SR - 12118 


\section{A. PERE ORMANCE PAR AMETERS}

Of the many gage parameters, the important ones which provide a measure of the performance and accuracy of a high-temperature gage are apparent strain, gage factor, drift, zero shift, repeatability, gage resistance, and resistance to ground. These parameters, although in somewhat general use, will be defined here and discussed in the interest of clarity and completeness.

\section{Apparent Strain}

Apparent strain is the spurious or false signal induced by changes in gage resistivity due to temperature and a mismatch between the coefficients of thermal expansion of the gage filament and the material to which the gage is bonded. Mathematically, it may be expressed as:

$$
\epsilon_{\text {app }}=\left[\left(\alpha_{m}-\alpha_{g}\right)+\frac{T C}{\mathrm{GF}}\right] \Delta \mathrm{T}
$$

where,

$$
\begin{aligned}
& \epsilon_{\text {app }}=\text { Apparent strain } \\
& \alpha_{\mathrm{m}}=\text { Coefficient of thermal expansion of the structure to which the gage } \\
& \quad \text { is bonded } \\
& \alpha_{\mathrm{g}}=\text { Coefficient of thermal expansion of the gage filament } \\
& \mathrm{GF}=\text { Gage factor } \\
& \mathrm{TC}=\text { Temperature coefficient of resistance } \\
& \Delta \mathrm{T}=\text { Temperature change }
\end{aligned}
$$

In short, it is that portion of the indicated strain which is the algebraic difference between the strain indicated by the readout equipment (hereinafter referred to as indicated strain) and the real strain being measured on the surface of the test article. Like unit strain, it is a dimensionless quantity which is generally designated in units of millionths of an inch per inch ( $\mu$ in./in.), or simplymicrostrain $(\mu \epsilon)$. Since the apparent strain must be subtracted from the indicated strain before the real or true strain can be determined, it is desirable that the magnitude of the apparent strain of a gage be as small and predictable as possible, in the interest of accuracy. It is not within the scope of this report to discuss, in general, strain gage circuits or ways in which apparent strain may be minimized or eliminated by special resistance networks. Many references are

$$
\text { NAA-SR - } 12118
$$


available on this subject; Reference 1 is one such source. In the case of the BLH gage, the apparent strain may be substantially reduced by using a dummy gage in the adjacent leg of the bridge; or, in the case of the Microdot gage, by using a temperature compensation resistor of a specified value in series with the active gage. Where it is not feasible to use a dummy gage or a temperature compensation resistor, one must then have available the apparent strain vs temperature curve for the gage.

\section{Gage Factor}

Gage factor is the ratio of the unit change in gage resistance to the unit change in strain in the metal to which the gage is bonded. It is dimensionless, and is a measure of the gage's sensitivity. It varies with temperature and with environmental and life exposure. To take quantitative strain measurements, the gage factor must be known.

\section{Drift}

Drift is the change in indicated strain of a gage, with time, in a stress-free condition, under constant temperature. It is generally expressed as a total drift (in units of microstrain per a given time interval), or as a drift rate (in units of microstrain per unit time). Like apparent strain, drift introduces an error which must be accounted for. The error is of particular significance where measurements over extended periods of time at temperature are involved. Its effect may be minimized by using a dummy gage, or by prestabilizing the gage for a minimum of $16 \mathrm{hr}$ at a temperature above the maximum test temperature. If it is not feasible to do this on the test article, the gage (in many instances) can be stabilized in a laboratory furnace. Drift may also be accounted for by applying a correction obtained from the drift vs time curve for the gage at the temperature in question.

\section{Zero Shift}

This is a general term, often related to hysteresis effects, associated with mechanical or thermal cycling.

a. Mechanical Zero Shift

Mechanical zero shift is the difference in the indicated strain reading between an increasing and a decreasing mechanical strain cycle (generally taken at zero mechanical strain) under constant temperature conditions. 


\section{b. Thermal Zero Shift}

Thermal zero shift is the difference in the indicated strain reading between an increasing and a decreasing thermal cycle (generally referred to ambient temperature) under constant (including zero) mechanical strain conditions. This gage parameter is of particular importance where repeated transient strain measurements are made, since the errors arising from zero shift can be cumulative. Zero shift may be minimized by strain and/or temperature cycling the gage slightly above the maximum temperature or strain level it will "see" during testing. Generally, three cycles are sufficient to stabilize a good gage. Where it is not feasible to accomplish this on the test article, the gage may often be cycled in a laboratory furnace.

\section{Repeatability}

Repeatability is the ability of the gage to faithfully reproduce the same indicated strain vs temperature curves, or indicated strain vs applied mechanical strain curves, when repeatedly subjected to the same set(s) of conditions. Without good repeatability, precalibration of a gage may not be meaningful, since the gage characteristics then become time dependent and also dependent upon the number of cycles to which the gage is subjected. Good gage repeatability and small zero shift go hand in hand. Errors stemming from lack of repeatability may be minimized by prestabilization, cycling, and the use of a dummy or temperature compensation resistor. Good repeatability is essential where accurate strain measurements must be made under repeated transient conditions.

\section{Gage Resistance}

This is the resistance of the gage, as determined by an accurate ohmmeter or a wheatstone bridge, and is usually measured at room temperature. The manufacturer generally provides such information, and guarantees the resistance of each gage to be within a given tolerance. The exact resistance of a gage is generally not important, provided the gage factor is known. However, uniformity of gage resistance is of concern, where multichannel signal conditioning and readout equipment is involved.

\section{Resistance to Ground}

This characteristic is sometimes referred to as the leakage resistance. It is the resistance between the strain gage lead wires and the material to which

$$
\text { NAA-SR - } 12118
$$


the gage is bonded. For room-temperature measurements, this parameter is of little or no consequence for gages that have been properly installed. However, at elevated temperatures, the ceramic cement or Rokide [used to bond the gage to the structure (or to the strain tube, in the case of the Microdot gage)] becomes conductive, electrically, and introduces a shunting effect, which in turn results in a spurious strain indication. Fortunately, for a good gage that has been properly installed, the magnitude of this error is small. Mathematically, it can be shown that the change in gage factor due to this shunting effect is negligible, and that the resistance to ground at temperature would have to drop to $1 \mathrm{M} \Omega$ to produce an error of $\sim 30 \mu \epsilon$, assuming a gage factor of 4 and a gage having a resistance of $120 \Omega$. For a $10 \mathrm{M} \Omega$ resistance to ground, the error would be only $3 \mu \epsilon$.

\section{B. PERF ORMANCE REQUIR EMENTS}

Ideally, gages used for steady-state and transient testing at el evated temperatures should meet the following requirements:

1) Be available commercially at a reasonable price with reasonable delivery schedules

2) Be self-temperature compensating

3) Show little variation in gage factor with temperature changes

4) Be stable, driftwise, at temperatures up to the maximum test temperature

5) Exhibit a minimum amount of apparent strain over the operating temperature range

6) Be uniform, from gage to gage, within close limits

7) Exhibit little hysteresis or zero shift with temperature or strain cycling

8) Be linear, over a large strain range

9) Exhibit good repeatability when subjected to the same time-temperaturestrain history

10) Have good mechanical and thermal fatigue or shock resistance 
11) Be fabricated from materials having the same, or nearly the same, coefficient of thermal expansion as the test article

12) Be available in gage lengths down to at least $1 / 8$ in.

13) Have a protective covering, to avoid damage due to handling or the effects of moisture or corrosion

14) Be capable of being installed in the field, in such a manner that a reliable bond is assured for the duration of the test

15) Be of such a design that the strain sensing element "sees" the same temperature as the test article material to which it is attached, with little or no time $1 \mathrm{ag}$.

The ideal requirements are enumerated to describe an ultimate goal for strain gage evaluation and development, even though all items are not achievable. The specific performance requirements which were the criteria for the evaluation of commercial gages in this report are:

1) They must be capable of withstanding temperatures in the field as high as 900 to $1200^{\circ} \mathrm{F}$, for periods of hundreds of hours, without marked deterioration from oxidation, moisture, or temperature. In other engineering applications, such as those involving the measurement of strains in rocket engines, turbine blades, supersonic aircraft, or space vehicles, the temperatures are either lower than $1200^{\circ} \mathrm{F}$; or, if greater, the strain measurements are of relatively short duration, sometimes of the order of a few seconds or less. Also, in many instances, only the dynamic peak-to-peak strain amplitudes are of primary interest, the steady-state component being of little or no concern. This simplifies matters considerably, in that the effects of drift or zero shift cause little or no error in the peak-to-peak values. In loop testing, where both the steady-state and transient strain magnitude are of interest, the effects of drift or zero shift cannot, in general, be ignored.

2) They must be capable of withstanding repeated transient cycles. 'During loop transient operations, including startups', shutdown, simulated "scrams," or emergency conditions, the gages are subjected to low cycle mechanical and thermal fatigue and subsequent cumulative damage which may ultimately lead to failure of the gage.

NAA-SR - 12118 
3) They must be capable of accommodating large thermal stresses, including the thermal stress generated within the gage itself. A majority of the sodium components are fabricated from austenitic stainless steel which, unfortunately, has a coefficient of thermal expansion which differs substantially from many of the alloys common to commercial high-temperature gages. This mismatch produces high thermal stresses in the strain sensing element of the gage at temperatures in the neighborhood of 1000 to $1200^{\circ} \mathrm{F}$ which, upon repeatedly cycling, can result in early failure of the gage.

4) They must be resistant to corrosion. Occasions may arise where gages are installed, then covered with thermal insulation, and left at ambient temperature for prolonged periods of time. Unless the gage is sealed or otherwise protected against moisture infiltration, corrosion of the gage may occur.

5) They must be amenable to field installation. Most sodium components are of such large size and mass that it is not feasible to cure cement-bonded foil gages, rated for use up to $1200^{\circ} \mathrm{F}$, because they require curing at $600^{\circ} \mathrm{F}$ for at least $1 \mathrm{hr}$. On laboratory specimens, this is done with little difficulty, with the use of infrared heating lamps or by curing the specimen in a laboratory oven.

In addition to these requirements, the reactor and pressure vessel designer desires that the stresses or strains at critical locations on the component be known within acceptable limits of accuracy. Where Code allowable values of stress are used and Code design procedures are applicable, an experimental stress analysis is not required, nor is high accuracy in the stress computation necessary. This stems from the fact that the Code allowable stresses provide for the inaccuracies and uncertainties inherent in stress calculations in complex stress fields or situations. However, where Code or other design procedures are not applicable, or they are of questionable validity, experimental stress analysis is performed to determine the stresses or to demonstrate the structural integrity of the component.

In a simple stress field, the designer can calculate stresses within "engineering accuracy," which is generally considered to be within several percent. In a complex stress field, the analytically computed stresses may deviate from the 
true stress by $\pm 25 \%$ or even greater limits. Since an experimental stress analysis is justified only in complex stress situations not amenable to mathematical analysis, the designer would naturally desire stress information from the strain gage which is accurate to at least $\pm 25 \%$. It was one of the objectives of the evaluation reported here to determine whether there were any commercially avail able gages which would meet this requirement on accuracy in the temperature range of 900 to $1200^{\circ} \mathrm{F}$.

\section{SELECTION OF GAGES FOR TEST}

In fulfillment of the objectives, a survey was conducted which included strain gage manufacturers and suppliers, strain gage users, and laboratories who are or have evaluated high-temperature electric resistance strain gages for use in the 900 to $1200^{\circ} \mathrm{F}$ range. (Full use was also made of existing information in the literature.) Included were Wm. T. Bean, Inc., Detroit, Michigan; Babcock \& Wilcox, Barberton, Ohio; NASA Flight Research Center, Edwards Air Force Base, California; Baldwin-Lima-Hamilton, Waltham, Massachusetts; Dentronics, Inc., Hackensack, New Jersey; and Microdot, Inc., Pasadena, California. The information obtained from this survey was supplemented with information obtained from the Western Regional Strain Gage Committee and the Technical Committee on Strain Gages of the Society for Experimental Stress Analysis. It should be noted that extensive information on electric resistance strain gages is available in the literature at temperatures below $900^{\circ} \mathrm{F}$. In the interest of brevity, the survey was limited to obtaining information on gages having potential at temperatures of $900^{\circ} \mathrm{F}$ and above.

The following basic types of commercial gages were included in the survey:

1) Wire strain gages (ceramic cement or flame-spray bonded)

2) Foil gages (ceramic cement bonded)

3) Weldable strain gages.

Of the wire strain gages, the only one rated for use in the 900 to $1200^{\circ} \mathrm{F}$ range was the BLH Type HT 1200 gage, which is rated for use up to $1200^{\circ} \mathrm{F}$. Aside from the manufacturer's information, little performance information was available from users of this gage, for temperatures in the neighborhood of $1200^{\circ} \mathrm{F}$. 
The gage has three advantages:

1) Availability in short gage lengths

2) Capable of being flame-spray bonded

3) Competitive in price.

Because of these advantages and the need for performance information in the vicinity of $1200^{\circ} \mathrm{F}$, this gage was included in the evaluation.

The foil gages were ruled out of the evaluation because they must be installed with ceramic cement, which, for reasons already mentioned, requires a type of heat cure which is not feasible for field installations. Also, they cannot be flame-spray bonded, because their geometry is such that they are damaged during the flame-spraying process. It would be possible to first cement them to coupons, then heat cure the assembly in a laboratory furnace, and then spot weld the assembly to the test article in the field. However, this results in a rosette size which, in general, is too large to permit meaningful strain measurements. Further, the foil gages which are stable above $650^{\circ} \mathrm{F}$ have a further dis advantage of exhibiting large apparent strains, since they cannot be temperature compensated by heat treatment.

Of the weldable strain gages, only two were rated for use in the 900 to $1200^{\circ} \mathrm{F}$ range. One was the BLH type FNWFB-50-12, which was ruled out primarily because the performance observed by other users indicated it could not meet the stringent conditions of this evaluation. The other weldable gage was the Microdot Type SG420 gage, which is rated for use up to $900^{\circ} \mathrm{F}$. Comments by users of this gage, plus other specification information obtained from the manufacturer, indicated that the gage was sufficiently promising to justify its inclusion in the evaluation, in spite of its relatively long gage length of $1-3 / 32$ in.

Because of the five mentioned a priori requirements and the information obtained during the survey, it was possible to limit the evaluation to the Microdot SG420 gage and the BLH Type HT 1212-5A gage. These gages will hereinafter be referred to as the Microdot gage and the BLH gage.

The Microdot gage is a completely sheathed gage which is readily attached to the test article in the field, by means of spot welding. This gage can be purchased with integral leads incased in a stainless steel sheath. In this configuration,

NAA -SR - 12118 
the gage is categorized as the Microdot Type SG423 gage, and may be considered to be a hermetically sealed gage. The BLH gage, while not sheathed, is readily flame-spray bonded to the test article with Rokide (molten aluminum oxide.) This piocess has been successfully used at Atomics International since 1962 for bonding wire filament electric resistance strain gages. It creates a stronger bond than the conventional ceramic cements, such as Allen PBX or Type H, and it requires no cure.

The following information on electrical and performance specifications on the Microdot and BLH gage were taken from the manufacturers' literature:

Microdot Gage (Type SG420)

Excitation current rated value, $50 \mathrm{ma}$

Minimum gage factor, 3.50

Nominal gage factor, 4.00

Dual element (active and dummy)

Nominal resistance per element, $115 \Omega$

Materials

Flange, Inconel $\mathrm{X}-750$

Strain tube, Inconel X-750

Sensing element, Pt-W

Sensing element insulation, $\mathrm{MgO}$

Gage length (flange length), 1-3/32 $\pm 1 / 32$ in.

Gage width (flange width), 3/16 in.

Maximum operating temperature, static measurements, $950^{\circ} \mathrm{F}$

Maximum drift rate, $20 \mu \epsilon / \mathrm{hr}$

BLH Gage (Type HT-1212-5A)

Excitation current, not stated

Gage factor, nominal, 4.0

Gage resistance, $120 \pm 2.5 \Omega$ 


\section{Materials}

Sensing element, Platinum Alloy 1200

Carrier tape, Teflon, Fiberglas reinforced

Gage length, 5/16 in.

Gage width (filament), $3 / 32$ in.

High recommended operating temperature, $1200^{\circ} \mathrm{F}$

Maximum drift rate, not stated

For schematic diagrams and photographs of these gages, refer to Figures 1 and 2 .

For additional information on the construction or other facets of these gages, the reader is referred to References 2 and 3. 

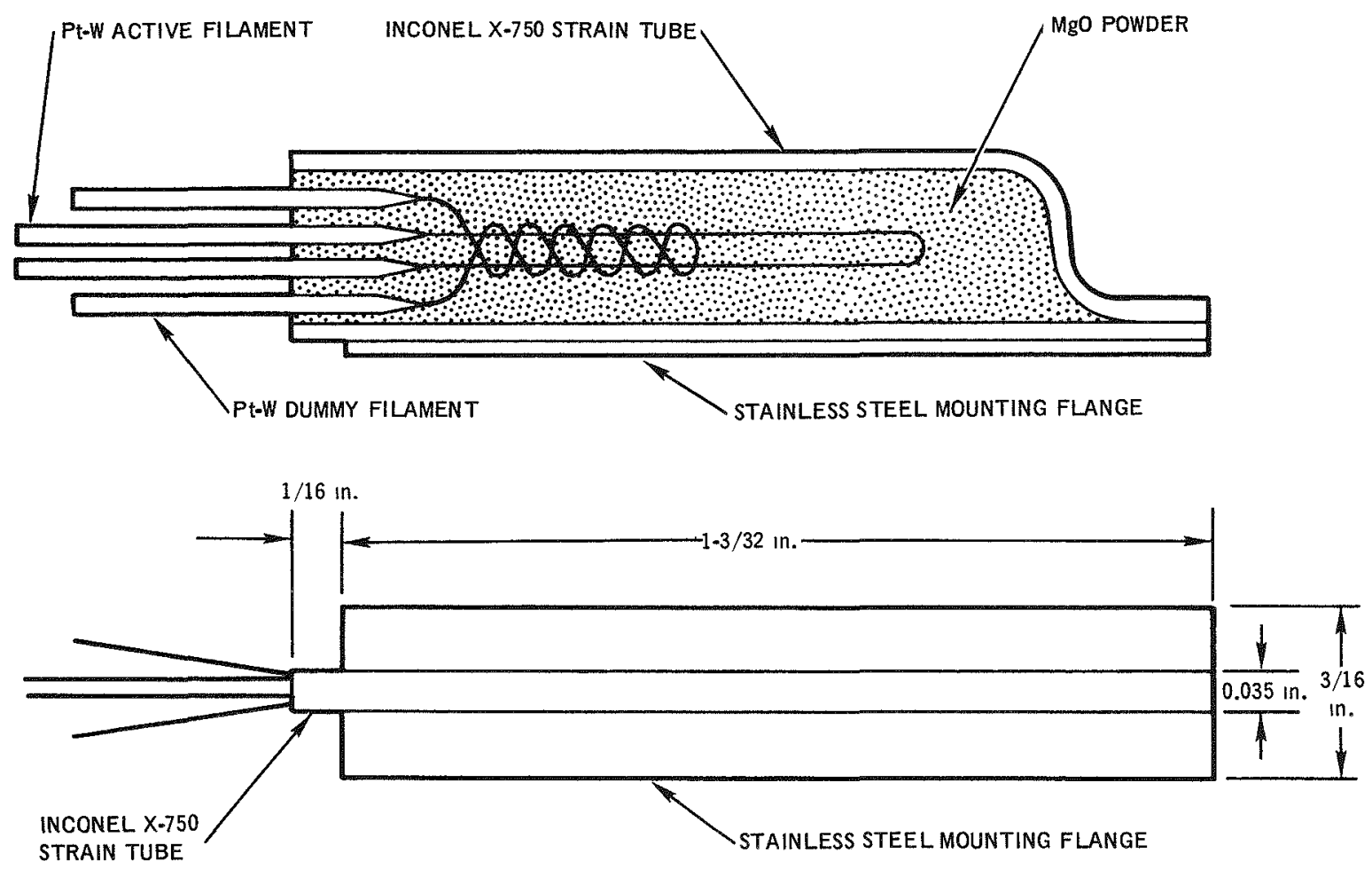

12.7 .66 UNC

7694-5501

a. Schematic

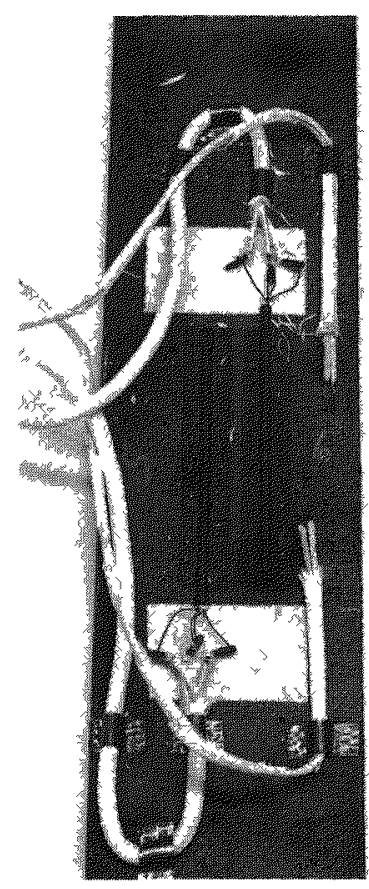

12-7-66 UNC b. Photograph of Installation

Figure 1. Microdot Gage 


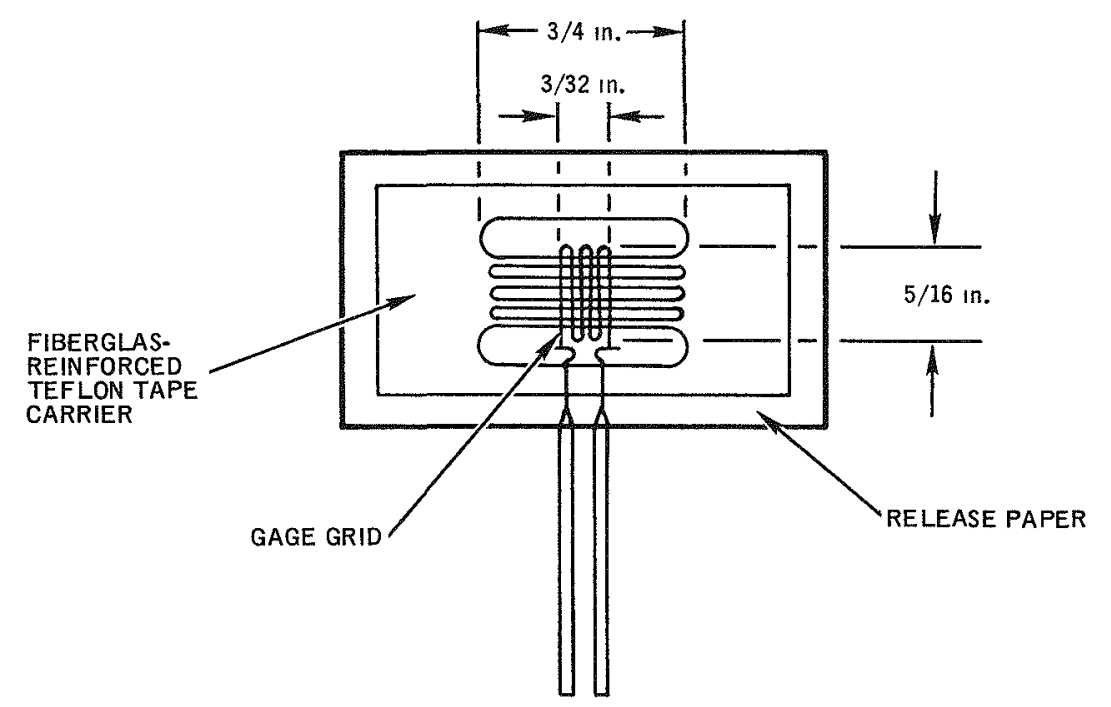

12-7-66 UNC

7694-5502

a. Schematic

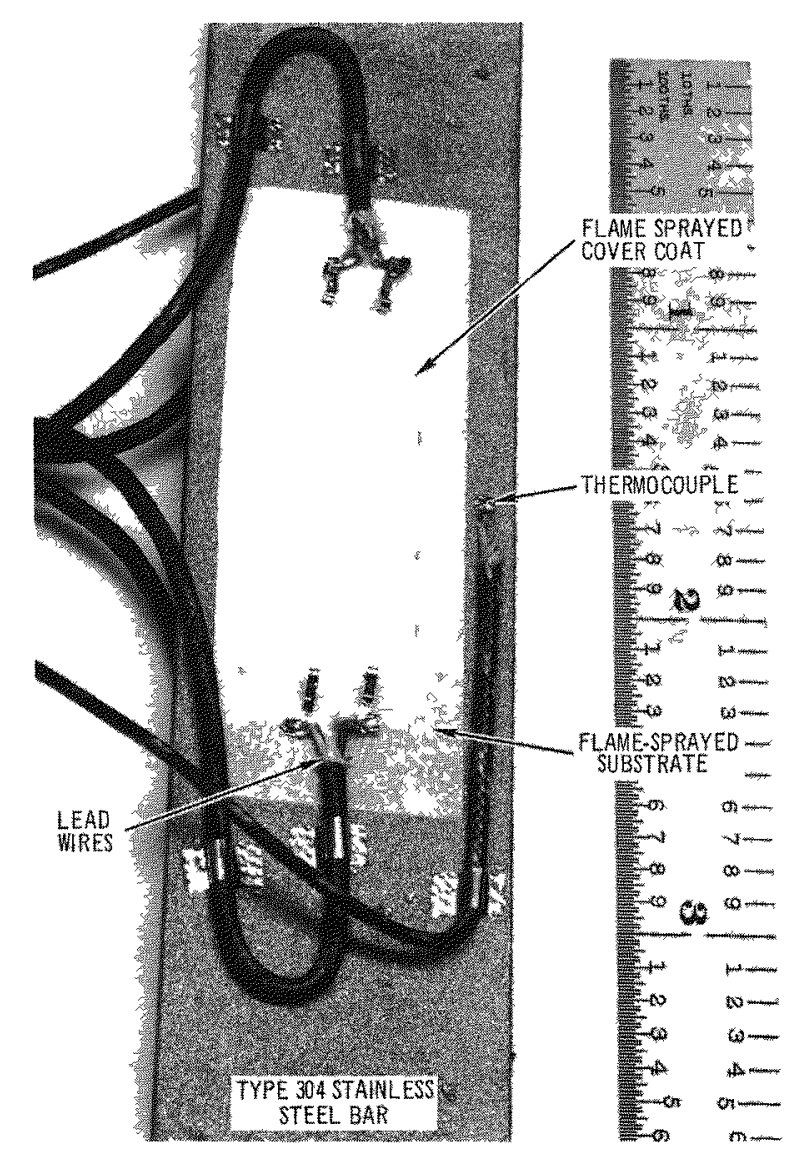

b. Photograph of Installation

12-7-66 UNC

$7682-4005$

Figure 2. BLH Gage

$$
\text { NAA-SR - } 12118
$$




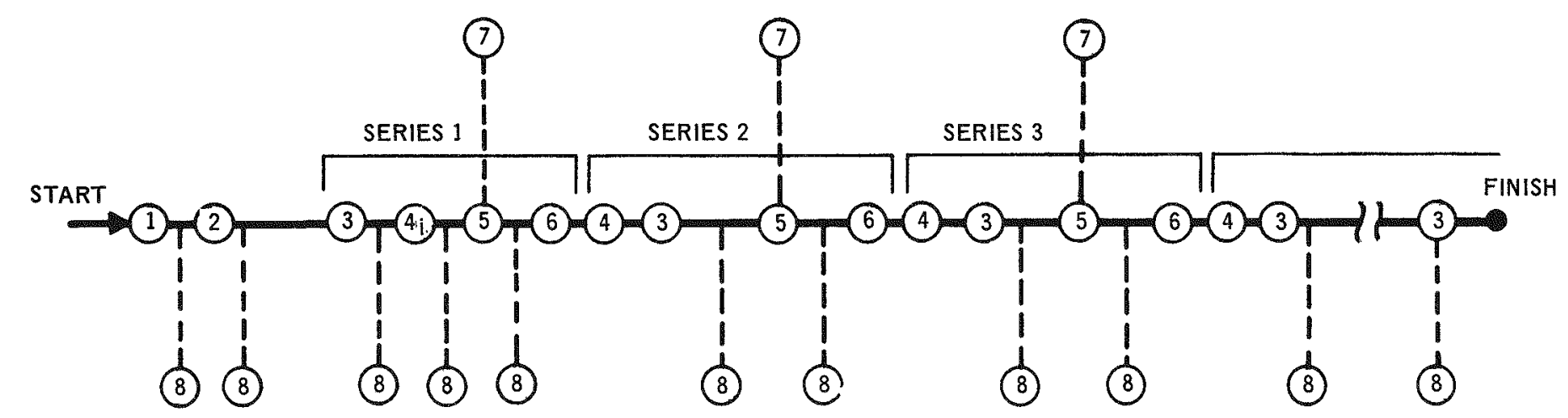

\section{EVENT}

1 ROOM-TEMPERATURE (RT) CHECKOUT OF "AS-RECEIVED" GAGES

2 STABILIZATION, AT CONSTANT TEMPERATURE, TO OR SLIGHTLY ABOVE MAXIMUM OPERATING TEMPERATURE (MOT)

3 ROOM-TEMPERATURE AND ELEVATED-TEMPERATURE GAGE FACTOR AND LINEARITY TESTS

$4_{i}$ INITIAL APPARENT STRAIN vS TEMPERATURE TESTS, CONSISTING OF 3 CYCLES FROM RT TO MOT

4 SAME AS 4 , EXCEPT FOR SERIES 2, 3, 4 ETC.

5 THERMAL SOAK (DRIFT) TESTS, UP TO AN ACCUMULATED $3000 \mathrm{hr}$ OR FAILURE, WHICHEVER OCCURS FIRST. SOAK INTERVALS - $300 \mathrm{hr}$ FOR BLH GAGE, AND $500 \mathrm{hr}$ FOR MICRODOT GAGE

6 THERMAL SHOCK TESTS - FOR THE MICRODOT GAGE, 30 CYCLES BETWEEN 350 AND $900^{\circ} \mathrm{F}$, CONSISTING OF 10 CYCLES AT $10 \mathrm{OF} / \mathrm{sec}, 10 \mathrm{CYCLES}$ AT $200 \mathrm{~F} / \mathrm{sec}$, AND $10 \mathrm{CYCLES} \mathrm{AT} 30^{\circ} \mathrm{F} / \mathrm{seC}$; FOR BLH GAGE, 30 CYCLES BETWEEN 350 AND $1200^{\circ} \mathrm{F}$, CONSISTING OF $10 \mathrm{CYCLES} \mathrm{AT} 50 \mathrm{~F} / \mathrm{sec}, 10 \mathrm{CYCLES} \mathrm{AT} 10{ }^{\circ} \mathrm{F} / \mathrm{sec}$, AND $10 \mathrm{CYCLES} \mathrm{AT} 250 \mathrm{~F} / \mathrm{sec}$

7 THERMAL SOAK (DRIFT) TEST, WITH SPECIMEN MECHANICALLY STRAINED, ON A LIMITED NUMBER OF GAGES

8 MEASUREMENTS OF GAGE RESISTANCE AND RESISTANCE TO GROUND, ONE OUT OF EVERY THREE GAGES.

Figure 3. Gage Evaluation Sequence 


\section{TEST PROGRAM}

After selecting gages that appeared promising for use in sodium loop component testing, a test program was planned that included setting up a test sequence, preparing specimens, and conducting tests.

\section{A. TEST SEQUENCE}

A test sequence was formulated which bracketed the range in time, temperature, and heating rates that could be anticipated in sodium component loop tests. This sequence is depicted in Figure 3, and consisted essentially of an "asreceived" checkout (Event 1), a temperature stabilization procedure (Event 2), and a test "series," each consisting of a sequence of events (Events 4, 3, 5, and 6), which was repeated until gage failure or until the accumulated high-temperature test time exceeded $3000 \mathrm{hr}$. For the first series, the sequence of events was Events 3, 4 $i, 5$, and 6 . Each series consisted of tests to measure the more important parameters discussed in Section I-A, a thermal soak period, and a number of thermal cycle exposures. All testing was done in an air environment.

The test sequence was not intended to duplicate a proposed sodium loop operating sequence, as such a sequence would involve a multiplicity of test condition variations. The test sequence did, however, provide a basis for comparing gages subjected to sodium loop conditions. It should be noted that the heating rates were representative of the more severe rates expected in actual operation, and the number of shocks were substantially more than would be expected in loop operations. These more severe conditions were used in the procedure to promote gage failure before $3000 \mathrm{hr}$, in order to pinpoint the failure.

The general test sequence was modified to accommodate each of the two types of gages. Pilot tests of the BLH gage resulted in early failures, so that the shorter thermal soak and lower thermal cycle rates were established. In this way, some data could be accumulated before termination of the testing. The pilot tests of the Microdot gage indicated that the longer soaks and higher cycle rates could be used, and would produce meaningful results.

NAA-SR- 12118 


\section{B. SPECIMEN PREPARATION}

Both the BLH and Microdot specimens were attached to Type 304 stainless steel test bars, $1 / 8 \mathrm{in.} \mathrm{thick,} 1 \mathrm{in.}$ wide, and $12 \mathrm{in.}$ long. In the case of the BLH gages, the gages were bonded to the test bars by the flame spray process. With this process, molten high-purity aluminum oxide was deposited, in the form of a substrate about 4 to 5 mils thick. A substrate of this thickness is necessary to provide at least $1 \mathrm{M} \Omega$ resistance to ground at $1200^{\circ} \mathrm{F}$. The purpose of the substrate is to provide an insulating layer between the gage and the material to which the gage is bonded. The gage was then positioned on the substrate and held in place temporarily by means of a special tape carrier. The gage was "tack-coated" to the substrate by spraying aluminum oxide through the slots in the carrier. The carrier was then removed and the final coat applied. Lead wires were spot welded to the gage lead tabs. The lead wires consisted of 3-conductor, 26-gage, stainless steel clad copper wire, with impregnated glass fiber insulation, which can be used at temperatures up to $1200^{\circ} \mathrm{F}$. A 3 -conductor lead wire system was used to eliminate lead wire errors. With this system, changes in lead wire resistance due to temperature are nulled out electrically. Figure $2 \mathrm{~b}$ shows a typical BLH strain gage installation, complete with lead wires. As a final step in preparation, the specimens were given a 16-hr temperature stabilization treatment at $1200^{\circ} \mathrm{F}$.

The Microdot gages were attached to the test bars by spot-welding, in accordance with the manufacturer's recommendations. Figure $1 \mathrm{~b}$ shows a typical Microdot gage installation, complete with lead wires, the same as for BLHgages. Theoretically, these gages require no stabilization before using. However, it was found that a substantial improvement in gage stability could be produced by stabilizing the gages, before using, with a $16-\mathrm{hr}$ soak at $\sim 1200^{\circ} \mathrm{F}$. This is $-250^{\circ} \mathrm{F}$ higher than the $950^{\circ} \mathrm{F}$ stabilization temperature used by the manufacturer.

Table 1 lists the test specimens prepared and used in this evaluation. All the Microdot specimens had two gages; but one group was stabilized at the manufacturer's recommended temperature of $900^{\circ} \mathrm{F}$, while another group was stabilized at $1200^{\circ} \mathrm{F}$ to observe the effects of a higher stabilization temperature. These groups were used in $900^{\circ} \mathrm{F}$ tests. One specimen, M-7, was tested at $1200^{\circ} \mathrm{F}$, and another, M-8, was kept under strain during the soak periods at 
TABLE 1

TEST SPECIMENS

\begin{tabular}{l|c|c|c}
\hline $\begin{array}{c}\text { Specimen } \\
\text { Designation }\end{array}$ & $\begin{array}{c}\text { Number } \\
\text { of Gages } \\
\text { per Specimen }\end{array}$ & $\begin{array}{c}\text { Thermal Soak } \\
\text { Temperature } \\
\left({ }^{\circ} \mathrm{F}\right)\end{array}$ & $\begin{array}{c}\text { Stabilization } \\
\text { Treatment }\end{array}$ \\
\hline $\begin{array}{l}\mathrm{M}-1, \mathrm{M}-2, \mathrm{M}-3 \\
\mathrm{M}-5, \mathrm{M}-6\end{array}$ & 2 & 900 & $16 \mathrm{hr}$ at $1200^{\circ} \mathrm{F}$ \\
$\mathrm{M}-7$ & 2 & 900 & $16 \mathrm{hr}$ at $900^{\circ} \mathrm{F}$ \\
$\mathrm{M}-8$ & 2 & 1200 & $16 \mathrm{hr}$ at $1200^{\circ} \mathrm{F}$ \\
$\mathrm{B}-1, \mathrm{~B}-2, \mathrm{~B}-3$, & 2 & $\begin{array}{c}900 \\
\mathrm{~B}-4\end{array}$ & $16 \mathrm{hr}$ at $1050^{\circ} \mathrm{F}$ \\
$\mathrm{B}-5, \mathrm{~B}-6, \mathrm{~B}-7$, & 4 & 1200 & $16 \mathrm{hr}$ at $1200^{\circ} \mathrm{F}$ \\
$\mathrm{B}-8$ & 2 & $16 \mathrm{hr}$ at $1200^{\circ} \mathrm{F}$ \\
\hline
\end{tabular}

$*_{\mathrm{M}}=$ Specimens with Microdot gages

B = Specimens with BLH gages The "dash number" after $M$ or $B$ indicates specimen number. In the text, a "dash number" after the specimen number indicates the gage number.

$900^{\circ} \mathrm{F}$ to compare drift with mechanical strain to drift without the mechanical strain present, as in Specimens $M-1, M-2$, and $M-3$.

All the BLH gages were stabilized at $1200^{\circ} \mathrm{F}$; and a large number were prepared, because numerous failures were anticipated, as observed in preliminary tests.

To obtain statistical information on gage-to-gage characteristics, a multiplicity of gages were tested at the main temperatures of interest.

\section{TEST APPARATUS AND PROCEDURES}

The test specimens listed in Table 1 were subjected to the test sequence shown in Figure 3. All tests were run in air, as is typical of exterior gages used in sodium loop tests.

1. Thermal Soak

Four resistance heating laboratory furnaces, capable of operating at temperatures up to $2000^{\circ} \mathrm{F}$, were used for the thermal soak tests, which correspond to Event 5 in Figure 3. Furnace temperatures for two of the furnaces were recorded 
and controlled with standard temperature recorder-controllers, capable of maintaining a specified temperature within $\pm 10^{\circ} \mathrm{F}$. The temperatures of the other two furnaces were controlled by saturable reactors, which were capable of controlling temperatures to $\pm 10^{\circ} \mathrm{F}$ or less. The latter furnaces were also used to stabilize the gages, and for the "slow" apparent strain vs temperature tests, which correspond to Events 4 and $4_{i}$ in Figure 3.

2. Drift

During soak testing at constant temperature, measurements of drift were taken daily and, when necessary, more frequently. These measurements were taken with the Baldwin Strain Indicator. The plots of drift vs time were obtained from these data. The strain indicator was zeroed at the beginning of each soak test. The total drift at any time was obtained by summing the drifts for each series.

To determine the effect of the presence of mechanical strain on drift characteristics, soak tests and measurements, which correspond to Event 7 in Figure 3, were performed on two gages which were subjected to $750 \mu \epsilon$ of mechanical strain in the constant moment fixture, while at constant temperature in the soak furnace. These tests and measurements were identical to those mentioned previously, except for the presence of the mechanical strain.

\section{Thermal Shock}

The thermal shock tests, which correspond to Event 6 in Figure 3, were conducted in a Research, Inc., cylindrical radiant heating furnace with a gold-plated reflector and nine, $2-\mathrm{kw}$ tubular quartz lamps, placed symmetrically around the test specimen, as shown in Figure 4. In some of the early tests, eighteen, $1-\mathrm{kw}$ lamps were used. The bore and length of the furnace were 5 and $13 \mathrm{in}$, respectively. The time-temperature thermal shock to which the specimen was subjected was programmed by a Research, Inc., Model 5052S Precorder. Power input into the furnace was readily controlled in this manner, with the thermocouple on the specimen used for feedback. The heating, rates represented the bare metal rates, and did not necessarily represent those for the gage filament. The $\mathrm{BLH}$ gages were insulated by the base coat of sprayed $\mathrm{Al}_{2} \mathrm{O}_{3}$; while the Microdot gages experienced a heat lag, caused by the heat conduction path through the flange and tube metal and the MgO packing within the tube. The 


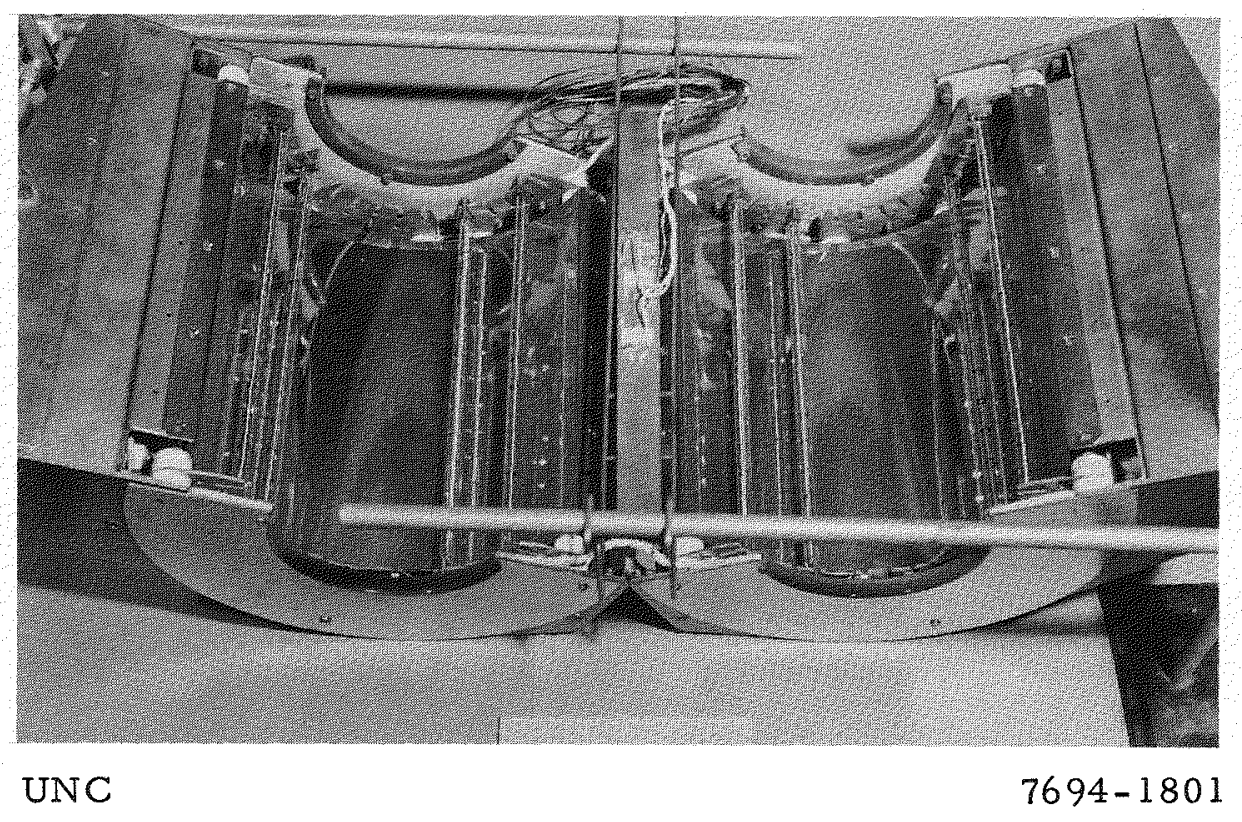

Figure 4. Radiant Heating Thermal Shock Test Furnace

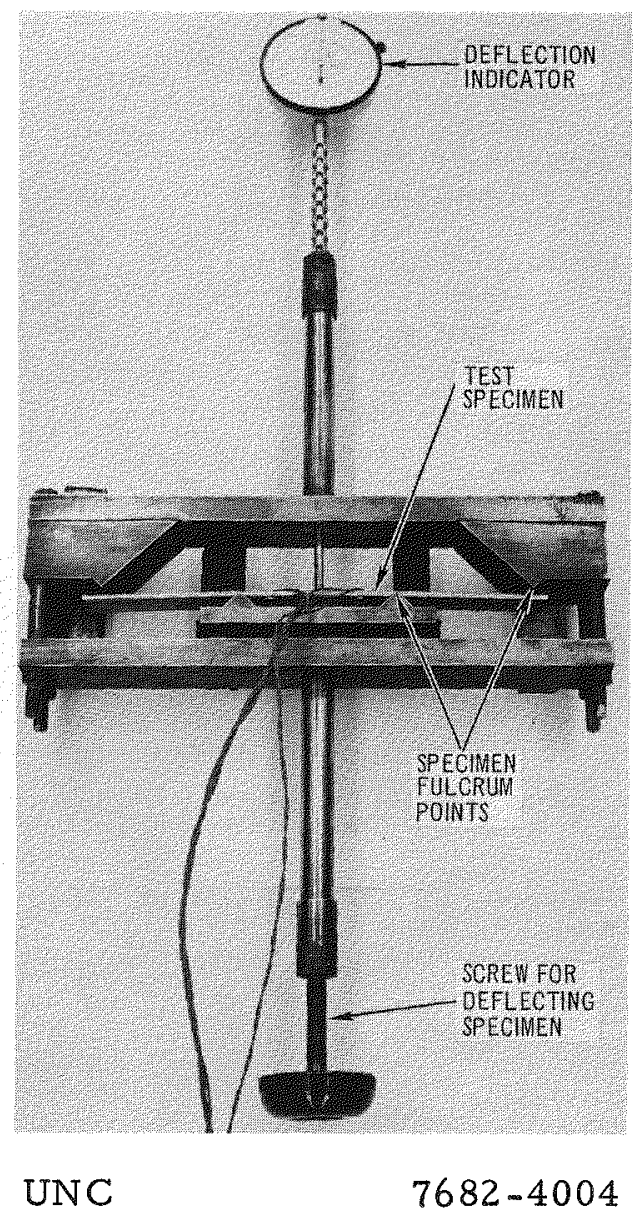

Figure 5. Constant Moment Fixture 
radiant heaters heated the gages from the outside, which differed from a sodium loop installation; but the data are satisfactory for comparison.

The outputs from the strain gage(s) and the thermocouple mounted adjacent to the strain gage during the thermal shock tests were recorded on a Heiland Model 1108 Visicorder. Data on as many as four gages on a specimen were simultaneously recorded in this fashion. Each galvanometer was calibrated before testing started. With these data, it was possible to make accurate cathode ray tube plots of strain vs temperature, at the different heating rates for each series of results, using a standard digital computer program for curve plotting.

\section{Gage Factor and Linearity}

The gage factor and linearity tests, which correspond to Event 3 in Figure 3, were conducted in a special fixture, which was inserted in a furnace and operated by controls external to the furnace. Figure 5 is a photograph of the fixture. In essence, the fixture is a simply supported "constant moment" beam, the bending moment of which is constant along the middle half of the beam. By "dialing in" a given central deflection, a uniform strain is produced over the middle half. With this arrangement, it was possible to determine the gage factor and linearity characteristics of several gages simultaneously, by observing the strain output of the gages on a Baldwin Type N Strain Indicator having a resolution of $10 \mu \epsilon$, used in conjunction with a multichannel switch and balance unit. Before testing started, the fixture was calibrated by applying increments of deflection to a calibration bar which was instrumented with gages of known gage factor. This calibration was checked by calculating the strain from the elementary beam equations, and comparing it with the measured strain. In actual use, it was merely necessary to dial in a given number of mils of deflection to produce a strain of a given value in the test specimen. The measured strains were corrected to account for the thin layer of material between the surface of the beam and the sensing element.

By conducting deflection vs strain tests at various temperatures, data were

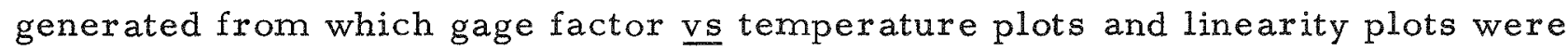
made.

NAA-SR -12118 
5. Repeatability

Repeatability characteristics were determined by comparing the apparent strain (steady-state and transient), drift, gage factor, etc., values measured during Series 1 (Figure 3) with the corresponding values obtained for each succeeding series.

\section{Zero Shift}

Zero shift characteristics were determined from measurements of the steadystate and transient apparent strain values at ambient temperature, before heating and after cooling in the soak or radiant heating furnace.

\section{Gage Resistance}

Gage resistance was monitored during testing with a Leeds and Northrup Model 5305 wheatstone bridge.

8. Resistance to Ground

Resistance to ground was monitored during testing with a General Radio Megger Model 1862C, using a 50-vdc potential. The measurement was made by connecting one lead of the megger to the test bar and the other lead to one of the strain gage leads.

The bridge excitation voltage for the steady-state measurements made with the Baldwin Strain Indicator was $3 \mathrm{v}$. The bridge excitation voltage applied to the gages during transient tests did not exceed $5 \mathrm{v}$. These voltages are low enough that any errors resulting from the increase in gage temperature due to gage current are negligible.

\section{Apparent Strain vs Temperature}

The apparent strain ys temperature tests were performed by slowly heating the specimen in the furnace in a stress-free condition and recording the strain experienced by the gage at various temperatures. The Microdot gage is a halfbridge gage, and incorporates an active and a dummy gage. It, like the BLH gage, is made from a $92 \% \mathrm{Pt}-8 \% \mathrm{~W}$ alloy, which inherently has a large apparent strain, and a coefficient of thermal expansion which is $-6 \mathrm{ppm} /{ }^{\circ} \mathrm{F}$ less than that of austenitic stainless steel. This alloy cannot be temperature compensated by heat treatment, hence the large apparent strain. The magnitude of the apparent strain of a single gage may be expressed by Equation 1. 
It is evident, from Equation 1, that the greater the mismatch in coefficients of thermal expansion between the test article and the gage, and the larger the temperature coefficient of resistance of the gage alloy, the larger will be the apparent strain. The dummy gage in the Microdot gage minimizes the amount of apparent strain due to changes in the coefficient of resistivity; but it does not, in practice, completely eliminate it. Theoretically it would, if the active and dummy gages were perfectly matched. By use of a trim resistor, as shown in Figure 6 , it is possible to further minimize that portion of the apparent strain

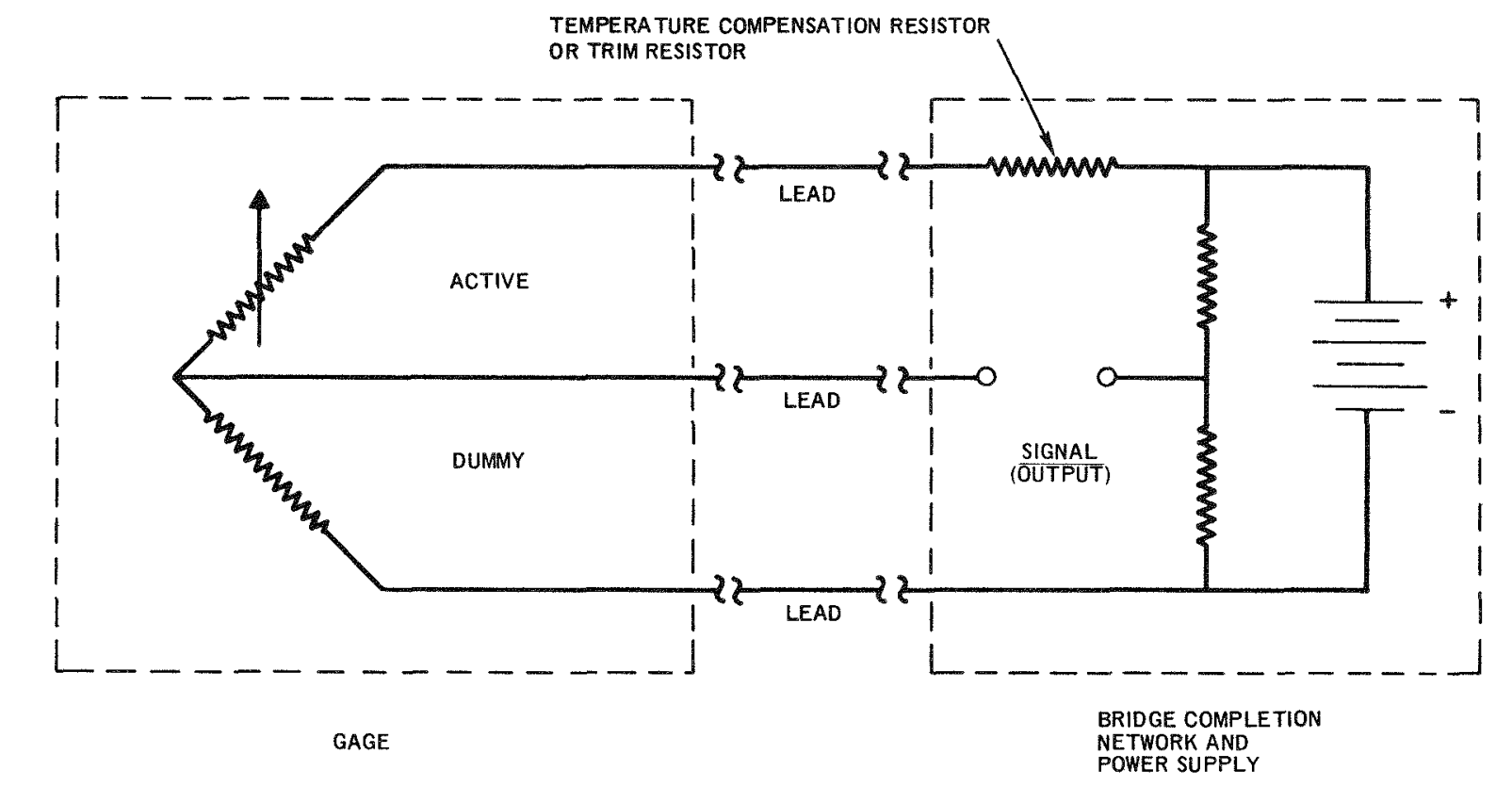

$12 \cdot 7.66$ UNC

$7694-5504$

Figure 6. Circuit for Microdot Gage With Temperature Compensation Resistor

of the Microdot gage due to mismatch between coefficients of thermal expansion. In fact, by proper choice of the value of the trim resistor, it is possible to make the apparent strain zero at any arbitrary temperature for a given material.

For most precise work, the trim resistor should be used as a part of the bridge completion network. (However, this entails a major modification of conventional multichannel bridge completion circuitry, since most of these systems cannot accommodate the mismatch in resistances between the active and dummy gages, resulting from the use of the trim resistors, whose value may be as much as $20 \Omega$.) 
From the preceding discussion, it is evident that the Microdot gage characteristics can be varied over a considerable range, by altering the value of the trim resistor. Though it would have been desirable to evaluate the Microdot gage for a multiplicity of trim resistor values, this was not possible in the time allocated for completion of the evaluation. Instead, it was decided to determine the basic characteristics of the Microdot gage, without a trim resistor. From a knowledge of these characteristics, it was then possible to appraise the performance of the gage for use at any temperature between ambient and $900^{\circ} \mathrm{F}$. To take full advantage of the temperature compensation afforded by the trim resistor, one must know, in advance, the temperature at which the apparent strain should be zero, since it cannot be made equal to zero over the entire operating range in temperature. Only with knowledge of the time-temperature history to which the gage will be subjected, during testing, can one select the optimum value of the trim resistor.

After the Microdot gages were tested without the trim resistors, the trim resistors were inserted in the bridge completion networks and the apparent strain vs temperature characteristics determined. The values of the $\operatorname{trim}$ resistors used were selected to make the apparent strain at $900^{\circ} \mathrm{F}$ a minimum. This was done to show the extent to which the apparent strain can be reduced by using a trim resistor. The trim resistor cannot be used with the BLH gage itself, since the BLH does not contain a dummy gage. However, the BLH gage can be used with a separate dummy strain gage.

NAA-SR- 12118 


\section{DISCUSSION OF TEST RESULTS}

\section{A. GENERAL}

The pertinent test results from this evaluation have been summarized in Figures 7 through 50 and in Tables 2 through 5. The figures, with few exceptions, are exact replicas of the cathode ray tube displays (CRT's). As such, they represent plots of the data points or graphs generated by connecting straight lines through the test points or values calculated by the digital computer, such as confidence limits, tolerance limits, gage factor, etc. After the data from the oscillograms and other records were reduced, the data was fed into the IBM 360, 7090, or 7094 digital computers, whose output was converted directly into CRT's, which hereinafter will be referred to as plots. The plots were not faired in any manner; consequently, any abrupt changes in the slopes of the plots do not necessarily imply erratic gage behavior. On the figures showing confidence and tolerance limits, such as Figure 11, the actual locations of the data points are obvious. In the other figures, the locations of the data points may not be obvious, because the lines connecting the points cover the data points. In those instances, the reader may locate these points, if he so desires, by noting that:

1) The apparent strain vs temperature curves were plotted from ambient $\left(100^{\circ} \mathrm{F}\right)$ to the peak temperature and back down to ambient in $100^{\circ} \mathrm{F}$ data point intervals

2) The transient (thermal shock) apparent strain vs temperature curves were plotted with data points at 350 and $400^{\circ} \mathrm{F}$, and at $100^{\circ} \mathrm{F}$ intervals there after to the peak temperature and back down to $350^{\circ} \mathrm{F}$

3) The figures showing the calculated vs measured strains were plotted with calculated points at 248-, 496-, and 745- $4 \epsilon$ intervals for the Microdot and BLH gages.

B. STATISTICAL ANALYSIS

The test results from this evaluation fall into two main categories: 
1) Results pertaining to life expectancy

2) Results pertaining to specific gage characteristics, such as apparent strain, gage factor, drift, etc.

To extract the maximum amount of information from the limited number (from a statistical standpoint) of gages of each type tested, a statistical analysis, based on small sampling theory and normal distributions, was performed. Specifically, the mean values, the $95 \%$ confidence limits, and the $95 \%-90 \%$ toler ance limits were determined for apparent strain, gage factor, and drift. These three gage characteristics are by far the most important ones to be used in connection with the determination of stresses from the measured strains. Without them, it is not possible to properly correct the "raw" strain data. With a knowledge of the statistical variations in these gage characteristics, one can determine the extent of the errors caused by such variations in the calculation of stresses.

The $95 \%$ confidence limits, as used in this report, represent the upper and lower limits of an interval or band, within which we may be $95 \%$ confident that the mean value of any subsequent groups of gages tested would fall. This, of course, assumes no change in the procedures or materials used in fabrication of the gages. In engineering work, the mean value of a set of measurements or properties is the most important statistic. Hence, the mean value curves contained in the CRT plots should be used to obtain values for apparent strain, drift, gage factor, etc. However, one is also interested in how much variation might be expected in any one sample from the population. In other words, what is the probability that a given percentage of individual samples taken from the population will lie within certain limits? To answer this question in a quantitative manner, the tolerance limits must be compiled for a specified probability and percentage. For this particular study, it was decided that the tolerance limits should be $95 \%-90 \%$ [i.e., that there be a $95 \%$ probability that $90 \%$ of the gages (gage characteristic in question) will fall within these limits]. If the percentages chosen had been higher, the tolerance interval or scatter band would be too broad to be meaningful, in terms of the gage-to-gage variations found in present day commercial gages.

NAA -SR-12118 
To compute the confidence limits, the following equations were used:

$$
\begin{aligned}
& \text { Upper Confidence Limit }=\bar{x}+t_{c} \sqrt{\frac{\overline{x^{2}}-(\bar{x})^{2}}{N-1}}, \\
& \text { Lower Confidence Limit }=\bar{x}-t_{c} \sqrt{\frac{\overline{x^{2}-(\bar{x})^{2}}}{N-1}},
\end{aligned}
$$

where

$\mathrm{N}=$ Number of gage samples

$\overline{x^{2}}=$ Mean of the square of the numerical value of the gage characteristic of each of the gage samples

$\bar{x}=$ Arithmetic mean of the numerical value of the gage characteristic of the gage samples

$t_{C}=$ Confidence coefficient for $95 \%$ confidence level and number of gage samples

The tolerance limits were computed from the equations:

$$
\begin{aligned}
& \text { Upper Tolerance Limit }=\bar{x}+K S, \\
& \text { Lower Tolerance Limit }=\bar{x}-K S,
\end{aligned}
$$

where

$$
\begin{aligned}
& \bar{x}=\text { (Same as for confidence limits) } \\
& K=\text { Tolerance factor for } 95 \%-90 \% \text { limits } \\
& S=\text { Standard Deviation }
\end{aligned}
$$$$
=\sqrt{\frac{\sum_{i=1}^{N}\left(x_{i}-\bar{x}\right)^{2}}{N-1}}
$$ 
where

$x_{i}=$ numerical value of the gage characteristic of the $i^{\text {th }}$ gage sample
$N=$ (same as for confidence limits)

These formulas, as well as tables for the numerical values of the confidence coefficients and tolerance factors, may be found in most references on statistical analysis; Reference 4 is one such reference.

A statistical analysis relating to life expectancy in terms of a failure law based on activation energy, fatigue damage, etc. was not conducted for the following reasons:

1) The large scatter in gage life and the short lives of many of the BLH gages strongly suggested that the gages were failing within the so-called "burn-in" period. In other words, these failures were not random failures in a statistical sense, but were failures due to variations in manufacturing of the gages, such as in the spot-welded joints, etc. Such variations cannot be readily analyzed, statistically.

2) The Microdot gages withstood the prescribed 3000-hr test without failure. A statistical failure analysis was therefore not possible.

\section{GAGE BEHAVIOR}

The various gage characteristics evaluated during the tests are discussed in the following sections: first, for the Microdot gages, and then for the BLH gages.

\section{Steady-State Apparent Strain}

a. Microdot Gages

As shown in Table 1, 10 gages (Specimens $M-1,-2,-3,-5$, and -6 ) were evaluated up to $900^{\circ} \mathrm{F}$; but they were in two groups, as to temperature of stabilization, as discussed in Section II-B. After four series of the evaluation procedure, the stability difference between gages stabilized at 900 and $1200^{\circ} \mathrm{F}$ was well established.

Figures 7 and 8 are plots of the average initial apparent strain vs temperature. The measurements, upon which these plots are based, were taken at points in 


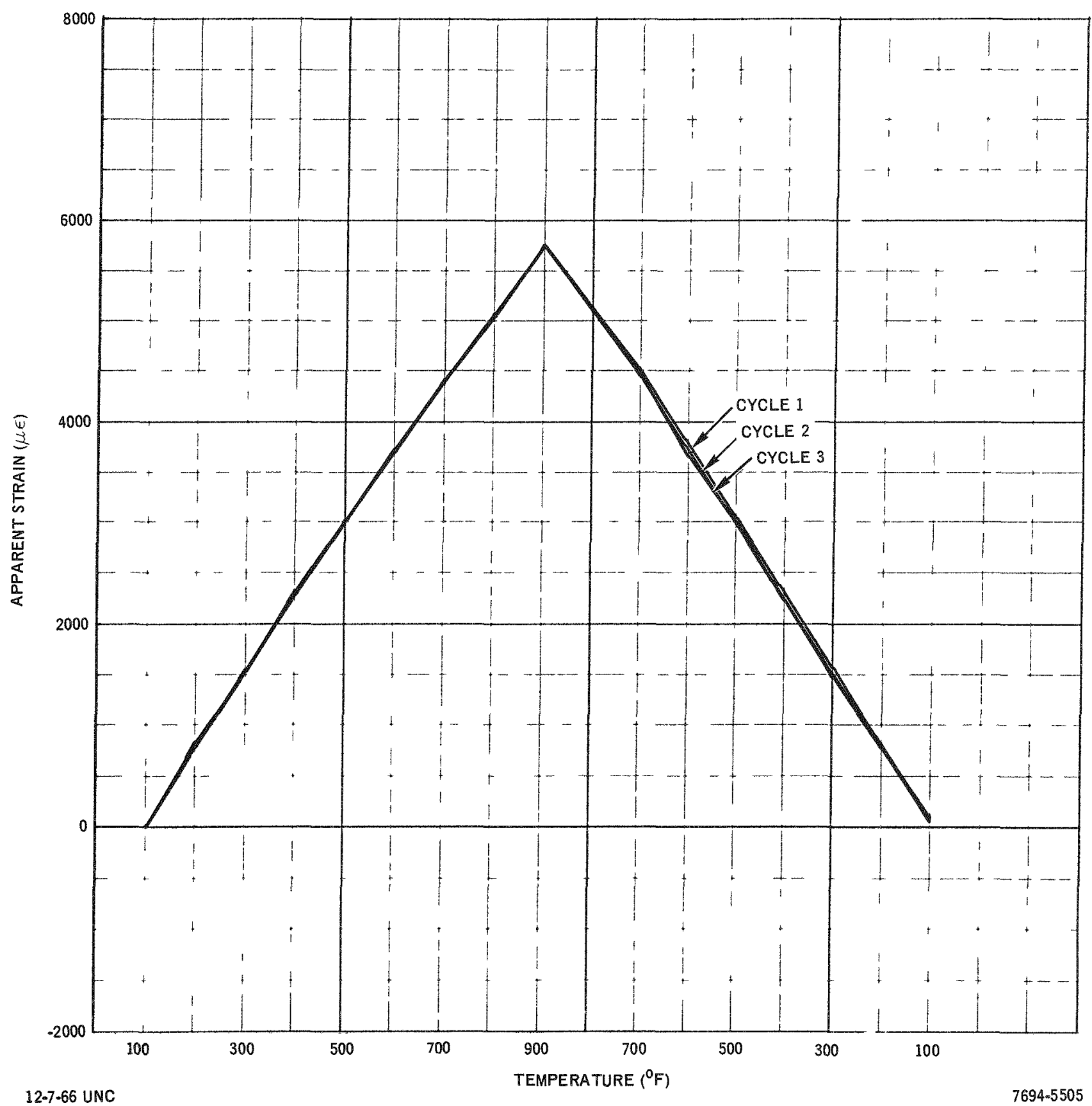

Figure 7. Average Initial Apparent Strain vs Temperature, Microdot Specimens $M-1$ Through $M-3$, Series 1 


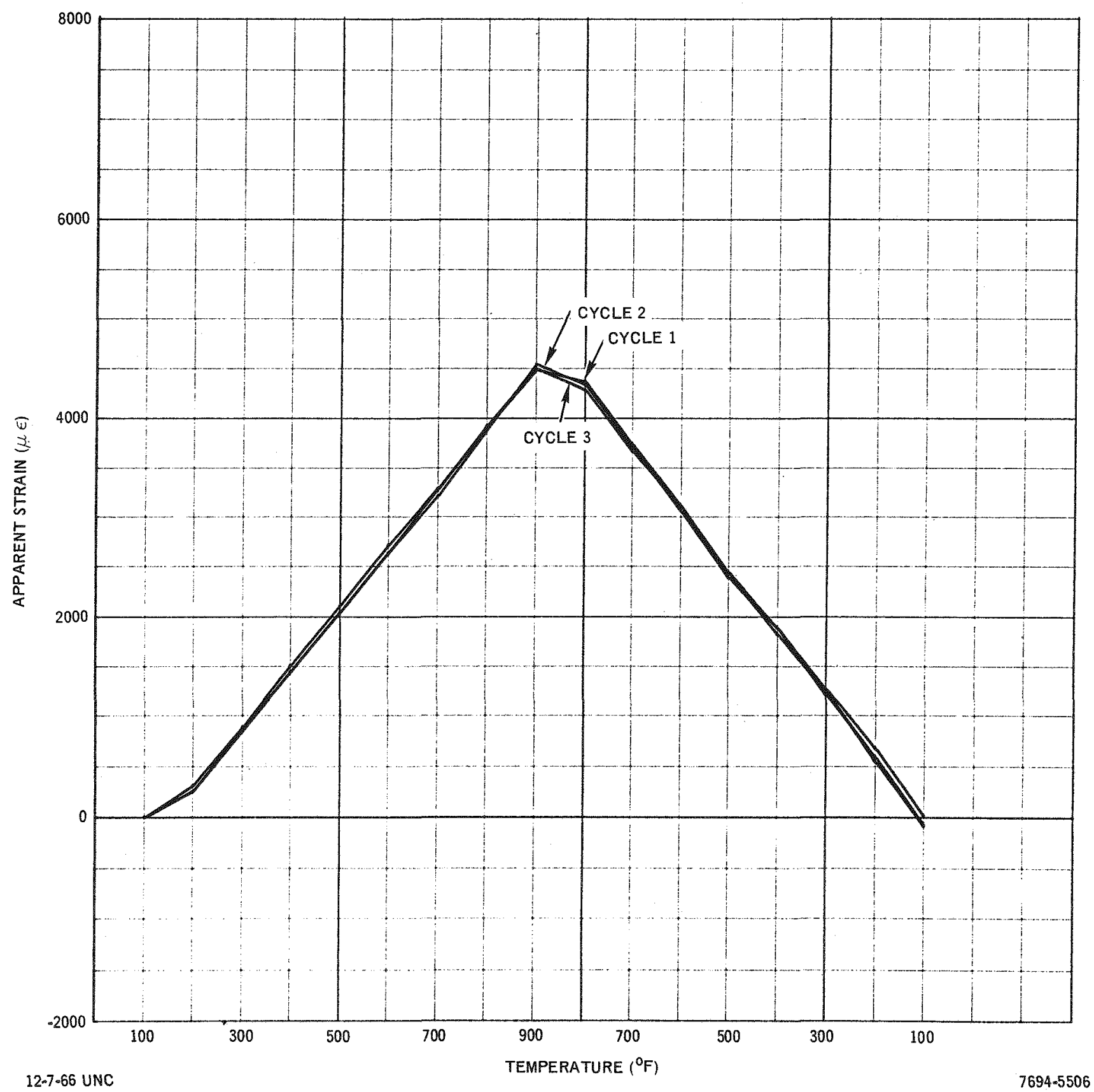

Figure 8. Average Initial Apparent Strain vs Temperature, Microdot Specimens $M-5$ and $M-6$, Series 1 


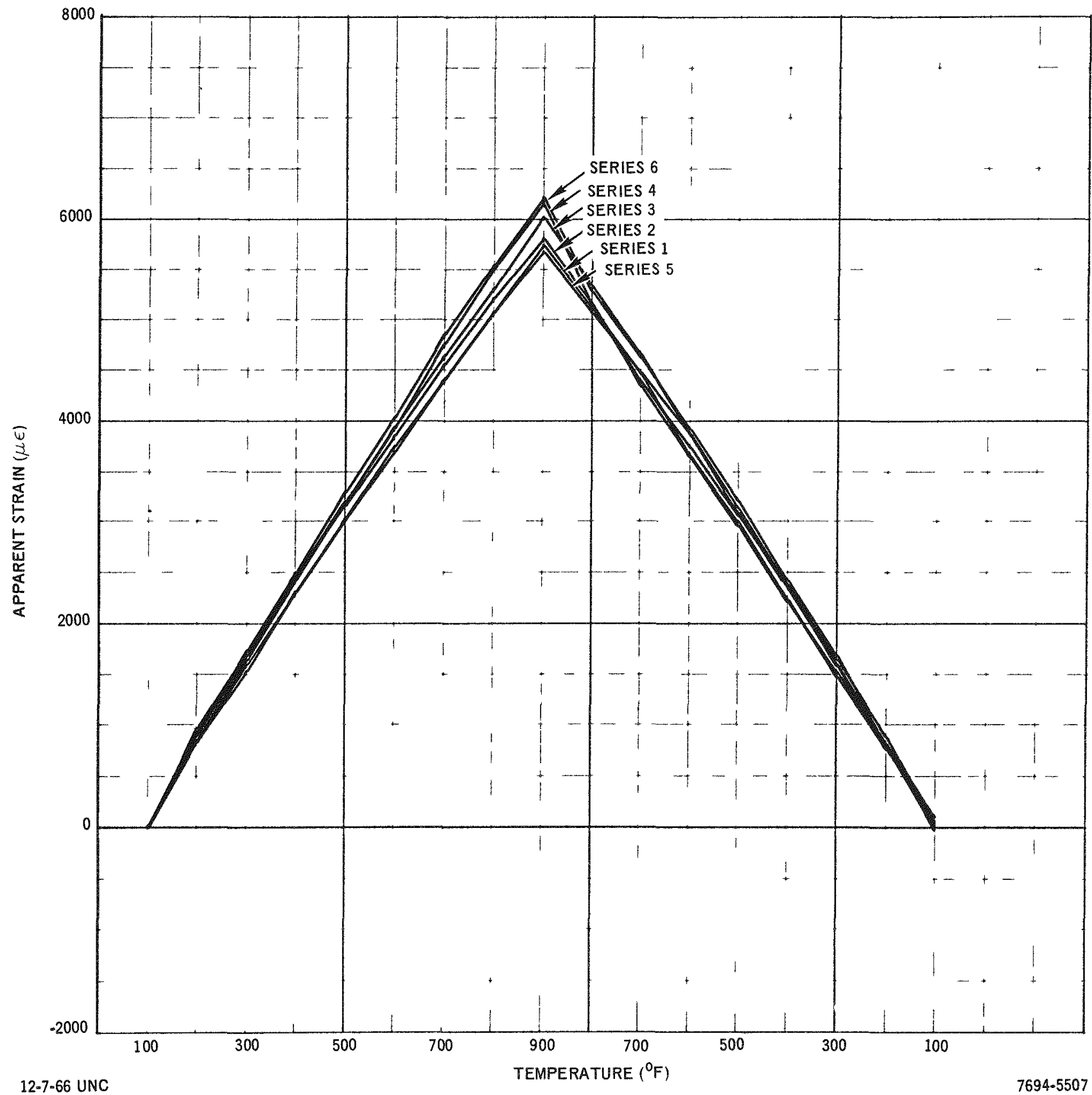

Figure 9. Average Apparent Strain vs Temperature, Microdot Specimens M-1 Through M-3, Cycle 1, Series 1 Through 6 
time corresponding to Event $4_{i}$ in Figure 3 . They represent the first three slow $\left(<40^{\circ} \mathrm{F} / \mathrm{min}\right)$ cycles of heating and cooling for Series 1 . Figure 7 represents the average of the six gages on Specimens $M-1$ through $M-3$. The repeatability is excellent, the zero shift after the first cycle is negligible, and excellent linearity exists for both the heating and cooling portions of the cycle. The maximum apparent strain, which occurs at the maximum test temperature of $900^{\circ} \mathrm{F}$, is only $\sim 5700 \mu \epsilon$, in spite of the fact that the temperature compensation resistor Nas not used.

In Figure 8 are similar plots for Microdot Specimens $M-5$ and M-6. They represent the average of four gages. There is some nonlinearity at the beginning of the heating cycle and at the beginning of the cooling cycle. This nonlinearity did not appear in the graphs for the gages on Specimens $M-1$ through $M-3$, which were stabilized at the higher temperature of $1200^{\circ} \mathrm{F}$. The repeatability, while still good, is slightly inferior to that exhibited by Specimens M-1 through M-3. A similar comment applies to the zero shift. The maximum apparent strain was $\sim 4500 \mu \epsilon$, in comparison to $5700 \mu \epsilon$ for Specimens $M-1$ through $M-3$.

Table 2 summarizes the variations in initial apparent strain at $900^{\circ} \mathrm{F}$ for each of the 10 Microdot gages, as a function of each thermal cycle. The maximum spread between gages is $2300 \mu \epsilon$. The maximum spread for the gages on Specimens $M-5$ and $M-6$ is only $910 \mu \epsilon$, in comparison to $2300 \mu \epsilon$ for the gages on Microdot Specimens $\mathrm{M}-1$ through $\mathrm{M}-3$. It appears that the higher stabilization temperature accentuates the differences from gage to gage, at least insofar as apparent strain is concerned. For measurement of strains within engineering accuracy, a spread of this amount is not permissible. However, with the temperature compensation resistor in the circuit, the magnitude of this strain can be reduced to an acceptable value, as will be discussed later.

Figure 9 shows plots of apparent strain vs temperature for Microdot Specimens $M-1$ through $M-3$. They represent the averages for all six gages, through six series in the test sequence. The measurements, upon which these plots are based, were taken at points in time corresponding to Event 4 in Figure 3 . It is noted that: 
TABLE 2

VARIATIONS IN INITIAL APPARENT STRAIN (SERIES 1) AT $900^{\circ} \mathrm{F}$, MICRODOT GAGES

\begin{tabular}{|c|c|c|c|c|}
\hline \multirow{2}{*}{$\begin{array}{l}\text { Specimen and } \\
\text { Gage No. }\end{array}$} & \multicolumn{4}{|c|}{$\begin{array}{c}\text { Apparent Strain } \\
(\mu \in)\end{array}$} \\
\hline & Cycle 1 & Cycle 2 & Cycle 3 & \\
\hline M1 - 1 & 5200 & 5200 & 5300 & \multirow{6}{*}{$\begin{array}{l}\text { Maximum } \\
\text { spread } \\
\text { between } \\
\text { gages } \\
=2300 \mu \epsilon\end{array}$} \\
\hline M1 -2 & 5400 & 5500 & 5500 & \\
\hline M2-1 & 5950 & 6000 & 5950 & \\
\hline$M 2-2$ & 5000 & 5025 & 5000 & \\
\hline M3-1 & 7300 & 7200 & 7200 & \\
\hline M3-2 & 5600 & 5600 & 5600 & \\
\hline M5-1 & 4850 & 4770 & 4720 & \multirow{4}{*}{$\begin{array}{l}\text { Maximum } \\
\text { spread } \\
\text { between } \\
\text { gages } \\
=910 \mu \epsilon\end{array}$} \\
\hline M5-2 & 4220 & 4160 & 4120 & \\
\hline M6-1 & 4080 & 4250 & 4200 & \\
\hline M6-2 & 4650 & 4990 & 4950 & \\
\hline
\end{tabular}

1) The maximum spread in average apparent strain between Series 1 and Series 6 is about $550 \mu \epsilon$, which is $\sim 1 / 4$ the maximum spread from gage to gage for the initial Series 1

2) Both the heating and cooling portions of the cycles are linear, except at the beginning of the heating cycle and at the beginning of the cooling cycle

3) The maximum zero shift (also in maximum spread in zero shift) is $\sim 100 \mu \epsilon$.

As mentioned previously, the apparent strain can be made negligibly small, through the use of a temperature compensation resistor

There is no precise pattern in the change of apparent strain as a function of soaks. In some instances, there is a slight decrease in strain at a given temperature. Yet, in other instances, there is a slight increase in apparent strain. This change in apparent strain may be accounted for in sodium loop tests, where a series of steady-state or transient tests are performed, by "zeroing" the instrumentation prior to the beginning of each test, and by using the appropriate apparent strain vs temperature curve. This is permissible, since the metal in

$$
\text { NAA -SR }-12118
$$


the sodium component returns essentially to the initial state after each test, because conservative design generally precludes creep or yielding of the component material. Also, we are primarily concerned with a determination of the stresses generated during a particular test. In this manner, not only is the change in apparent strain accounted for, but also the zero shift which accompanies the change in apparent strain.

In Figure 10 are shown similar plots for Series 1 through 4 for Microdot Specimens $M-5$ and $M-6$, also without a temperature compensation resistor in the circuit. The maximum apparent strain is $\sim 1000 \mu \epsilon$ less than that for Specimens $M-1$ through $M-3$, but that there is more nonlinearity and more spread.

Table 3 summarizes the variations, from series to series, in apparent strain at $900^{\circ} \mathrm{F}$ for each gage, for al1 10 Microdot gages on Specimens $M-1$ through $M-3, M-5$, and $M-6$. The maximum spread between any two gages for Series 1 through 6 is $2830 \mu \epsilon$ for Specimens $M-1$ through $M-3$, and $1910 \mu \epsilon$ for Specimens $M-5$ and $M-6$. This spread is believed due to small differences in materials and assembly, from gage to gage.

TABLE 3

SERIES-TO-SERIES VARIATIONS IN APPARENT STRAIN AT $900^{\circ} \mathrm{F}$, MICRODOT GAGES

\begin{tabular}{|c|c|c|c|c|c|c|c|}
\hline \multirow{2}{*}{$\begin{array}{c}\text { Specimen } \\
\text { and } \\
\text { Gage No. }\end{array}$} & \multicolumn{6}{|c|}{$\begin{array}{c}\text { Apparent Strain } \\
(\mu \in)\end{array}$} & \\
\hline & $\begin{array}{c}\text { Series } \\
1\end{array}$ & $\begin{array}{c}\text { Series } \\
2\end{array}$ & $\begin{array}{c}\text { Series } \\
3\end{array}$ & $\begin{array}{c}\text { Series } \\
4\end{array}$ & $\begin{array}{c}\text { Series } \\
5\end{array}$ & $\begin{array}{c}\text { Series } \\
6\end{array}$ & \\
\hline $\mathrm{M} 1-1$ & 5200 & 5550 & 6100 & 6270 & - & - & \multirow{6}{*}{$\begin{array}{l}\text { Maximum } \\
\text { spread } \\
\text { between } \\
\text { gages } \\
=2830 \mu \epsilon\end{array}$} \\
\hline M1-2 & 5400 & 5800 & 6200 & 6400 & 6210 & 6300 & \\
\hline $\mathrm{M} 2-1$ & 5950 & 5600 & 5850 & 5900 & 4770 & 5950 & \\
\hline$M 2-2$ & 5000 & 4850 & 5100 & 4940 & 5000 & 5430 & \\
\hline M3-1 & 7300 & 7300 & 7250 & 7600 & 6970 & 7570 & \\
\hline M3-2 & 5600 & 5800 & 5600 & 5850 & 5420 & 5840 & \\
\hline M5-1 & 4850 & 4850 & 4440 & 4910 & 5370 & 5330 & \multirow{4}{*}{$\begin{array}{l}\text { Maximum } \\
\text { spread } \\
\text { between } \\
\text { gages } \\
=1910 \mu \mathrm{\epsilon}\end{array}$} \\
\hline M5-2 & 4220 & 4300 & 4370 & 4910 & - & - & \\
\hline M6-1 & 4080 & 4300 & 5990 & 5450 & - & - & \\
\hline M6-2 & 4650 & 5000 & 5040 & 5150 & - & - & \\
\hline
\end{tabular}




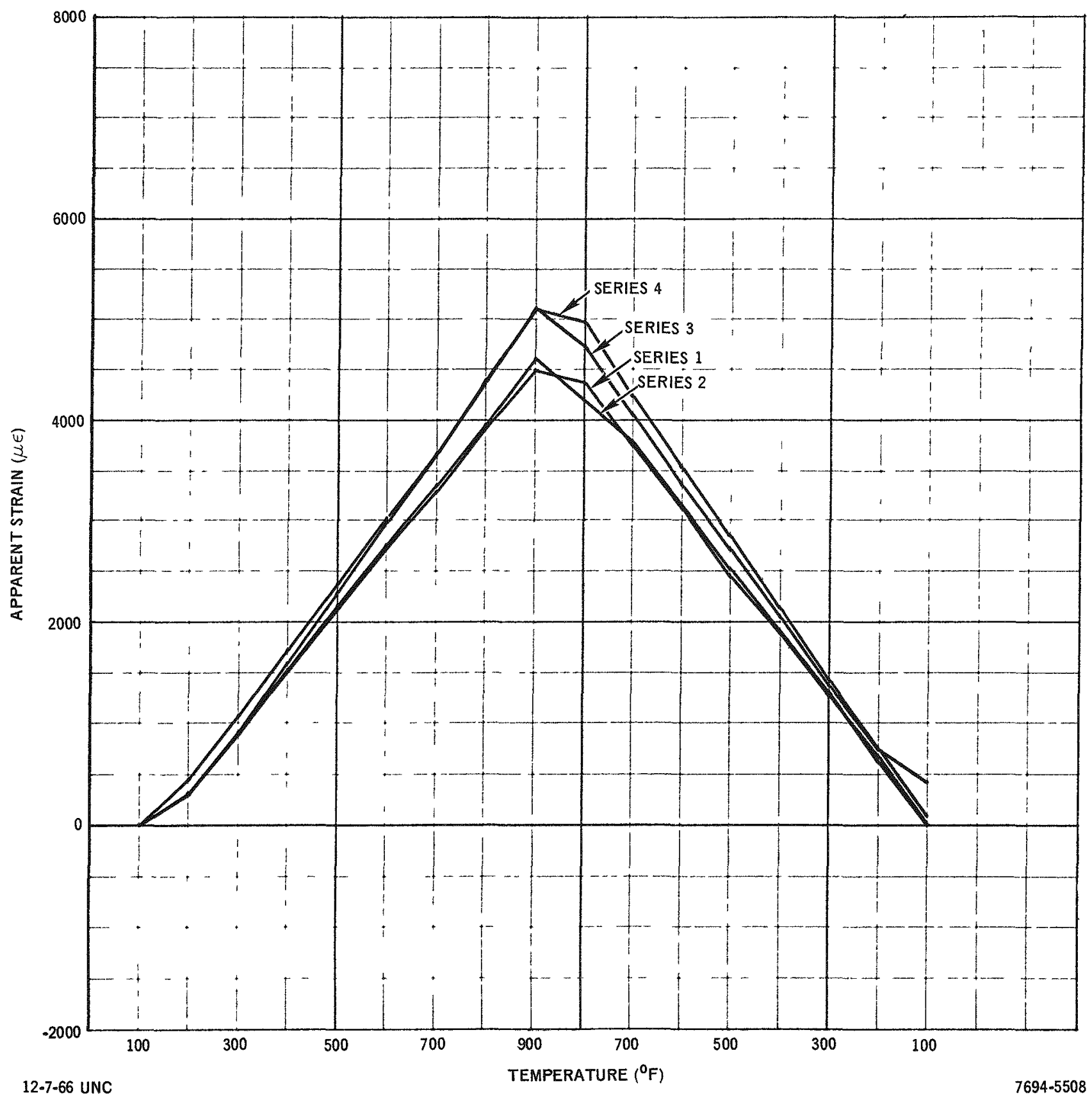

Figure 10. Average Apparent Strain vs Temperature, Microdot Specimens $M-5$ and $M-6$, Cycle 1 , Series 1 Through 4 
Figures 11 through 16 show the apparent strain vs temperature data points, mean values, confidence limits, and tolerance limits for the first cycle of each series. The $95 \%$ confidence interval, within which the mean value of apparent strain for a group of samples should lie, is substantially narrower than the tolerance limit interval. This is as would be expected, since one would expect larger deviations from the individual samples than from the means of groups of samples taken from the same population.

In these figures, most of the data points fall within the $95 \%$ confidence limits, and all the data points are well within the tolerance limits, particularly the lower tolerance limits. This means that, on the basis of the samples tested, the tolerance limits are conservative, and they could be relaxed to $90 \%-90 \%$ or even less. The magnitude of the confidence limit interval remained essentially unchanged for the first four series, but increased somewhat for the fifth and sixth series. For the first four series, the width of the confidence interval was $\sim 1500 \mu \epsilon$; whereas, for the last two series, it was as wide as $2260 \mu \epsilon$. (Beyond a certain point, exposure and cycling tend to accentuate the differences between individual gages to the extent that, eventually, erratic behavior or failure of the gage occurs.) The maximum width of the tolerance interval was $7770 \mu \epsilon$. The large tolerance interval width stems primarily from the conservatism as sociated with the lower tolerance limit. Spreads of these magnitudes are too great for meaningful strain measurements. Ways of minimizing this spread will be discussed later.

Figure 17 is a summary of the apparent strain vs temperature plots obtained after completion of the standard gage evaluations on Microdot Specimens $\mathrm{M}-1$, $M-2, M-3, M-5$, and $M-6$, with the temperature compensating resistor in the circuit. During the standard evaluation, only the basic gage characteristics were determined, without the use of a temperature compensation resistor. The value of the temperature compensation resistor was arbitrarily chosen to make the apparent strain at $900^{\circ} \mathrm{F}$ essentially zero. The maximum apparent strain does not exceed $\sim 390 \mu \epsilon$ at any point during the heating and cooling portions of the cycle. The maximum spread is only $\sim 180 \mu \epsilon$. This represents a very substantial decrease in apparent strain. Without the compensation (trimmer) resistor, the apparent strain was $5700 \mu \epsilon$ at $900^{\circ} \mathrm{F}$. Thus, by use of a temperature compensation resistor, it is possible to reduce the magnitude of the apparent

NAA-SR -12118 


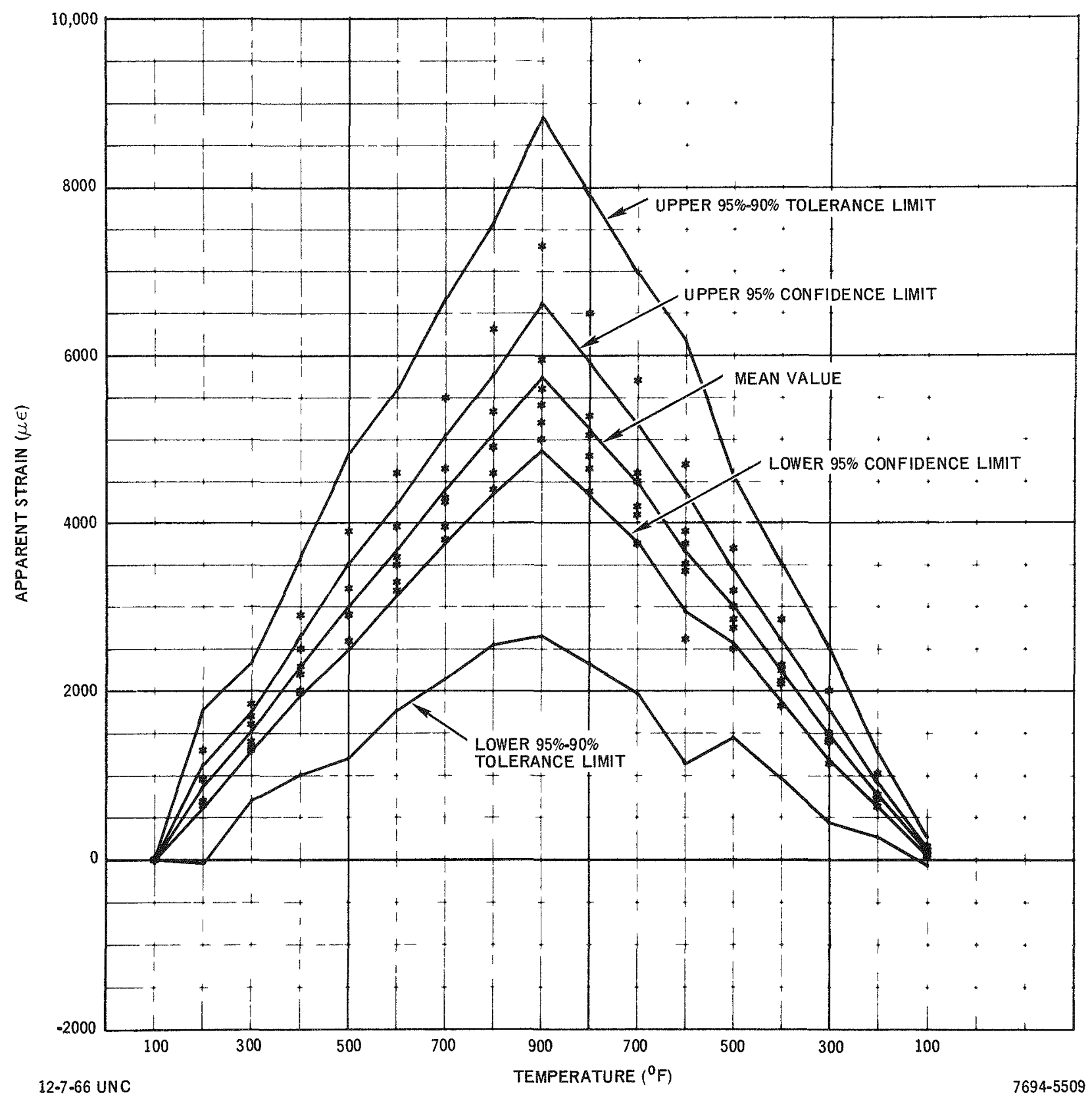

Figure 11. Apparent Strain vs Temperature, With Confidence and Tolerance Limits, Microdot Specimens $M-1, M-2$, and M-3, Gages No. 1 and No. 2, Series 1, Cycle 1 


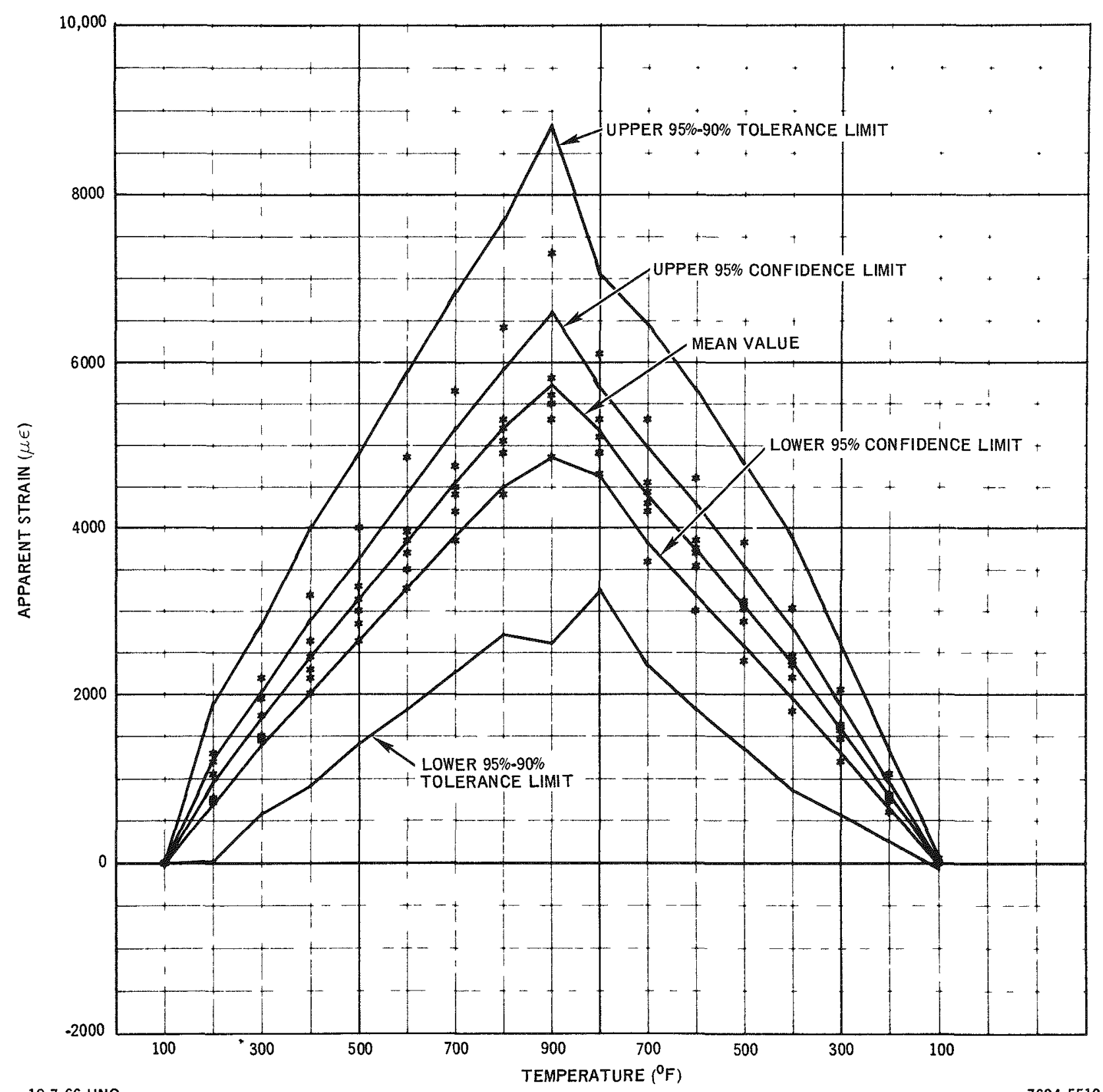

12-7-66 UNC

$7694-5510$

Figure 12. Apparent Strain vs Temperature, With Confidence and Tolerance Limits, Microdot Specimens $\mathrm{M}-1, \mathrm{M}-2$, and M-3, Gages No. 1 and No. 2, Series 2, Cycle 1 


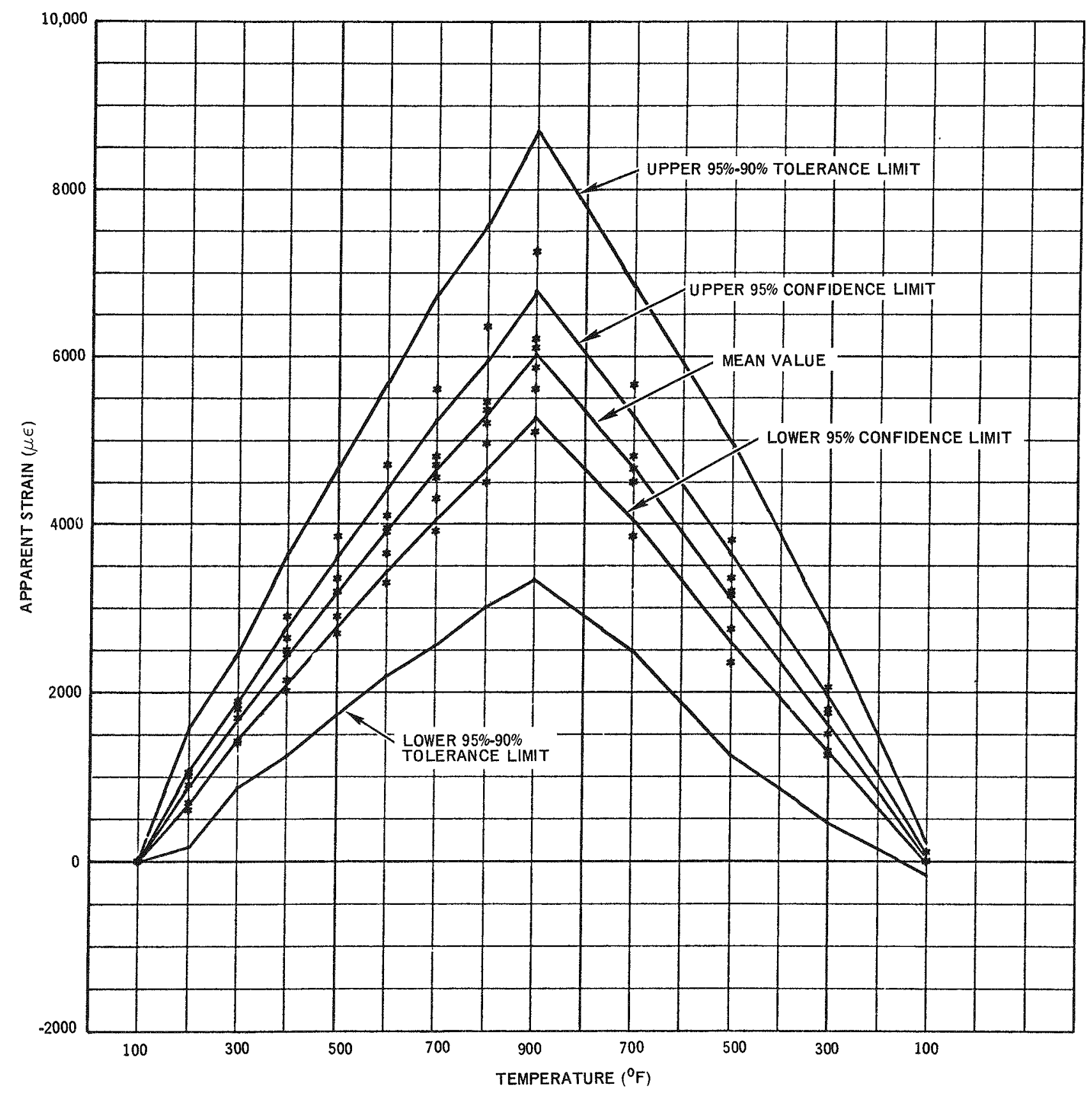

$12.7 \cdot 66$ UNC

Figure 13. Apparent Strain vs Temperature, With Confidence and Tolerance Limits, Microdot Specimens M-1, M-2, and M-3, Gages No. 1 and No. 2, Series 3, Cycle 1 


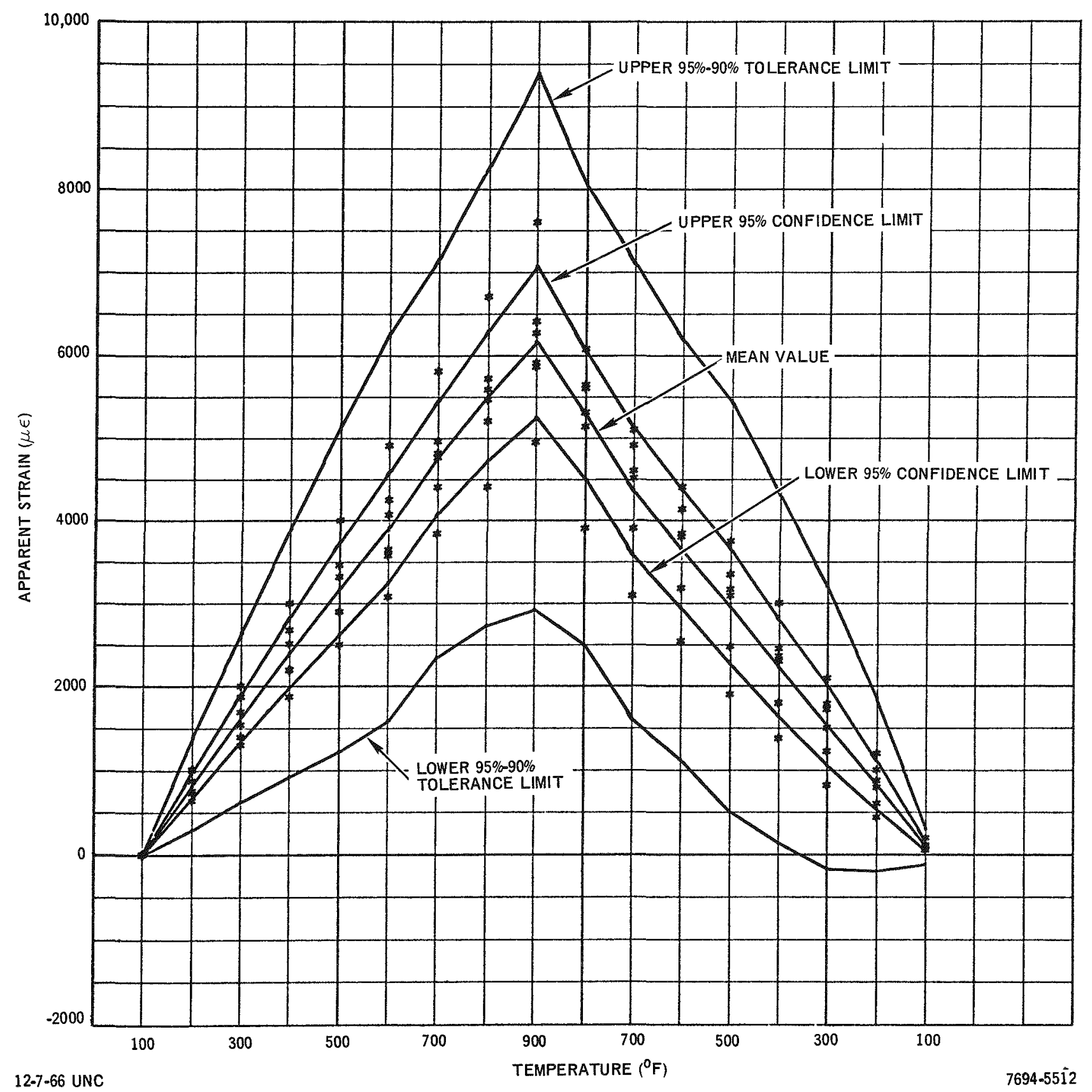

Figure 14. Apparent Strain vs Temperature, With Confidence and Tolerance Limits, Microdot Specimens $\mathrm{M}-1, \mathrm{M}-2$, and M-3, Gages No. 1 and No. 2, Series 4, Cycle 1 


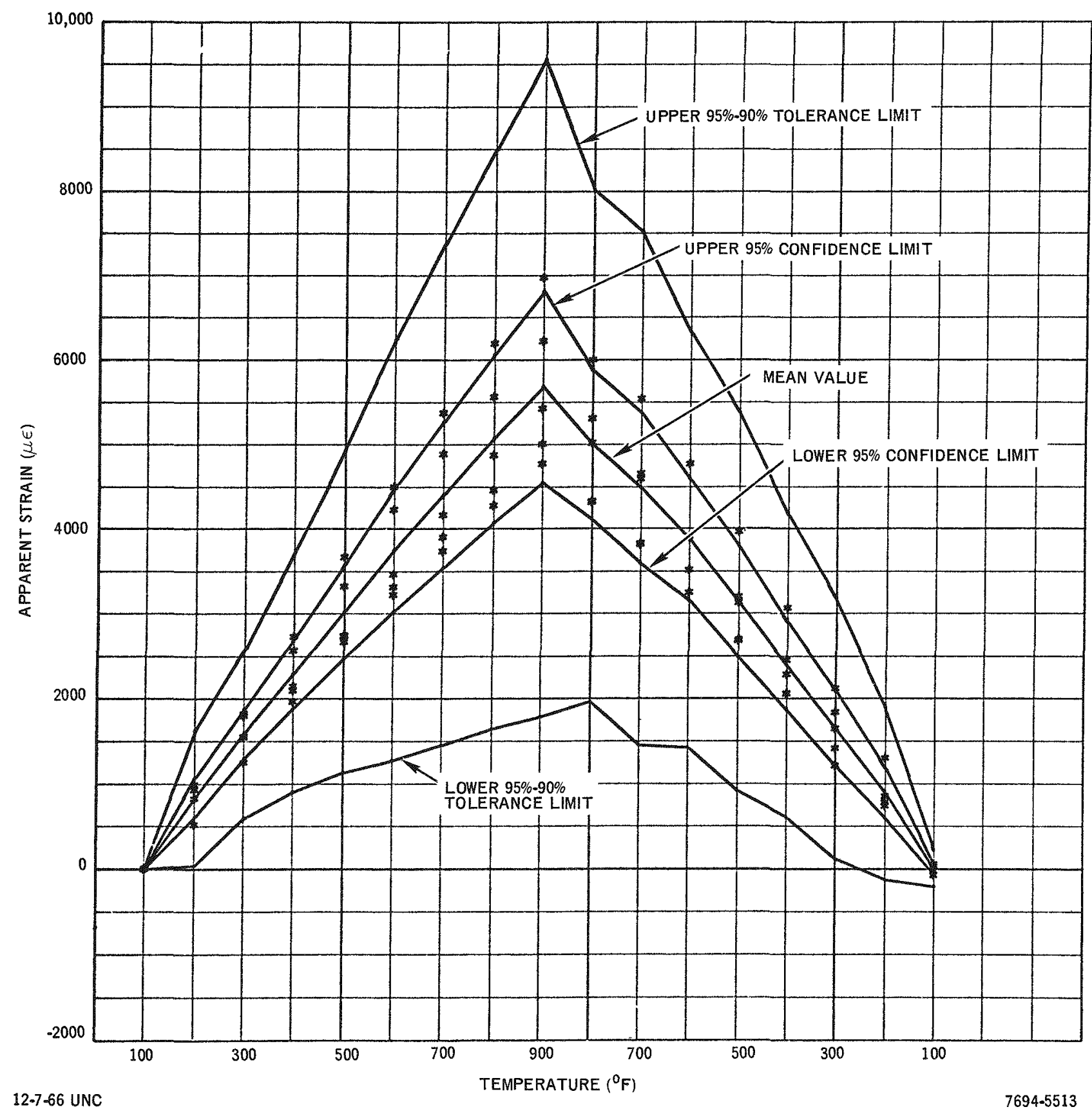

Figure 15. Apparent Strain vs Temperature, With Confidence and Tolerance Limits, Microdot Specimens $\mathrm{M}-1, \mathrm{M}-2$, and $\mathrm{M}-3$, Gages No. 1 and No. 2, Series 5, Cycle 1 


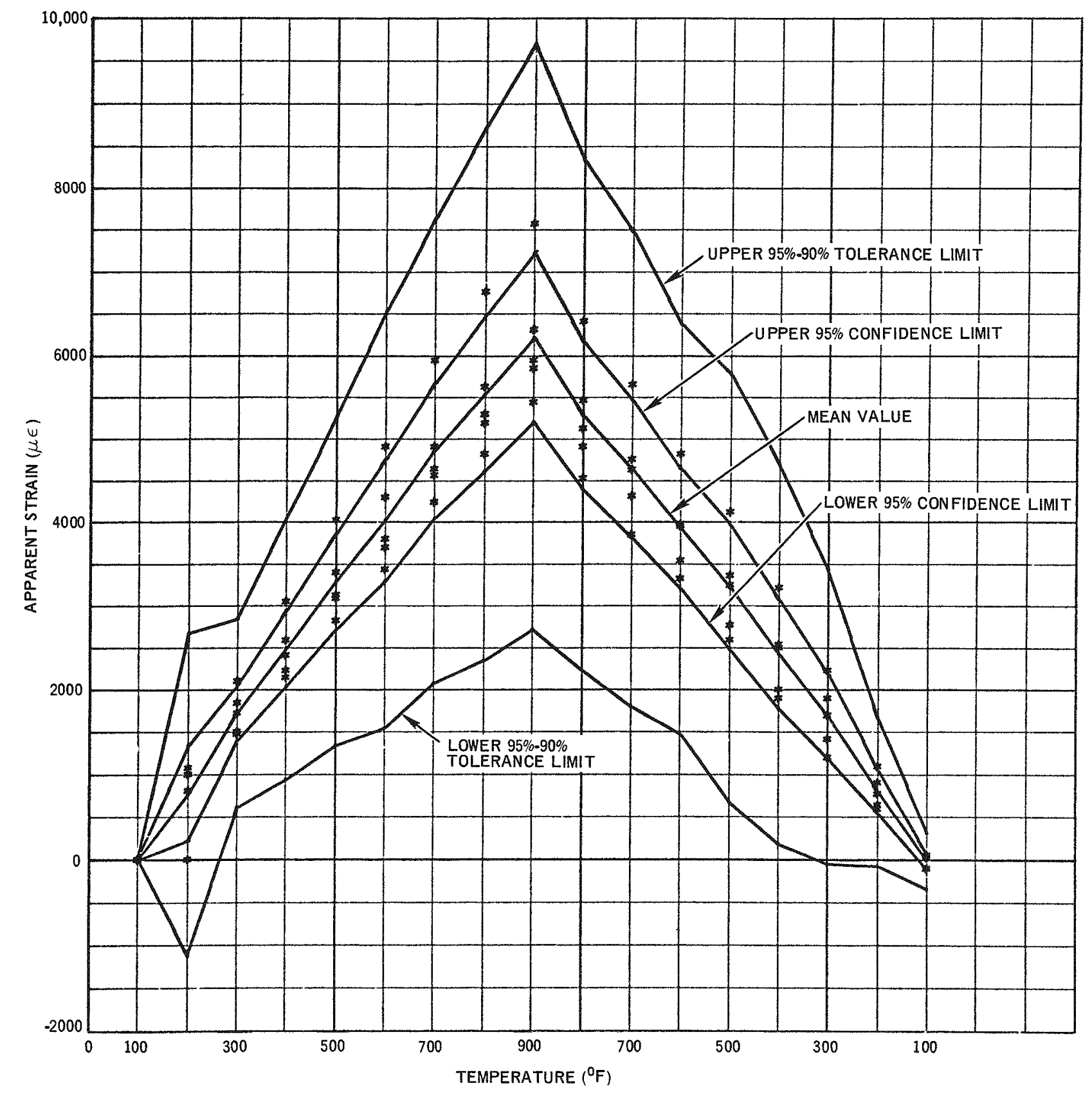

12-7-66 UNC

Figure 16. Apparent Strain vs Temperature, With Confidence and Tolerance Limits, Microdot Specimens $\mathrm{M}-1, \mathrm{M}-2$, and M-3, Gages No. 1 and No. 2, Series 6, Cycle 1 


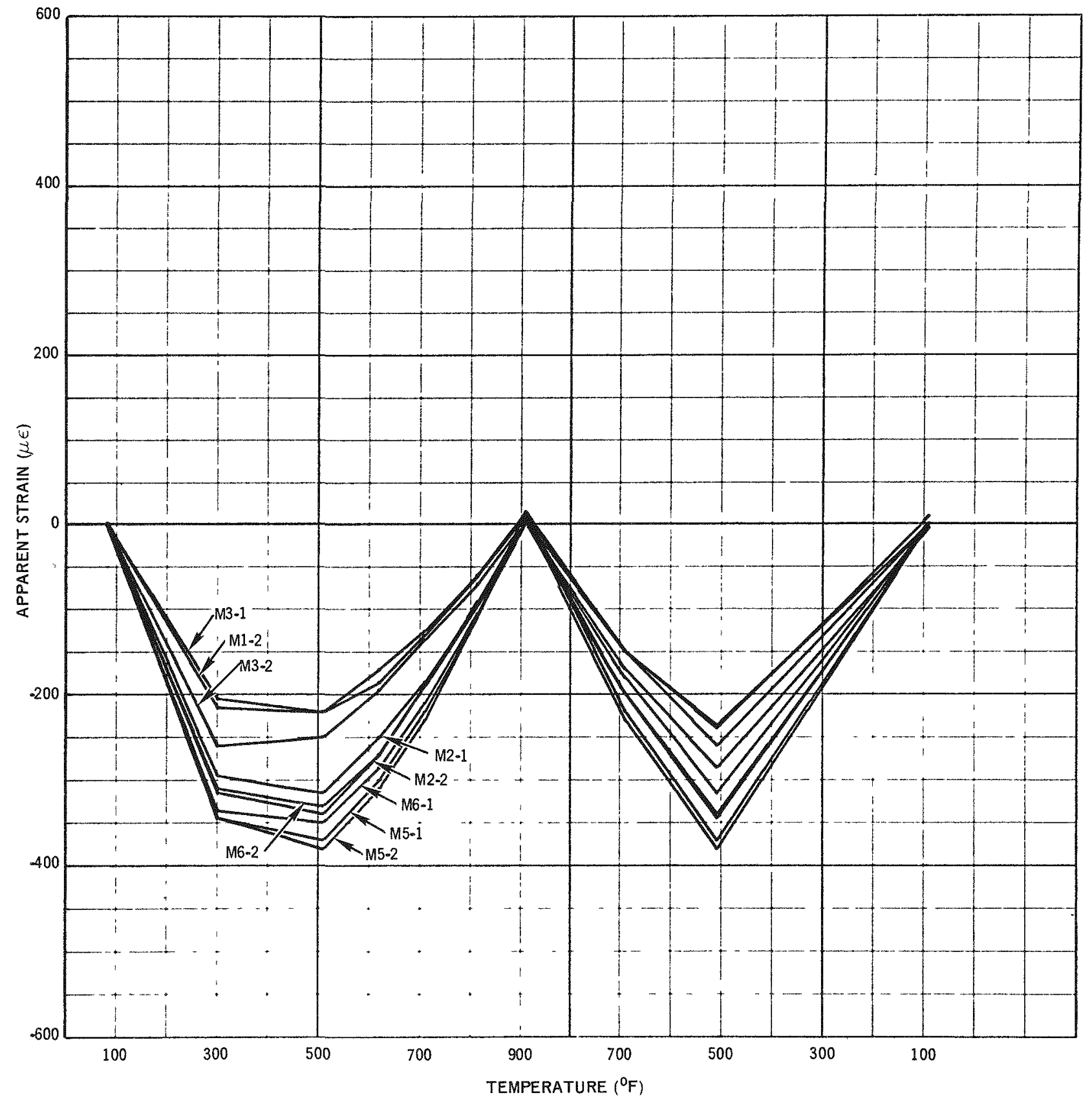

$12 \cdot 7-66$ UNC

7694.5515

Figure 17. Apparent Strain vs Temperature, Microdot Specimens $\mathrm{M}-1$, $\mathrm{M}-2$, and $\mathrm{M}-3$, With Optimum Temperature Compensation Resistor in Cixcuit 
strain by $93 \%$. Figure 18 shows the apparent strain vs temperature, data points, mean values, confidence limits, and tolerance limits for Specimens $M-1$ through M-3, with the temperature compensation resistor in the circuit. By using the resistor, not only was there a $93 \%$ reduction in the apparent strain, but a reduction in the width of the confidence interval, from $\sim 2000 \mu \epsilon$ to a maximum of $140 \mu \mathrm{\epsilon}$, which also amounts to about a $93 \%$ reduction. Likewise, the width of the tolerance limit interval is reduced from $\sim 7000 \mu \epsilon$ to $\sim 470 \mu \epsilon$, which also constitutes a reduction of $\sim 93 \%$.

The benefits to be accrued by use of a temperature compensation resistor are now clearly evident. Without the use of such a resistor, meaningful or sufficiently accurate strain measurements are not possible, unless one were to precalibrate each gage before use. A $100-\mu \epsilon$ uncertainty or error in the meas ured strain on austenitic stainless steel at $900^{\circ} \mathrm{F}$ results in an uncertainty or error in an uniaxial stress field of $\sim 2500$ psi stress. Whether an uncertainty or error of this magnitude can be tolerated depends primarily on the magnitude of the strain being measured. If the magnitude of the strain is of the order of $1000 \mu \epsilon$, then the error in stress, due to a $100-\mu \epsilon$ error in measurement, would be $10 \%$. For larger strains, the error would be proportionately less; and, for smaller strains, proportionately greater.

b. BLH Gages

Figure 19 is a plot of initial apparent strain vs temperature for BLH specimens $B-1$, and $B-5$ through $B-8$, for the first cycle. It is noted that:

1) The apparent strain is quite large $\left(\sim 66,000 \mu \epsilon\right.$ at $\left.1200^{\circ} \mathrm{F}\right)$

2) There is substantial spread from gage to gage $(\sim 16,000 \mu \epsilon$, which is considered excessive).

Figure 20 is a plot of the initial apparent strain vs temperature for the second cycle. It is noted that:

1) A considerable change in the shape of the plot has occurred

2) The curves are quite nonlinear

3) The maximum apparent strain (at $1200^{\circ} \mathrm{F}$ ) has decreased from about 66,000 to $62,000 \mu \epsilon$.

It should also be noted Gage B6-1 failed during the second cycle.

NAA-SR - 12118 


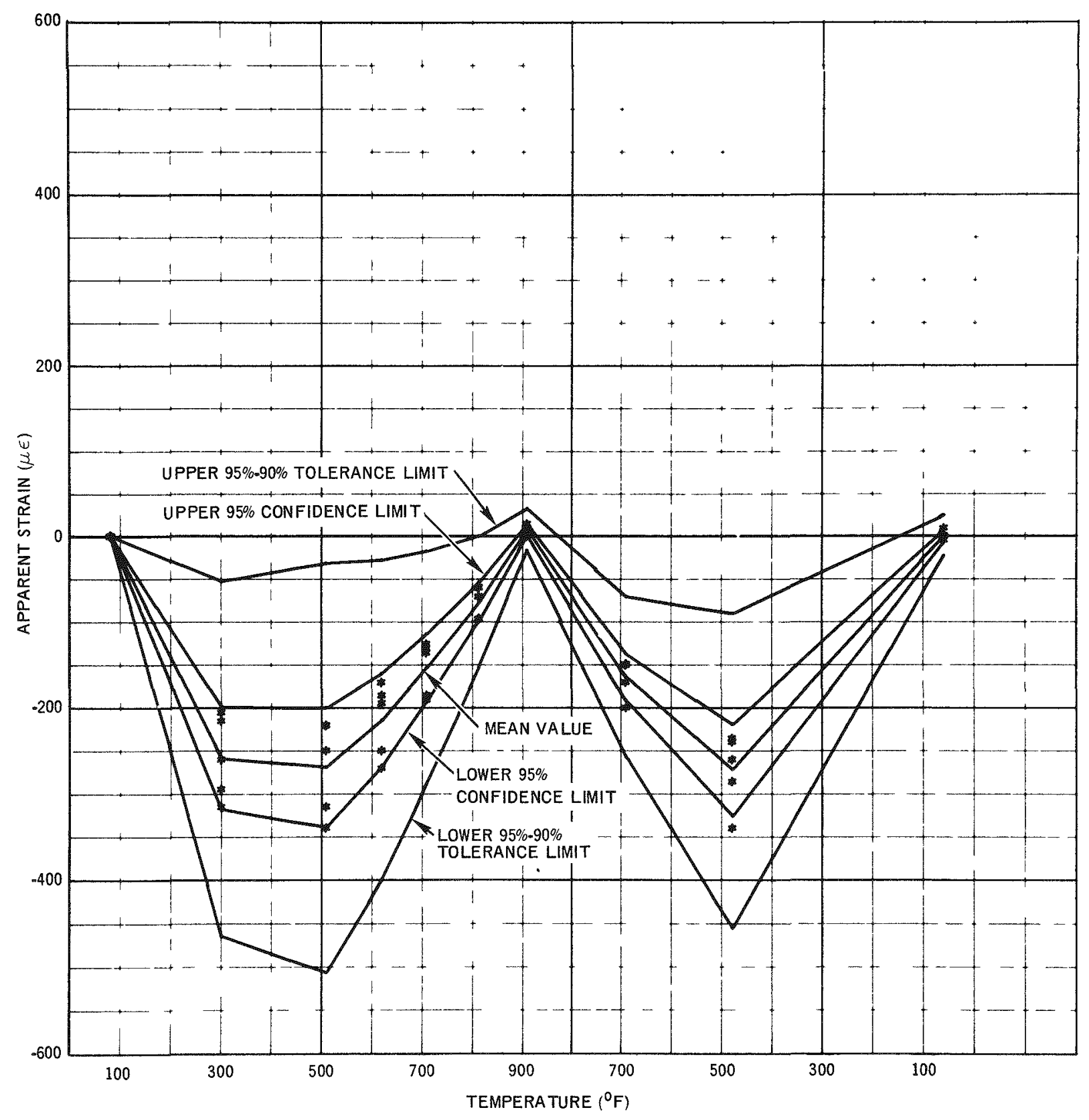

12-7-66 UNC

Figure 18. Apparent Strain vs Temperature, With Confidence and Tolerance Limits, Microdot Specimens $M-1, M-2$, and $M-3$, Gages No. 1 and No. 2, With Optimum Temperature Compensation Resistor in Circuit 


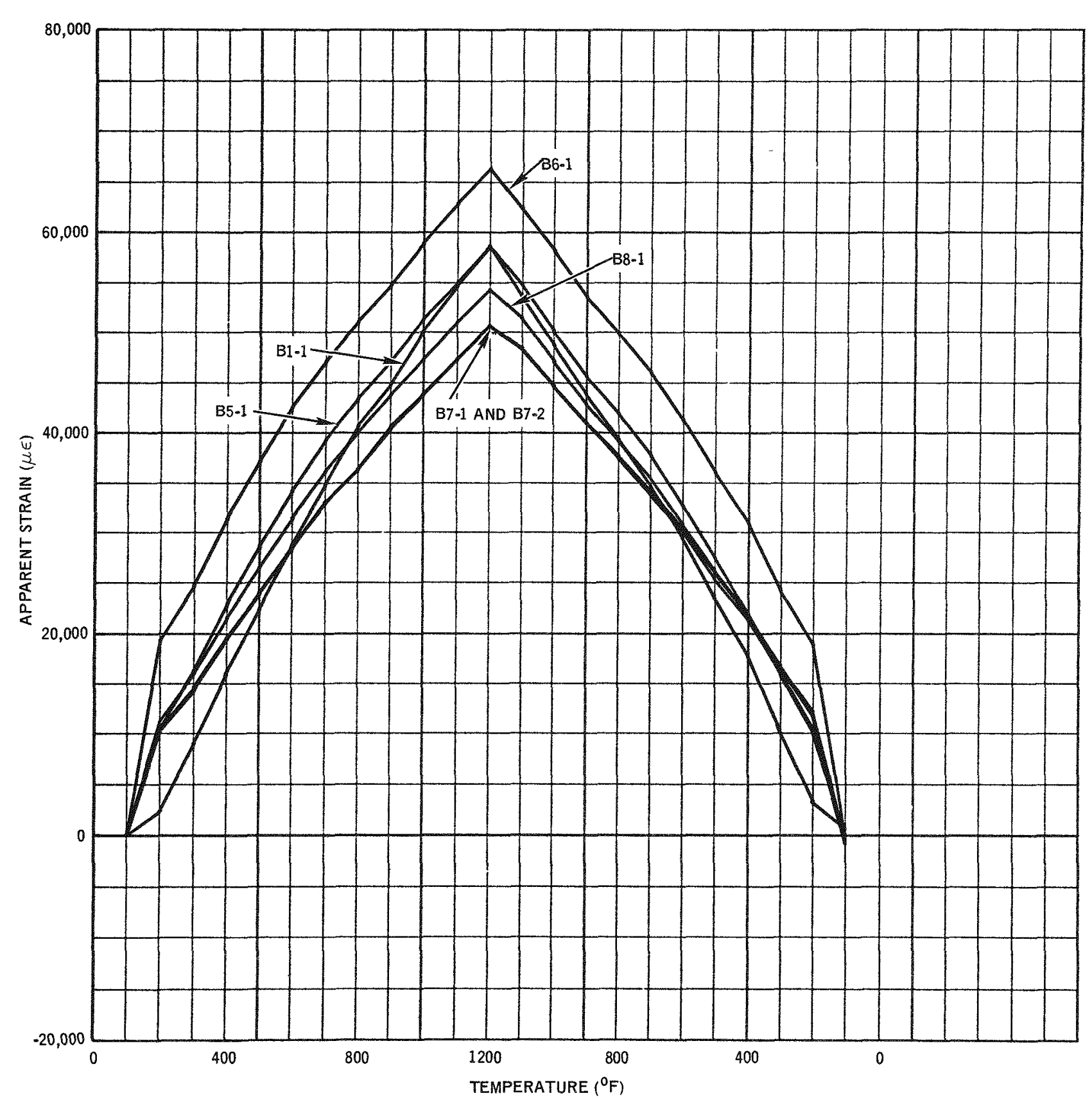

12-7-66 UNC

$7694-5517$

Figure 19. Initial Apparent Strain vs Temperature, BLH Specimens B-1, and B-5 Through B-8, Gages No. 1 and No. 2,

Series 1, Cycle 1

$$
\begin{aligned}
& \text { NAA-SR }-12118 \\
& 53
\end{aligned}
$$




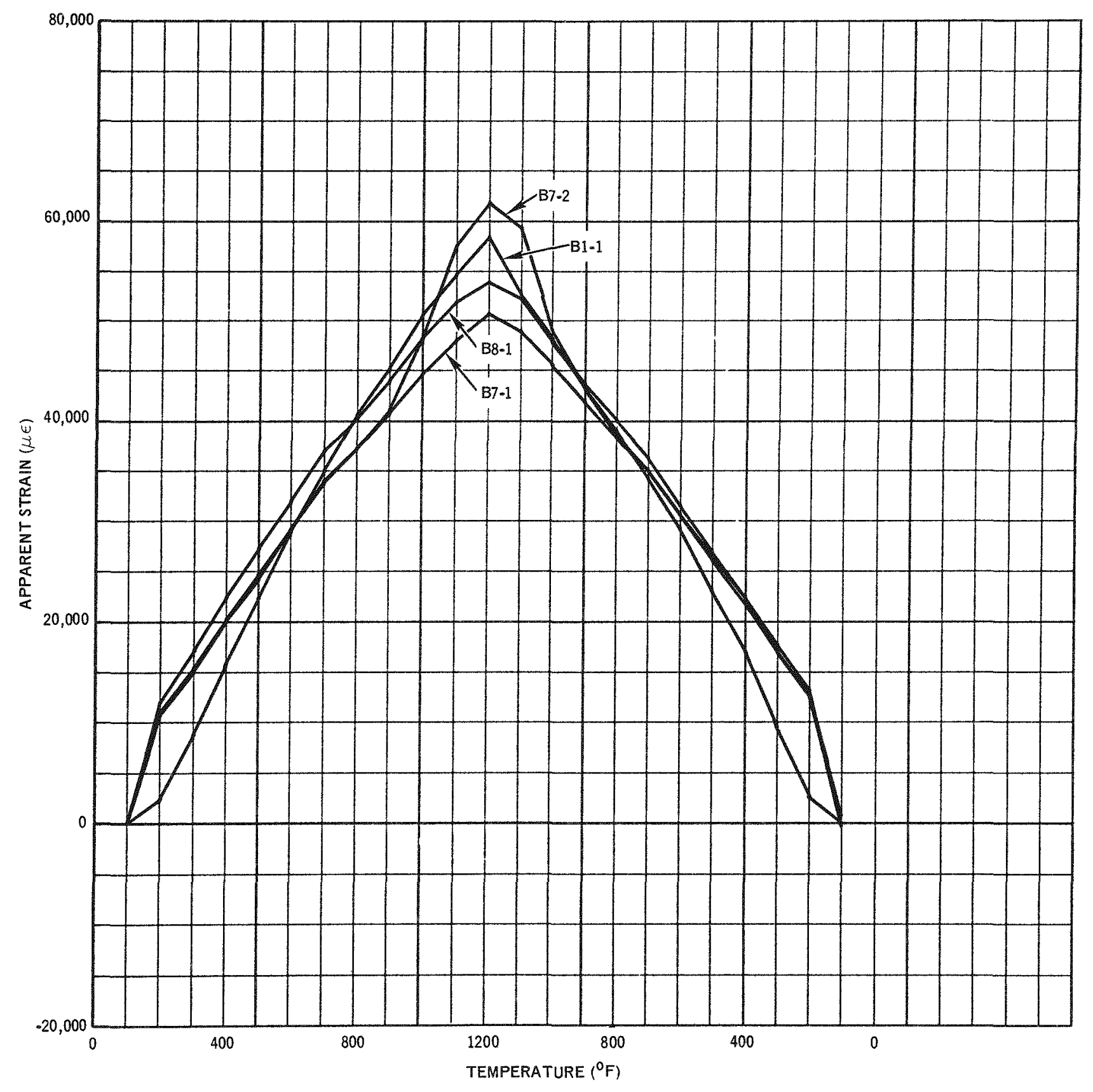

$12.7-66$ UNC

$7694-5518$

Figure 20. Initial Apparent Strain vs Temperature, BLH Specimens $B-1, B-7$, and B-8, Gages No. 1 and No. 2, Series 1, Cycle 2

NAA-SR-12118 
A similar plot for the third cycle has not been presented, since there were not enough gages remaining to justify making the plot. Also, since none of the gages survived the first test series, plots showing the series-to-series variations are not presented.

Figure 21 shows the initial apparent strain (Cycle 1) data points, mean values, $95 \%$ confidence limits, and the 95\%-90\% tolerance limits for the BLH specimens. A majority of the gages fall within the $95 \%$ confidence limits, and all points are well within the $95 \%-90 \%$ tolerance limits.

The widths of the confidence limit interval and the tolerance limit interval, at $1200^{\circ} \mathrm{F}$, are $\sim 13,000$ and $44,000 \mu \mathrm{\epsilon}$, respectively. Variations of this magnitude raise some question as to whether this gage would be satisfactory, even if a dummy gage were used, unless the dummy gage were a "near-perfect" match for the active gage.

Figure 22 shows a similar plot for the BLH gages for Series 1, Cycle 2. There is a drastic difference in the shapes of the curves for Cycles 1 and 2, although the difference in the widths of the confidencelimits is relatively small. The widths of the tolerance limits increase from $\sim 44,000$ to $52,000 \mu \mathrm{E}$.

2. Transient (Thermal Shock) Apparent Strain Characteristics

a. Microdot Gages

Figures 23 through 25 are plots of the transient apparent strain vs temperature for Specimen $\mathrm{M}-1$, for heating rates of 10,20 , and $30^{\circ} \mathrm{F} / \mathrm{sec}$. (These plots may be regarded as typical for all the gages stabilized at $1200^{\circ} \mathrm{F}$.) They show Cycles 1, 5, and 10 for the first series, and the first cycle for each subsequent series. As the heating rate increases, the curves become more nonlinear; and the spread, from series to series, becomes greater at the intermediate temperatures, as shown by the lows in the curves. However, at $900^{\circ} \mathrm{F}$, there is little difference in either the spread or the strain magnitudes for the three heating rates. The greater spread at the intermediate temperatures is believed to be due to one or a combination of the following:

1) A complex thermal stress field which develops within the gage, itself, due to temperature gradients and thermal lag within the gage assembly under transient heating conditions. Even if is othermal conditions existed, there 


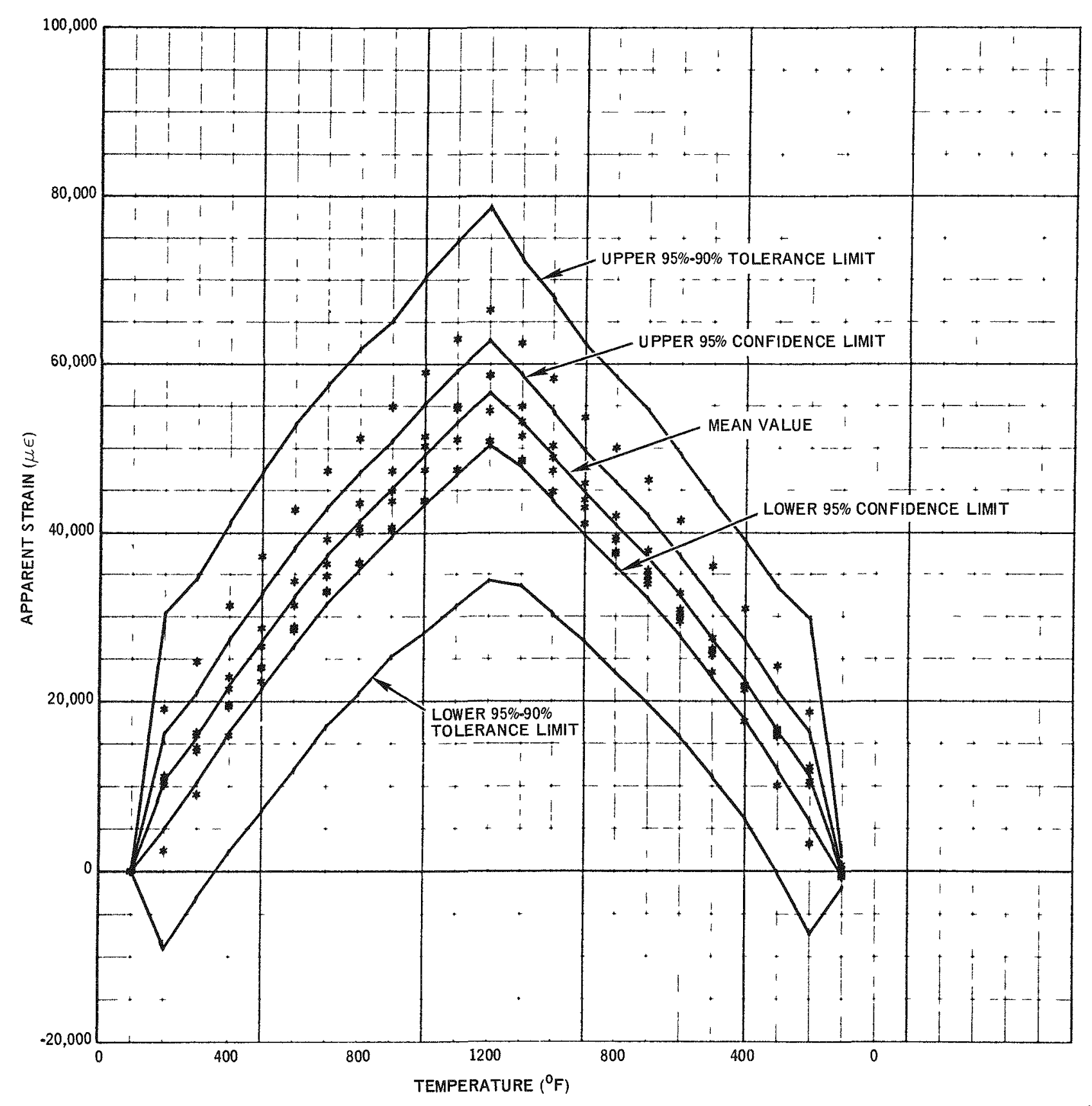

12.7.66 UNC

$7694-5519$

Figure 21. Initial Apparent Strain vs Temperature, With Confudence and Tolerance Limits, BLH Specimens, Series 1, Cycle 1 


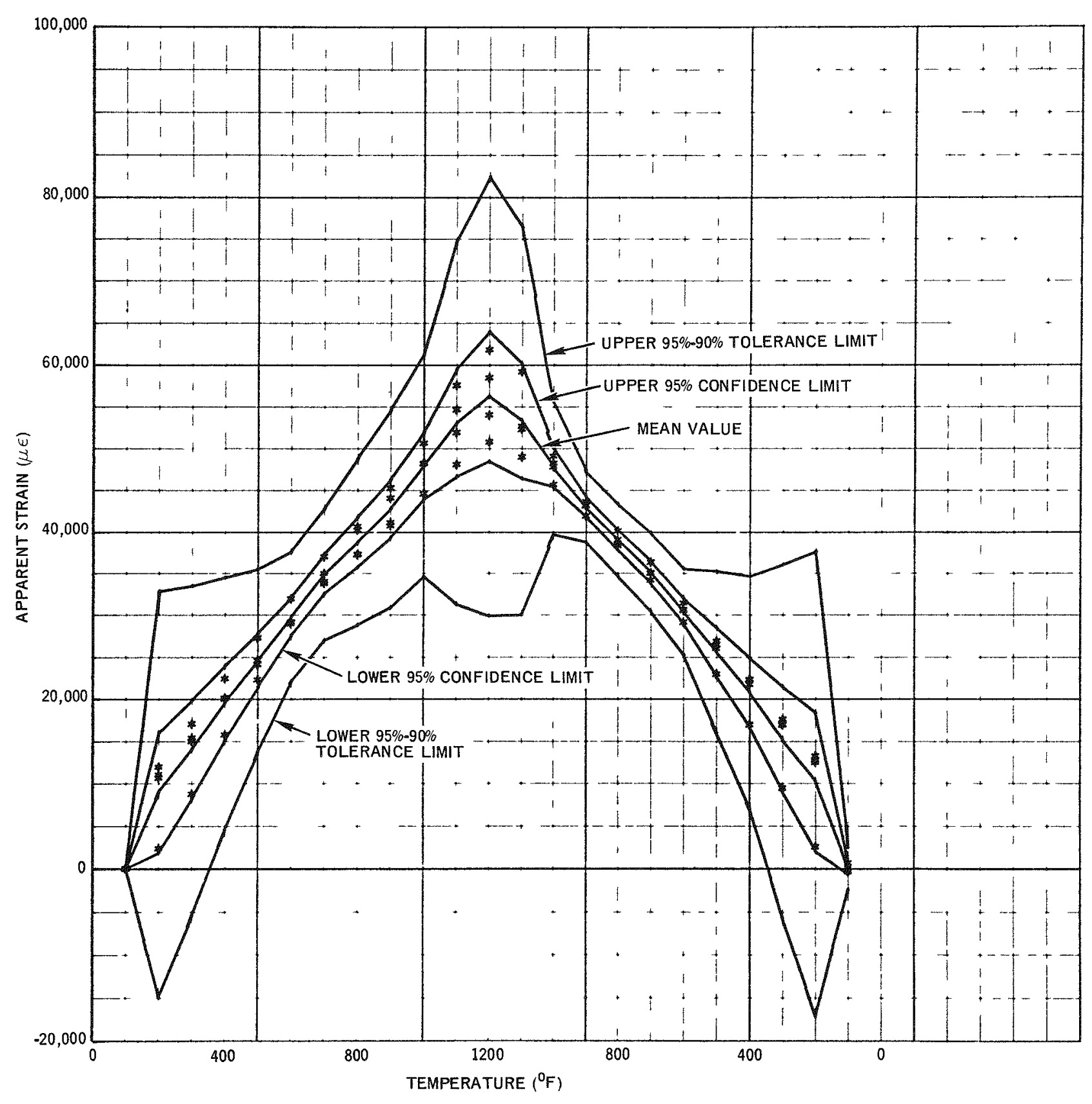

12-7-66 UNC

Figure 22. Apparent Strain vs Temperature, With Confidence and Tolerance Limits, BLH Specimens B-1, and B-5 Through B-8, Gages No. 1 and No. 2, Series 1, Cycle 2 


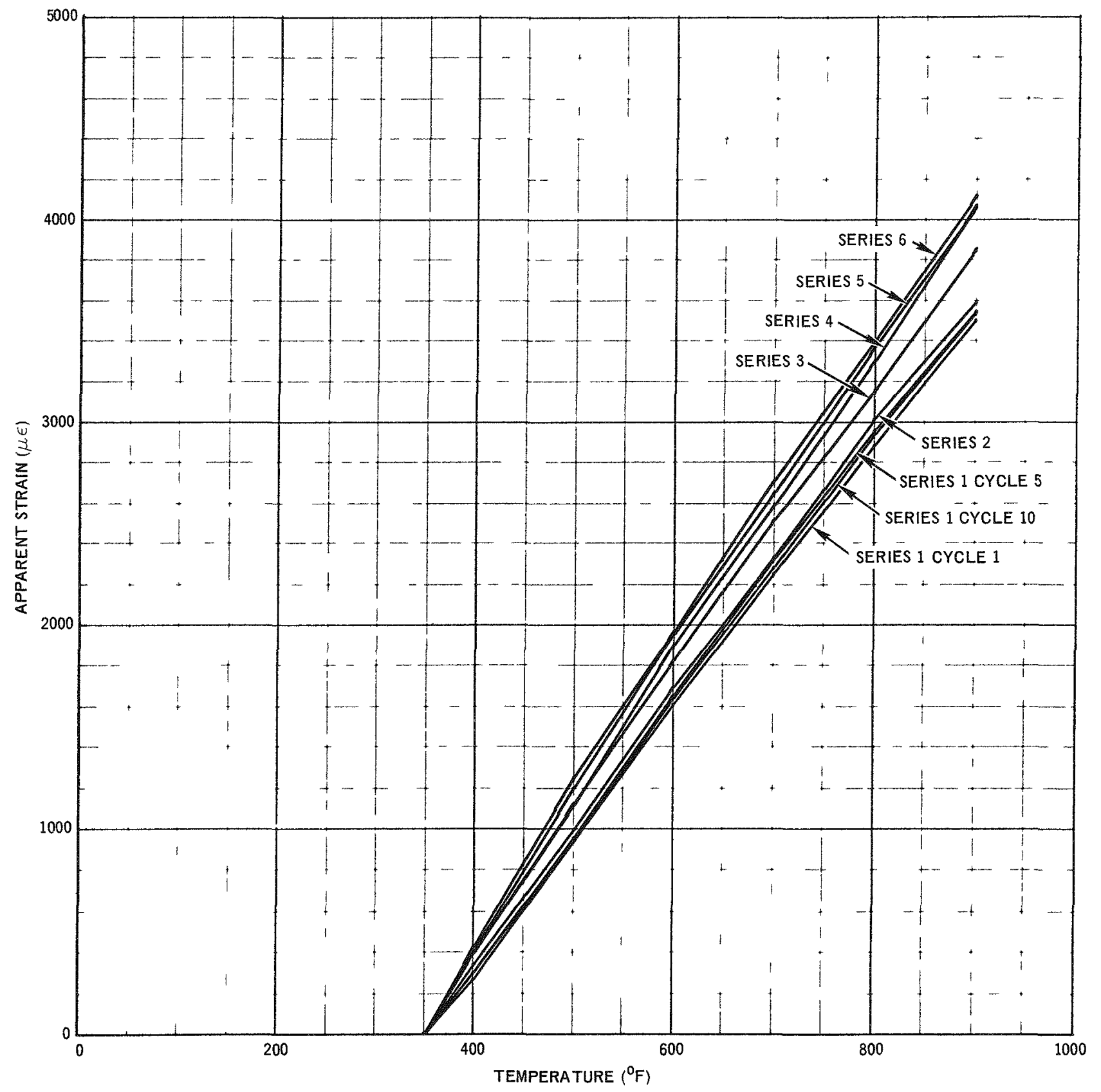

$12.7-66$ UNC

7694-5521

Figure 23. Transient (Thermal Shock) Apparent Strain vs Temperature, Microdot Specimen $\mathrm{M}-1,10^{\circ} \mathrm{F} / \mathrm{sec}$, Series 1 Through 6 


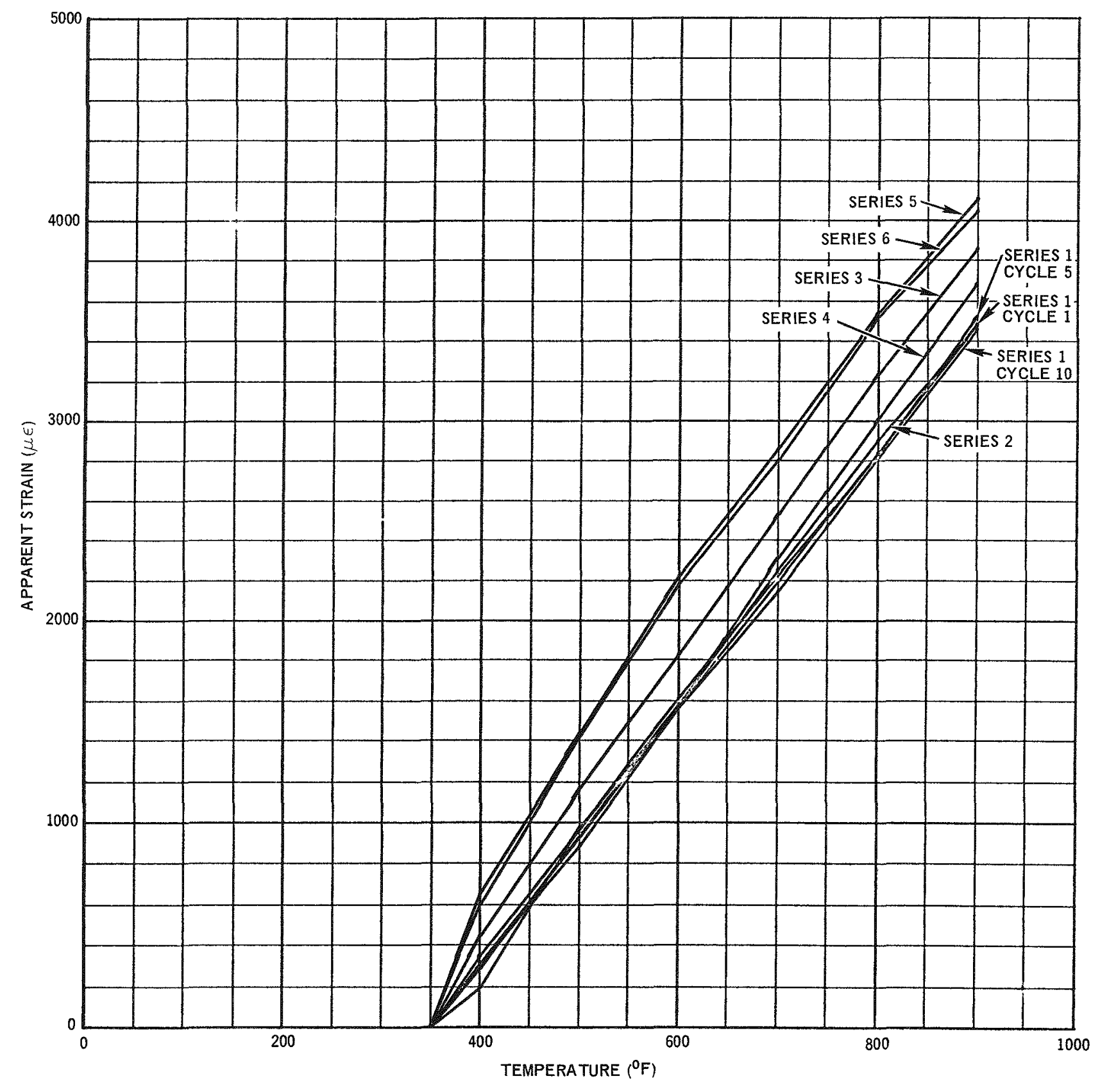

$12-7-66$ UNC

$7694-5522$

Figure 24. Transient (Thermal Shock) Apparent Strain vs Temperature, Microdot Specimen $\mathrm{M}-1,20^{\circ} \mathrm{F} / \mathrm{sec}$, Series 1 Through 6

NAA -SR - 12118 


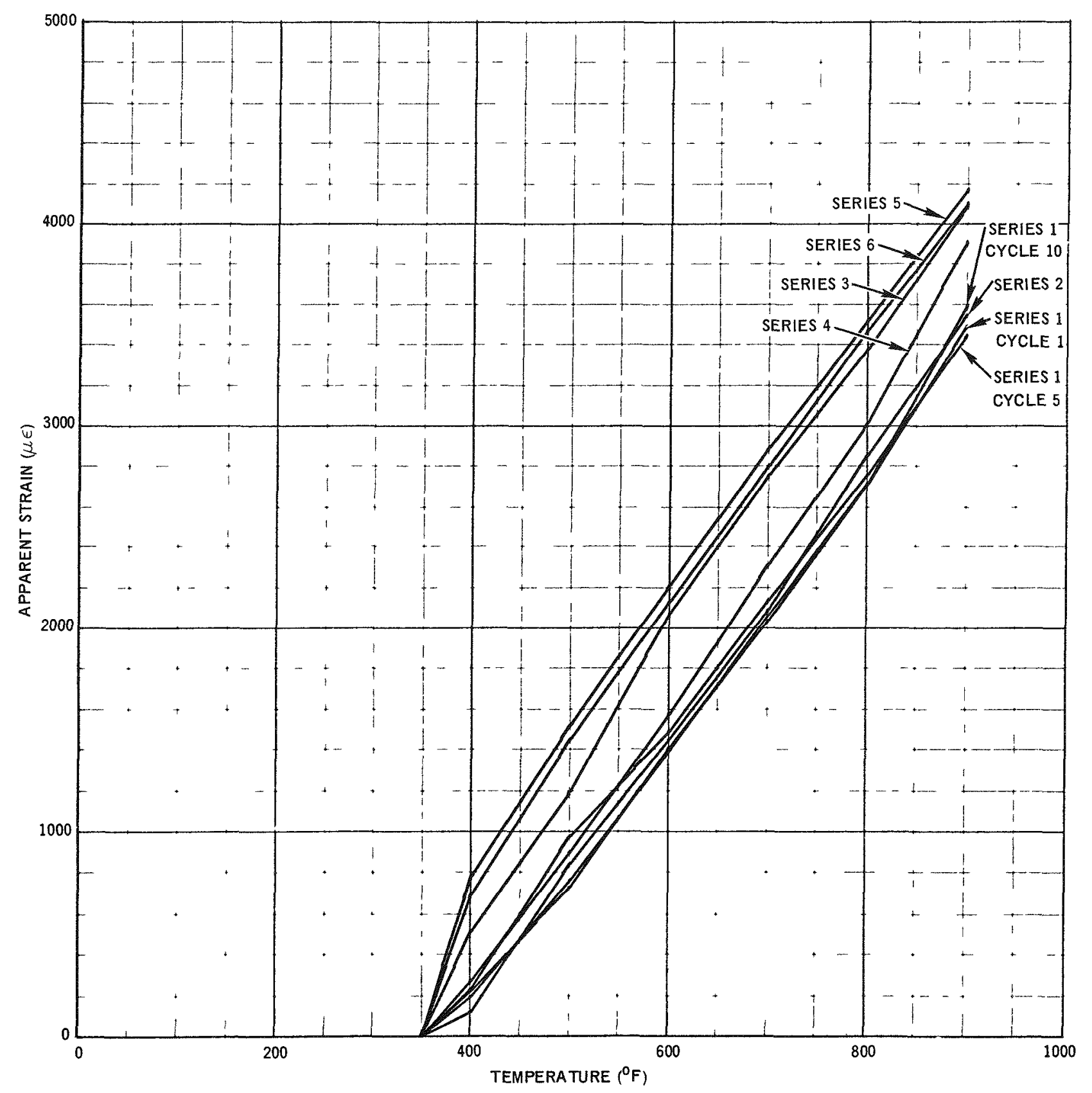

12-7-66 UNC

$7694-5523$

Figure 25. Transient (Thermal Shock) Apparent Strain vs Temperature, Microdot Specimen $\mathrm{M}-1,30^{\circ} \mathrm{F} / \mathrm{sec}$, Series 1 Through 6 
would be some thermal stress within the gage, due to differences in the coefficients of thermal expansion of the various elements comprising the gages. This mismatch creates an apparent strain, in the same manner that a mismatch between the gage and the material to which the gage is bonded creates an apparent strain. Also, since the coefficients of thermal expansion are not truly linear with temperature, the thermal stresses, and hence the apparent strain, would be expected to be somewhat nonlinear.

2) The radiant heating furnace does not produce a true isothermal temperature distribution throughout the gage and test bar. This results in a temperature lag between the bare metal of the specimen to which the thermocouple is welded and the gage filament. The effect of this lag is shown in Figure 26, which is a plot of the transient apparent strain vs temperature for Specimen M-1, Series 1, Cycle 1. The steady-state apparent strain vs temperature curve is also shown. The steady-state curve is virtually a straight line, the slight curvature probably being due to the nonlinearity in coefficients of thermal expansion. The $10^{\circ} \mathrm{F} / \mathrm{sec}$ curve, while not as straight as the steady-state curve, is still reasonably straight. At the $20^{\circ} \mathrm{F} / \mathrm{sec}$ heating rate, the effect of the temperature lag is more pronounced, as evidenced by the sag in the curve, which becomes still more pronounced at $30^{\circ} \mathrm{F} / \mathrm{sec}$. For the $30^{\circ} \mathrm{F} / \mathrm{sec}$ curve, the tangent to the curve at $350^{\circ} \mathrm{F}$ has a slope which is substantially less than that for the other curves; while the tangent to this same curve, at $900^{\circ} \mathrm{F}$, has a tangent whose slope is much greater than that for the other curves. This means that, at the beginning of the cycle, the temperature of the gage filament is lagging the temperature of the bare specimen. As the maximum temperature is approached, the gage filament temperature is leading the bare metal temperature. In between these two end points, the temperature of the gage filament more closely approaches that of the bare metal temperature, as evidenced by the fact that, except near the end points, the average slopes for all of the curves are about equal.

Figure 27 is a plot of transient apparent strain vs temperature for a $10^{\circ} \mathrm{F} / \mathrm{sec}$ heating rate for Specimen $\mathrm{M}-5$, which was stabilized at $900^{\circ} \mathrm{F}$ instead of $1200^{\circ} \mathrm{F}$. (This plot may be considered typical for all gages on Specimens $M-5$ and $M-6$. ) Shown on this plot are the transient apparent strains for Cycles 1, 5, and 10 for

NAA-SR - 12118 


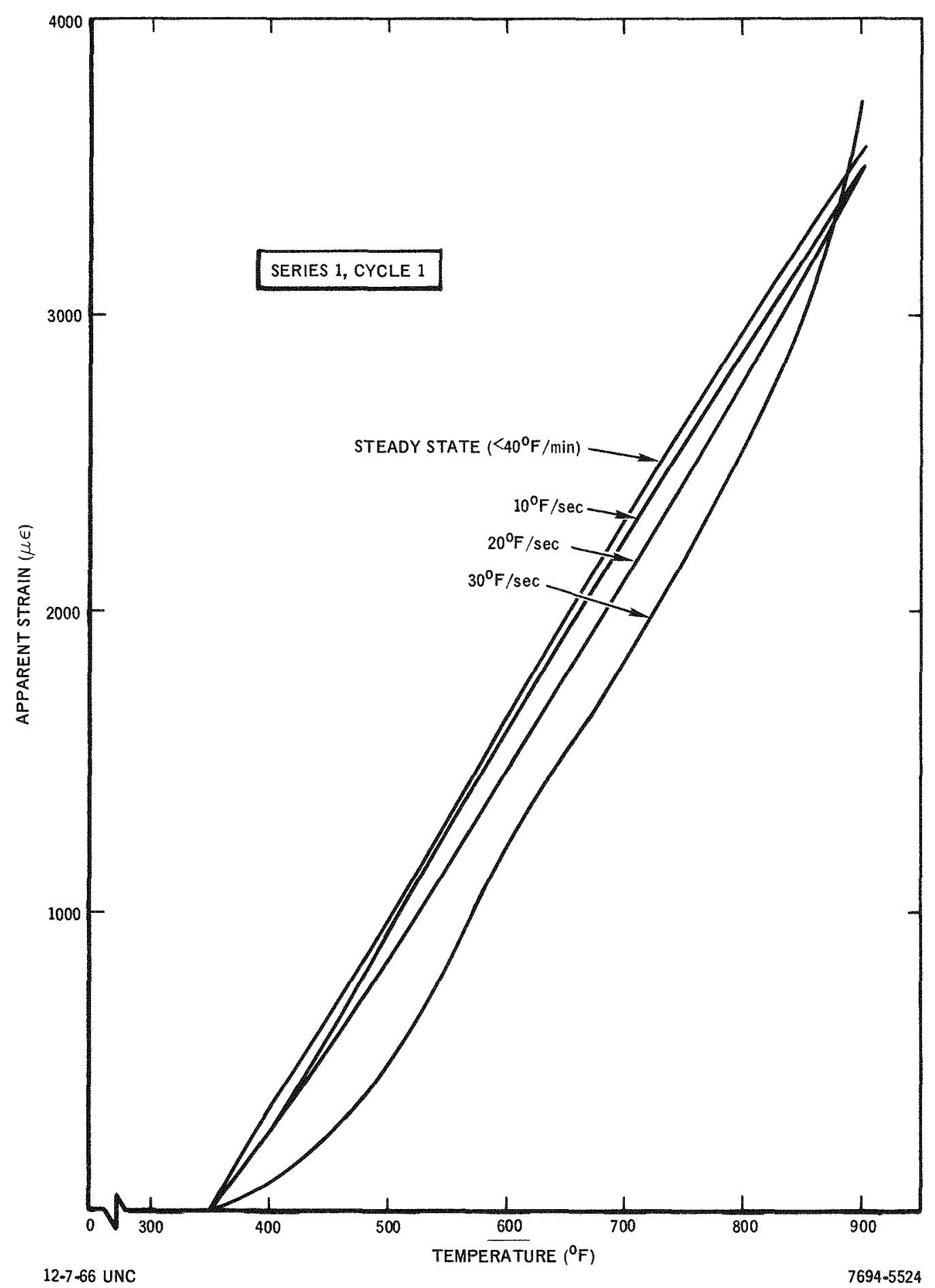

Figure 26. Apparent Strain vs Temperature for Different Heating Rates, Microdot Specimen M-1 


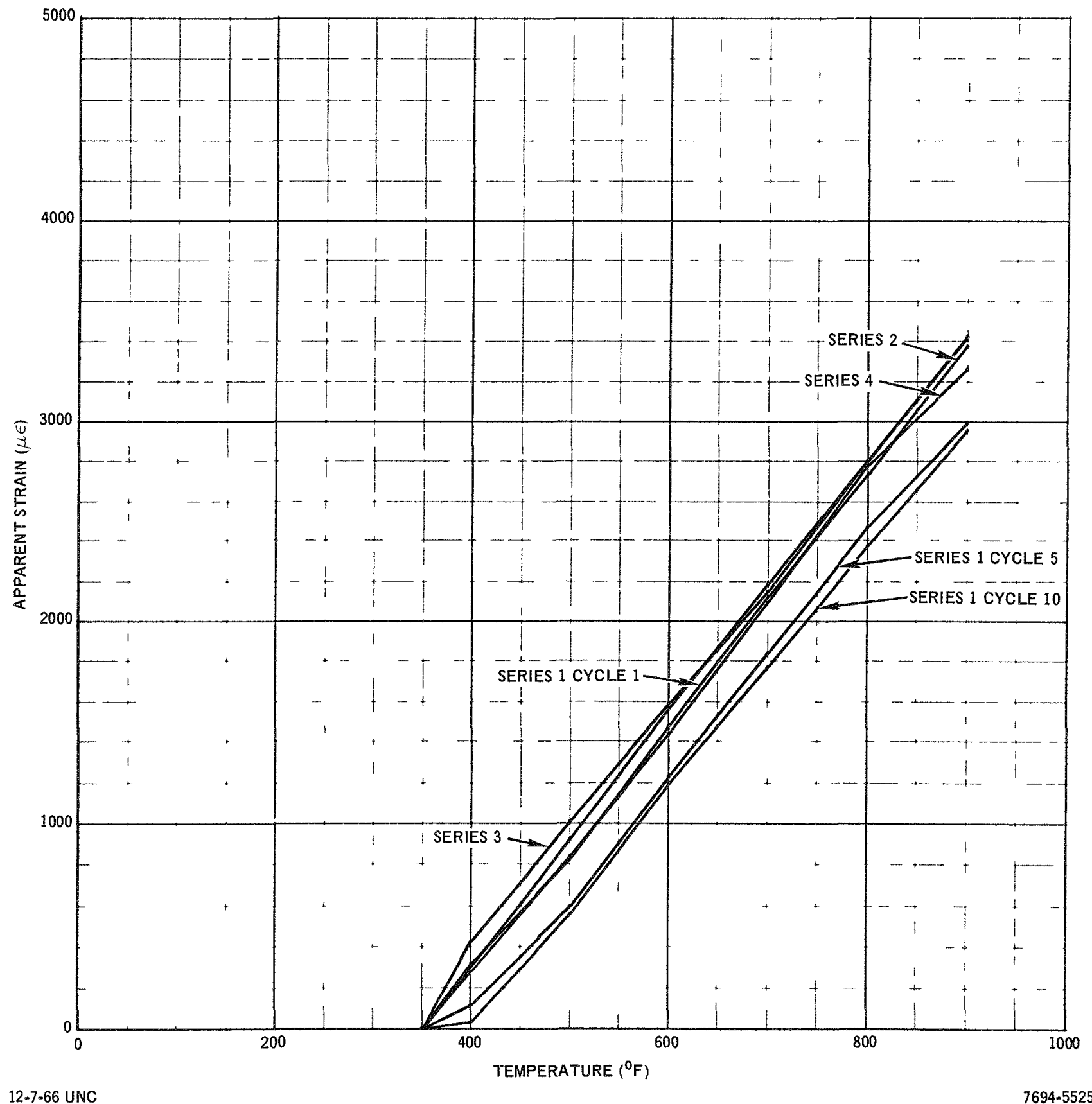

Figure 27. Transient (Thermal Shock) Apparent Strain vs Temperature, Microdot Specimen M-5, $10^{\circ} \mathrm{F} / \mathrm{sec}$, Series 1 Through 4 


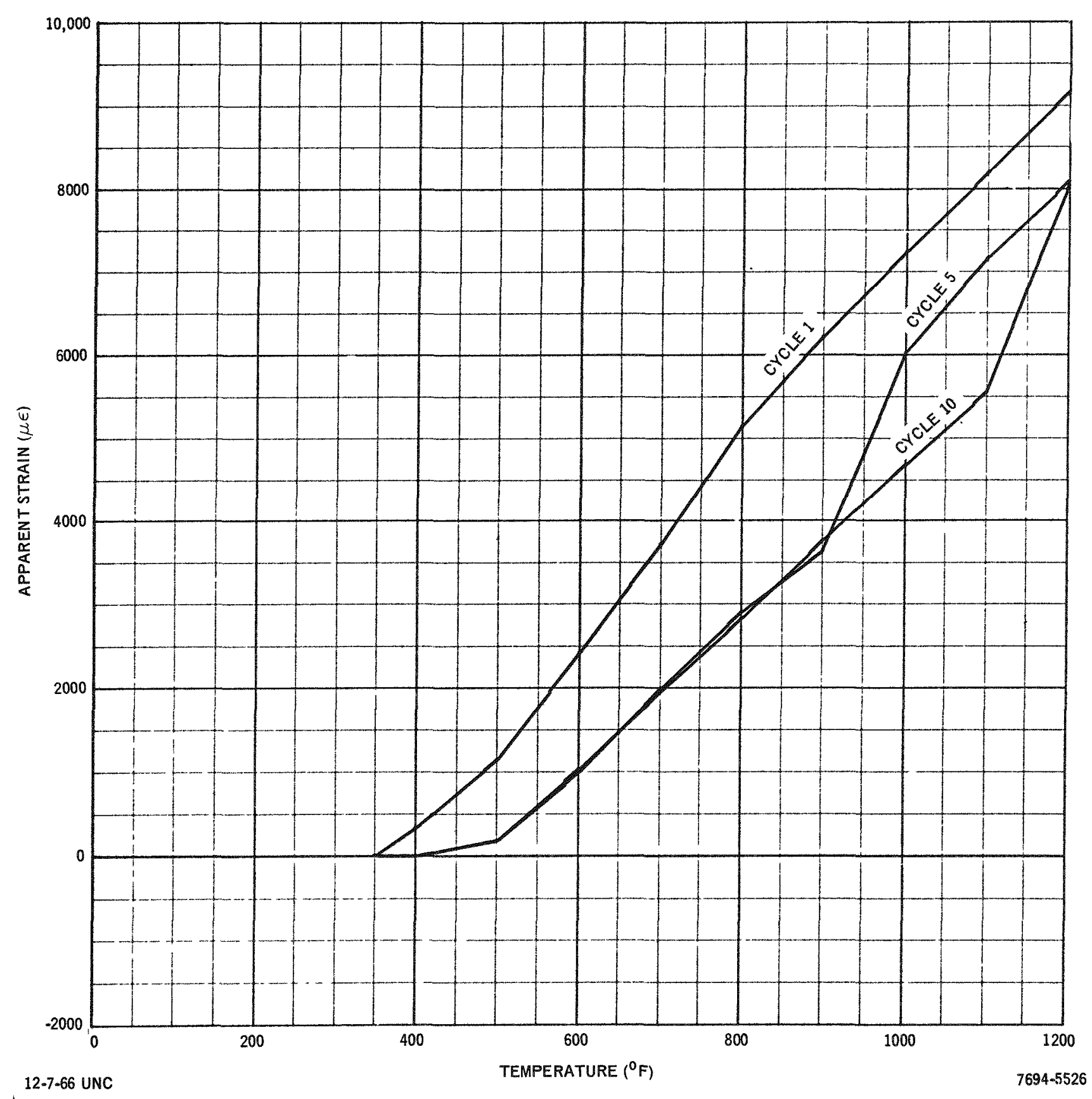

Figure 28. Transient (Thermal Shock) Apparent Strain vs Temperature, Microdot Specimen $\mathrm{M}-7,10^{\circ} \mathrm{F} / \mathrm{sec}$, Series 1 
the first series, and for the first cycle of each subsequent series. There is no precise sequential pattern, although, in general, the apparent strains increase as the number of soaks increase. The apparent strain at $900^{\circ} \mathrm{F}$ is somewhat less than that for specimens stabilized at $1200^{\circ} \mathrm{F}$; however, there is more spread from series to series. This is due to the greater nonlinearity which exists at the lower ends of the curves.

Figure 28 is a plot of transient apparent strain vs temperature for the $10^{\circ} \mathrm{F} /$ sec heating rate for Specimen $M-7$, which was stabilized at $1200^{\circ} \mathrm{F}$ and tested to temperatures of $1200^{\circ} \mathrm{F}$. The plot is for Cycles 1,5 , and 10 for the first series only, since the poor performance of the gage did not justify testing beyond the first series. There is quite a large amount of spread between Cycle 1 and Cycles 5 and 10 ; and, above $900^{\circ} \mathrm{F}$, there is an abrupt change in the curves for Cycles 5 and 10 . In addition to the erratic behavior above $900^{\circ} \mathrm{F}$, the magnitude of apparent strain at $1200^{\circ} \mathrm{F}$ is about twice that at $900^{\circ} \mathrm{F}$. This erratic behavior and marked increase in apparent strain above $900^{\circ} \mathrm{F}$ may be due, in part, to the more rapid migration of gold plating in the $\mathrm{Pt}-\mathrm{W}$ gage filament leads at the higher temperature.

b. BLH Gages

Figures 29 through 31 are the transient apparent strain vs temperature plots which were obtained by averaging the strain for Specimens B-1, B-2, B-5, B-6, and $\mathrm{B}-7$ for Cycles $1,4,7$, and 10 at heating rates of 5,10 , and $25^{\circ} \mathrm{F} / \mathrm{sec}$. These were the only specimens remaining with operating gages. Originally, it was planned to evaluate these gages at the same heating rates as those used for the Microdot gages $\left(10,20\right.$, and $\left.30^{\circ} \mathrm{F} / \mathrm{sec}\right)$. However, because of the large number of BLH gages which failed at heating rates below $10^{\circ} \mathrm{F} / \mathrm{sec}$ during the pilot testing, it was decided to reduce the heating rates to these three 15,10 , and $25^{\circ} \mathrm{F} / \mathrm{sec}$ ). The repeatability of these gages through the first series, from cycle to cycle, was found to be excellent for heating rates not exceeding $10^{\circ} \mathrm{F} /$ sec. At $25^{\circ} \mathrm{F} / \mathrm{sec}$, there was a loss in repeatability, as is evident from Figure 31. Information beyond the first series is not reported, because none of the BLH gages survived beyond the first series. It is believed that early failure of these gages was due to the large thermal stresses which developed within the

NAA-SR -12118 


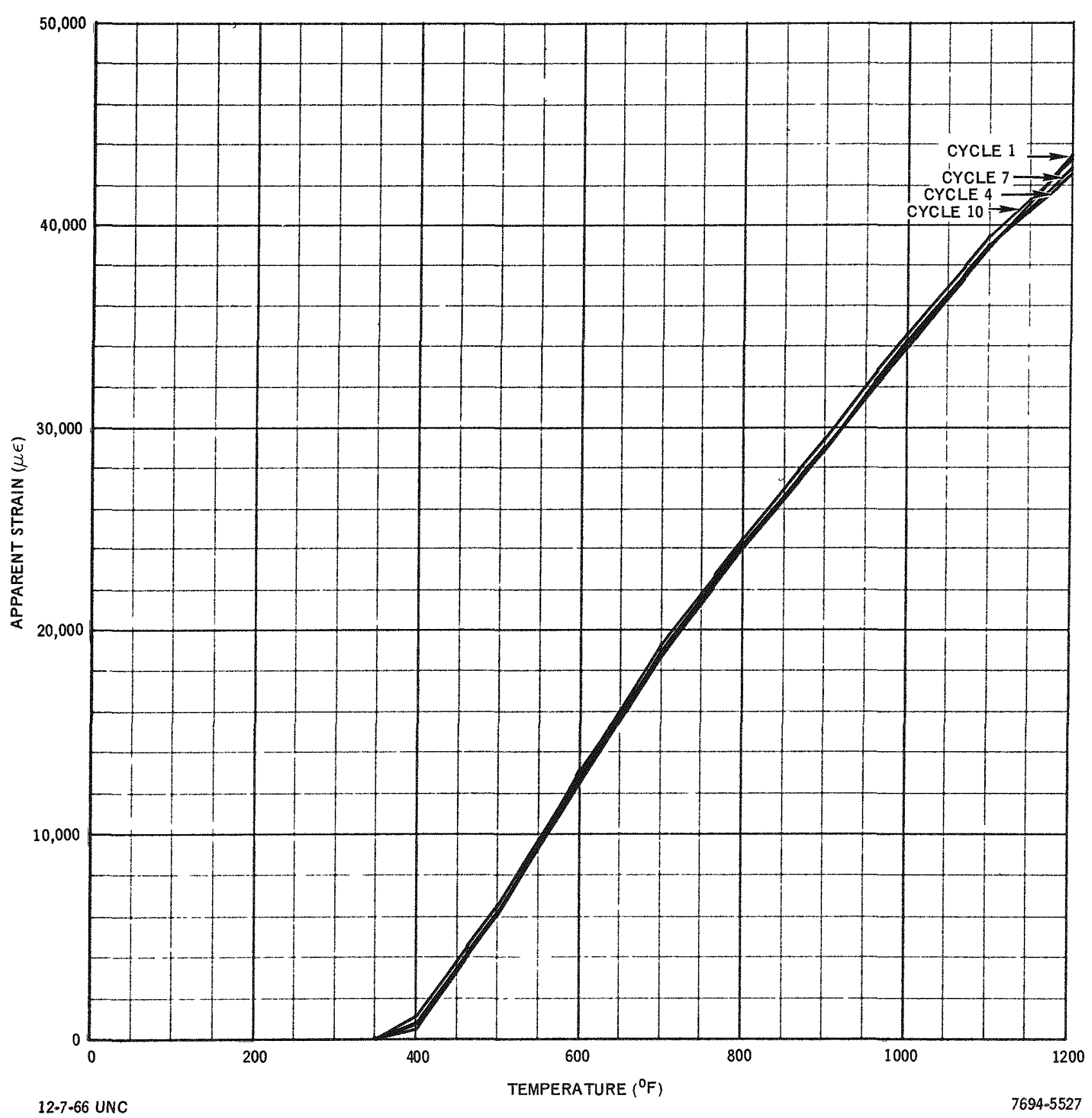

Figure 29. Average Transient (Thermal Shock) Apparent Strain vs Temperature, BLH Specimens, $5^{\circ} \mathrm{F} / \mathrm{sec}$, Series 1 


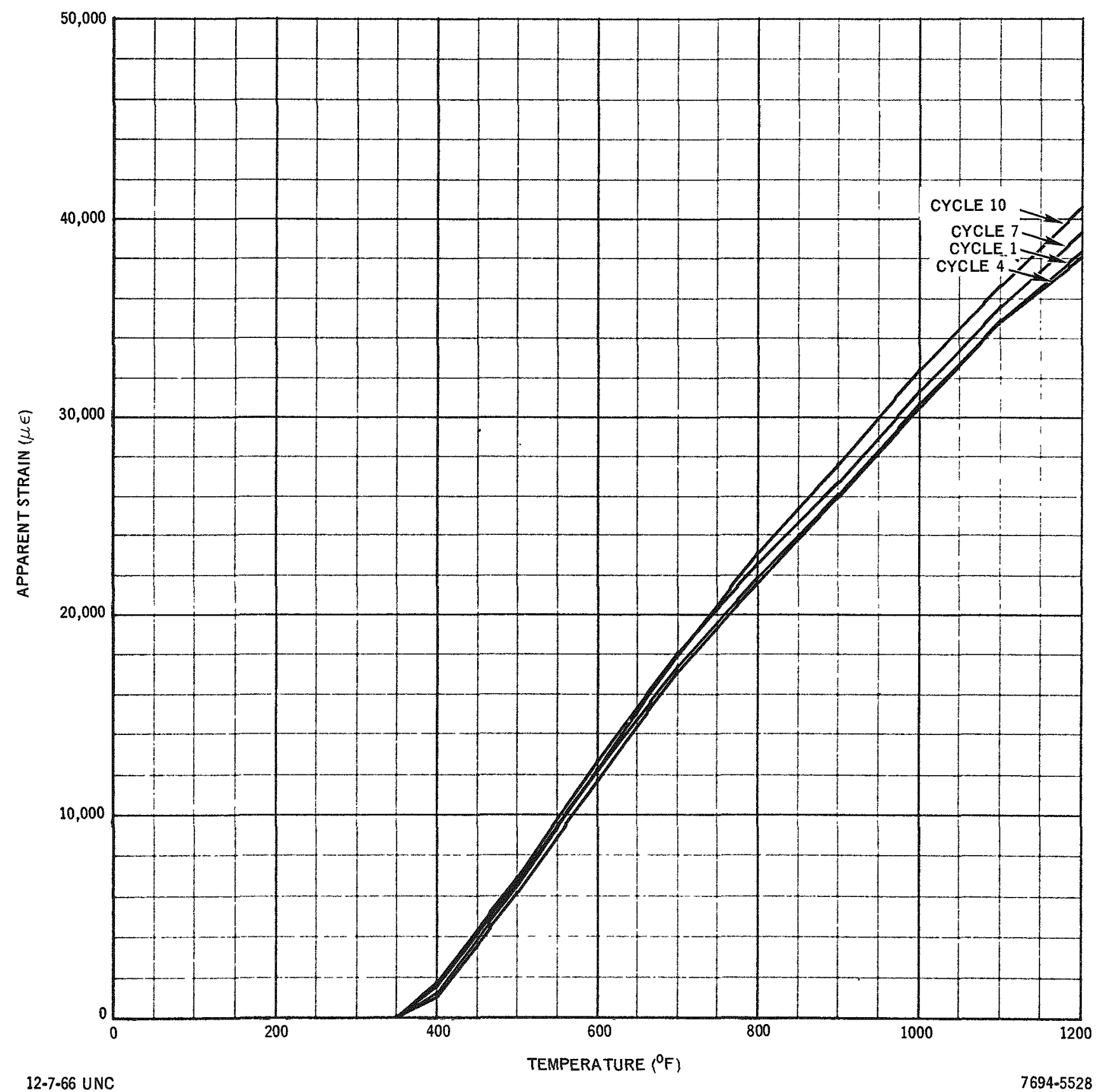

Figure 30. Average Transient (Thermal Shock) Apparent Strain vs Temperature, BLH Specimens, $10^{\circ} \mathrm{F} / \mathrm{sec}$, Series 1 


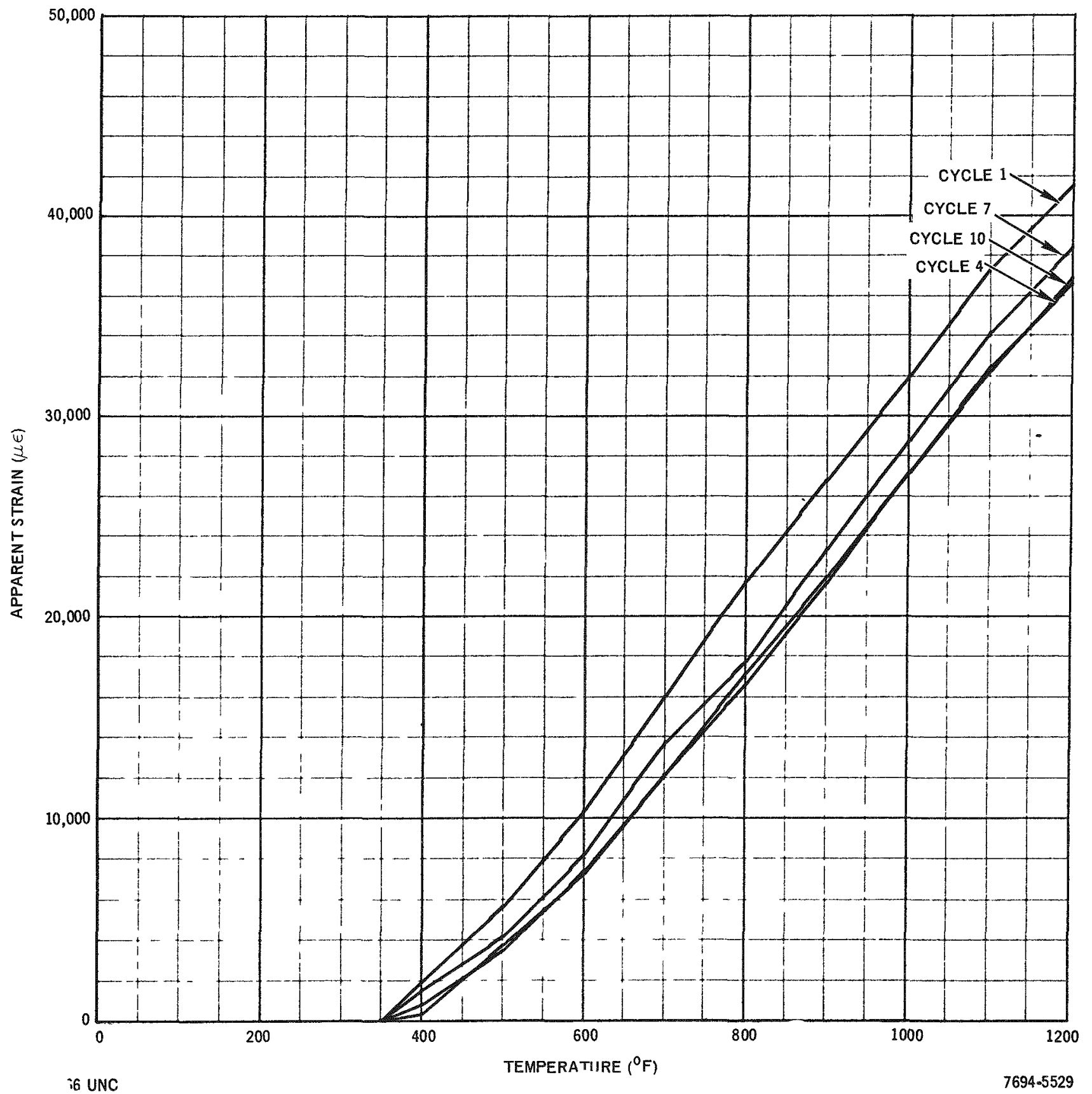

Figure 31. Average Transient (Thermal Shock) Apparent Strain vs Temperature, BLH Specimens, $25^{\circ} \mathrm{F} / \mathrm{sec}$, Series 1 
gage, itself, because of mismatch in the coefficients of thermal expansion between the gage filament and the metal to which the gage was bonded.

\section{Gage Factor Characteristics \\ a. Microdot Gages}

Figures 32 through 34 are plots of the gage factor data points, mean values, confidence limits, and tolerance limits for Specimens $M-1$ through $M-3$, for Series 1, 3, and 6. The gage factor decreases as the temperature is increased, all data points fall well within the tolerance limits, and most of them fall within the confidence limits. Unfortunately, time did not permit obtaining data at intermediate temperatures in all instances. In these cases, a straight line was drawn to connect the ambient data points and the points corresponding to the maximum temperature. This was a reasonable assumption, since the plot with the intermediate temperature is virtually a straight line. At $900^{\circ} \mathrm{F}$, the duration or spread in the mean values through the series is less than a few percent, which is considered very good. Also, the width of the confidence interval, in general, is less than $10 \%$, which is considered very good, in terms of the severe time-temperature history to which the gages were subjected.

Figures 35 through 37 are plots of the gage factor data points, mean values, confidence limits, and tolerance limits for Specimens M-5 and M-6, Series 1 , 2, and 3. It is noted, from Figure 35, that there is a slight bow in the mean curve. The bow is so slight, however, that the error in using a straight line between ambient and the maximum temperature on the other plots should be negligible for most measurements. The spread in the mean value at $900^{\circ} \mathrm{F}$ is less than a few percent, for the series; and all points fall within the confidence limits, again pointing up the conservatism associated with the tolerance limits.

A gage factor plot for Specimen M-7, which was evaluated at $1200^{\circ} \mathrm{F}$, is not shown; since the Microdot gage was found to be unsatisfactory for use above $900^{\circ} \mathrm{F}$.

\section{b. BLH Gages}

Figure 38 is a plot of the gage factor data points, mean values, confidence limits, and tolerance limits, at ambient and $1200^{\circ} \mathrm{F}$, for Specimens B-1, B-2, and B-5 through B-8, Series 1. These were the only specimens remaining with 


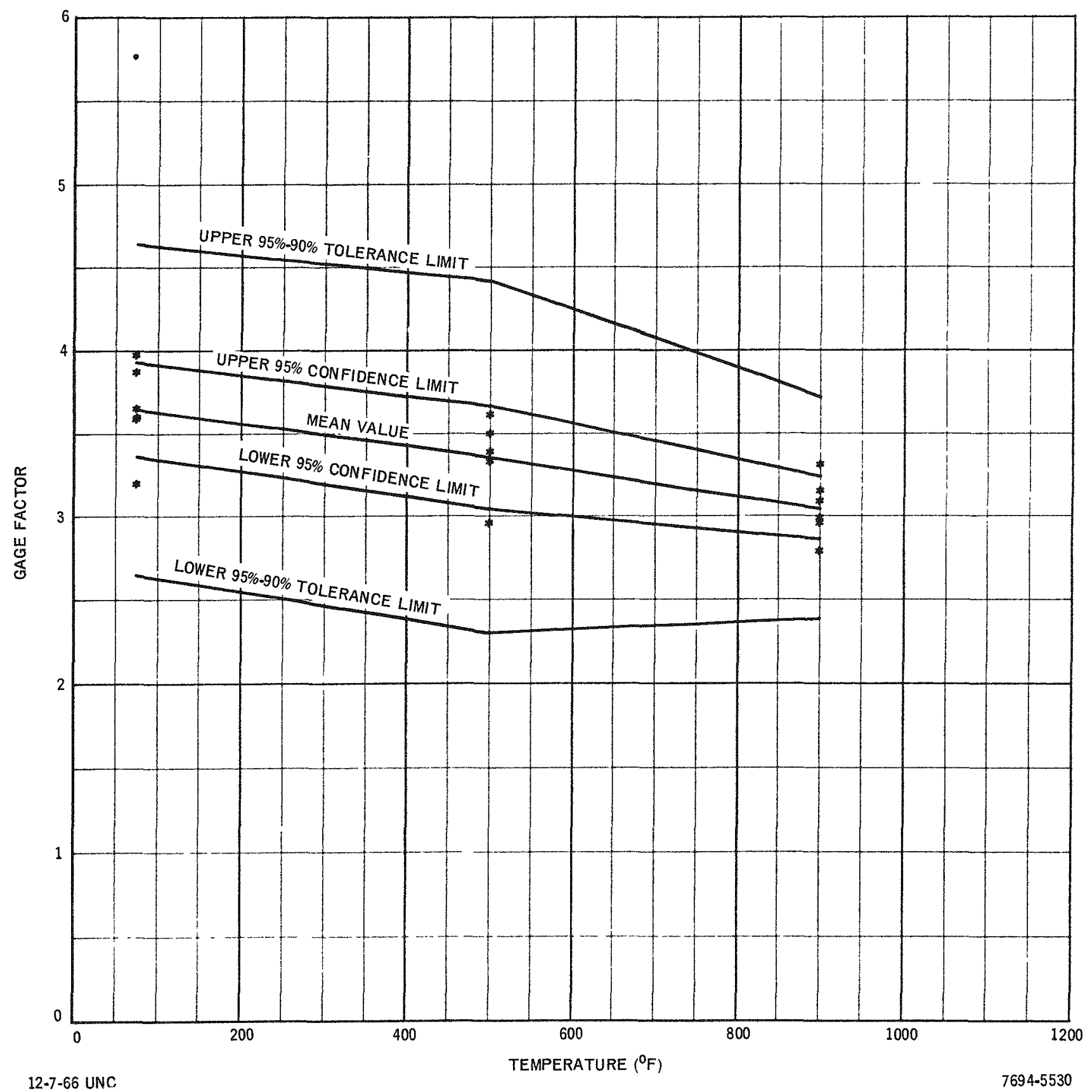

Figure 32. Gage Factor vs Temperature, With Confidence and Tolerance Limits, Microdot Specimens M-1 Through M-3, Series 1 


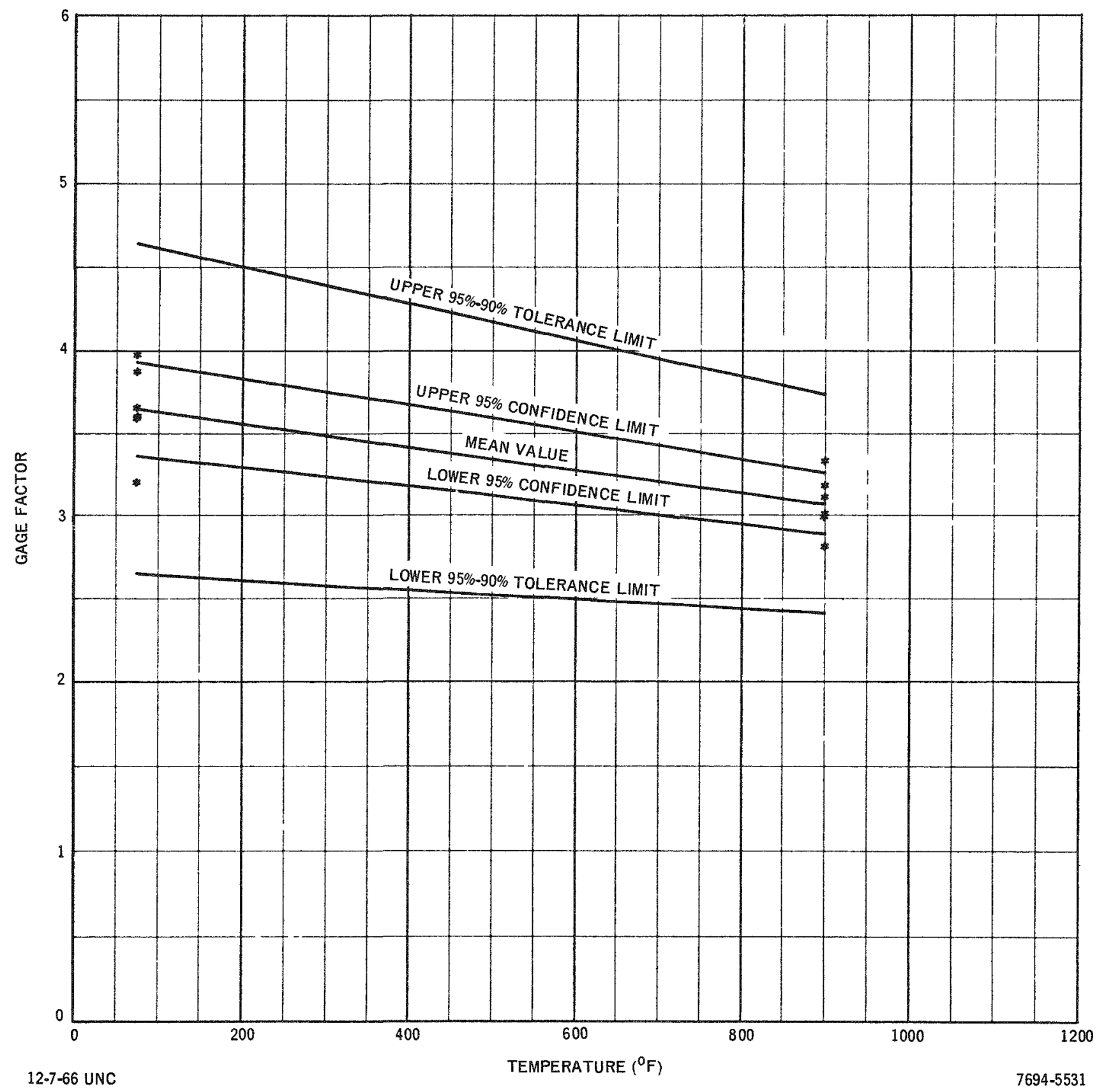

Figure 33. Gage Factor vs Temperature, With Confidence and Tolerance Limits, Microdot Specimens M-1 Through M-3, Series 3 


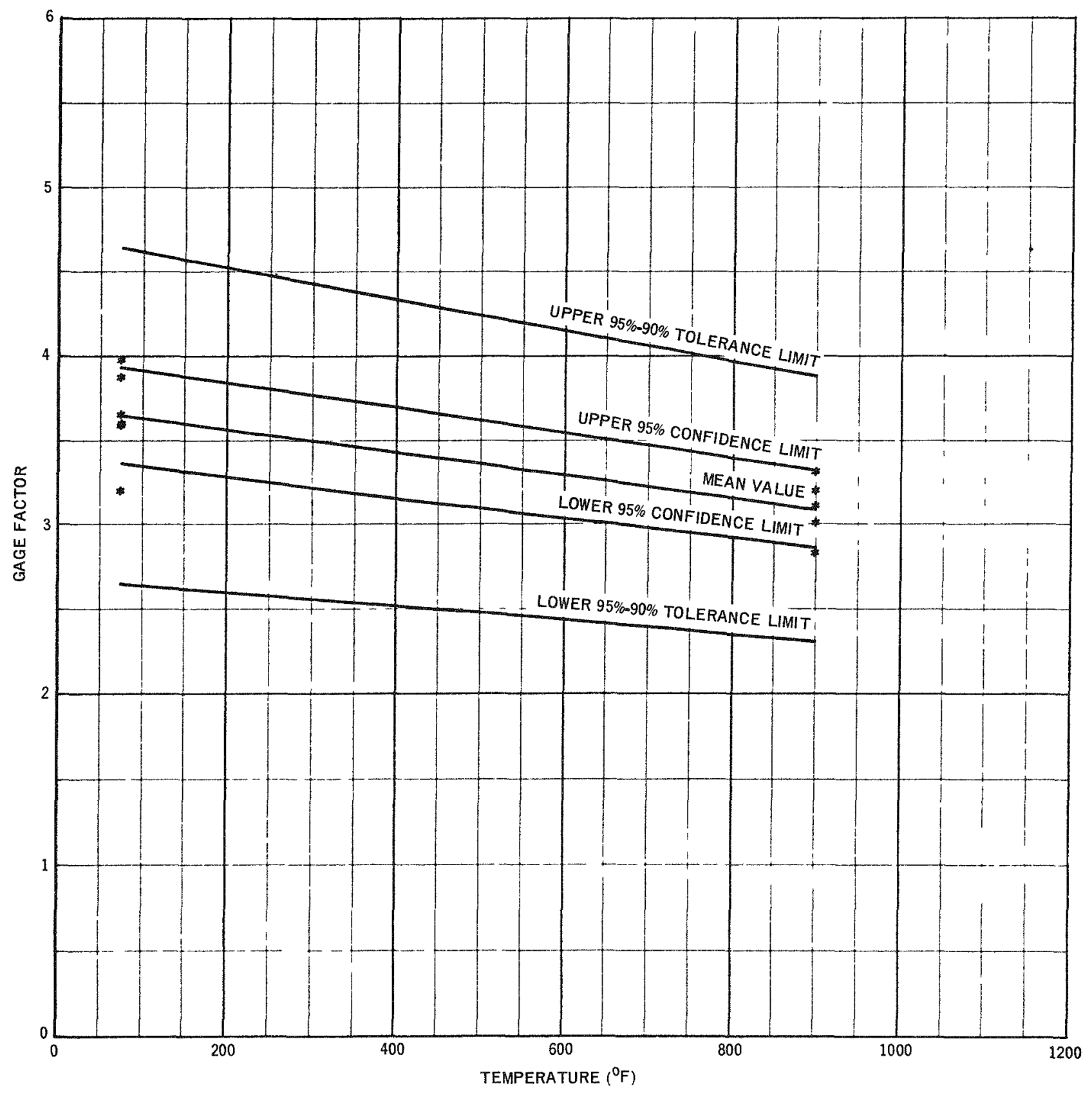

12-7-66 UNC

7694-5532

Figure 34. Gage Factor vs Temperature, With Confidence and Tolerance Limits, Microdot Specimens M-1 Through M-3, Series 6 


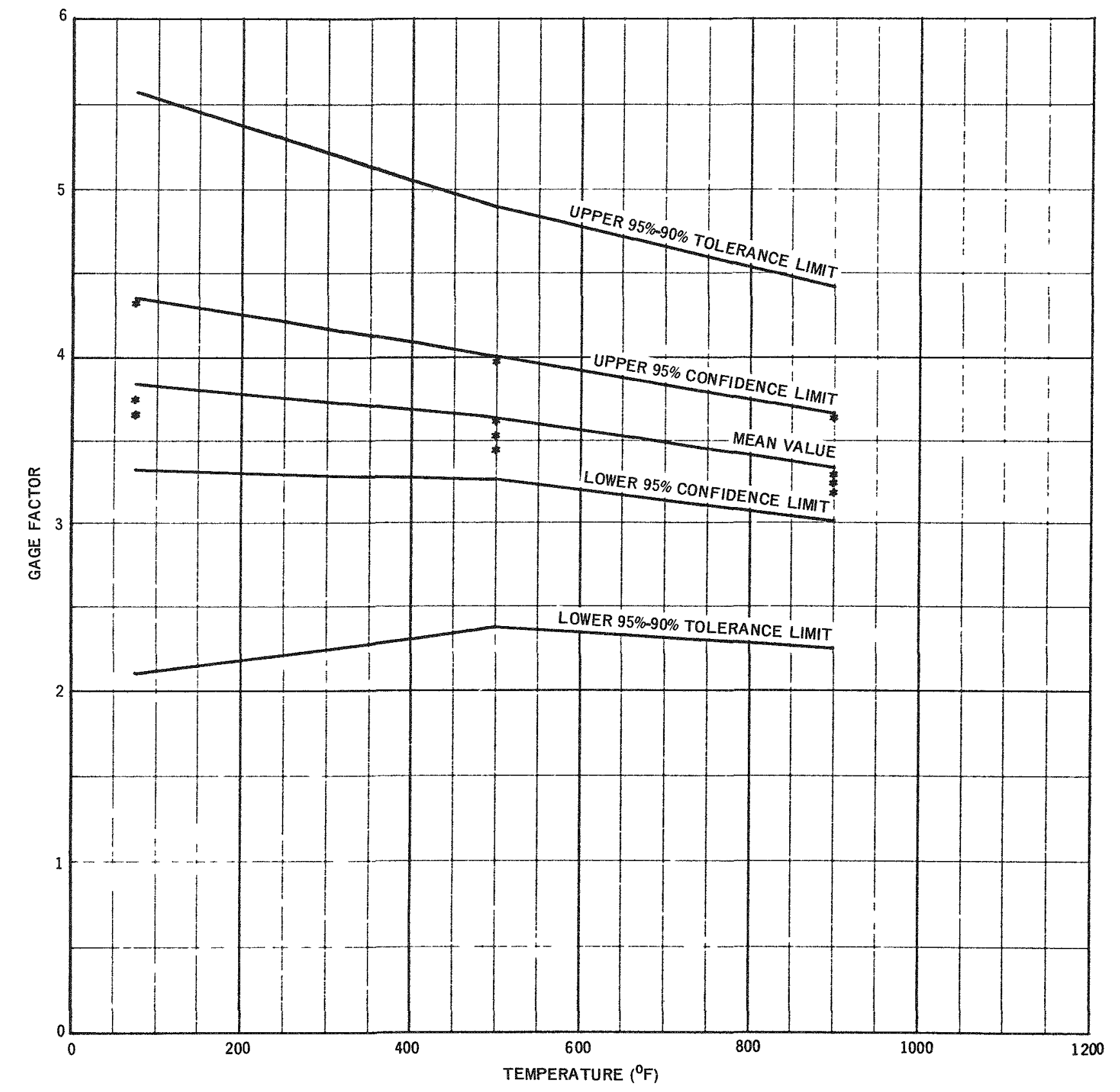

12.7 .66 UNC

Figure 35. Gage Factor vs Temperature, With Confidence and Tolerance Limits, Microdot Specimens $M-5$ and $M-6$, Series 1 


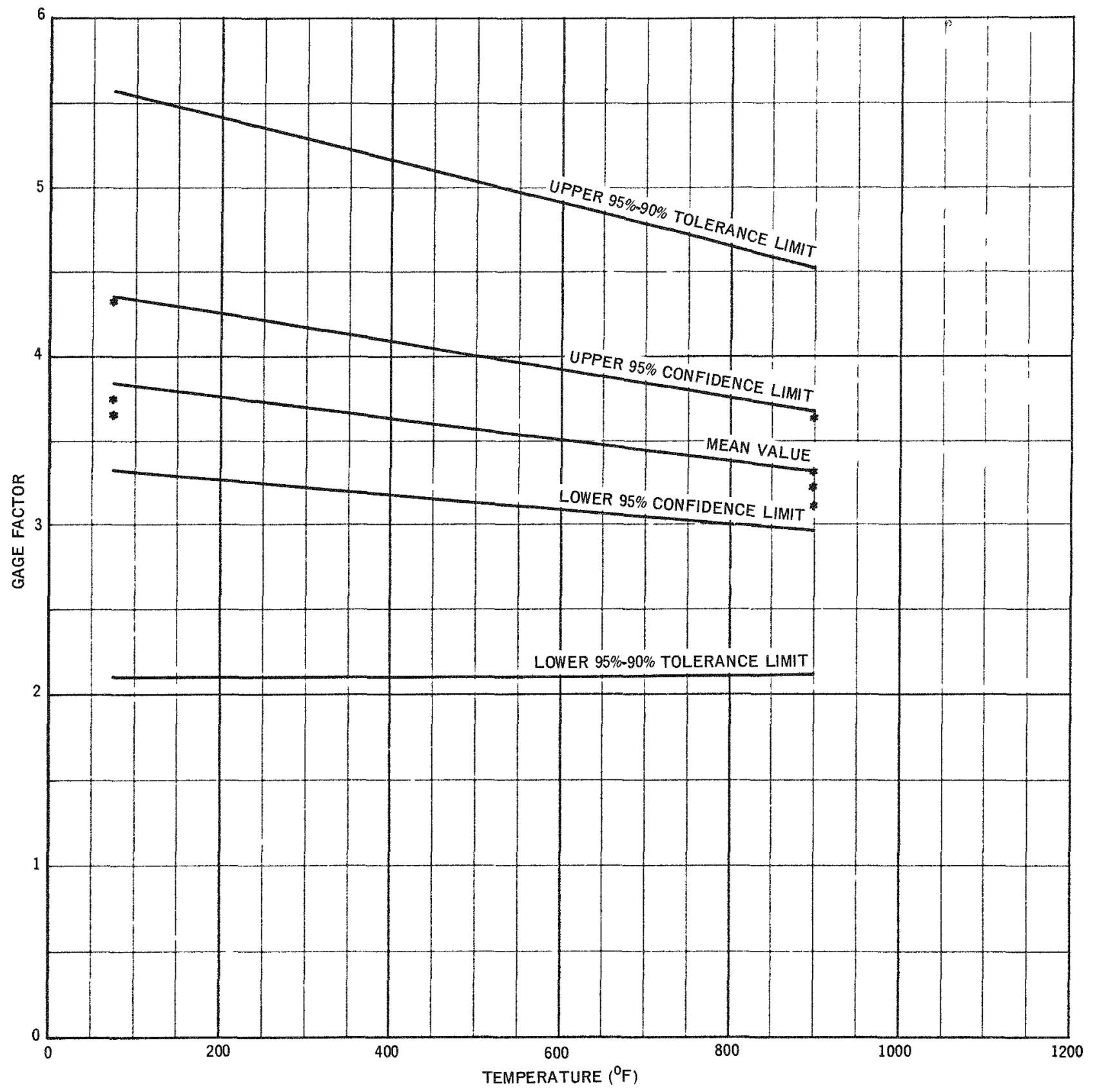

12-7-66 UNC

$7694-5534$

Figure 36. Gage Factor vs Temperature, With Confidence and Tolerance Limits, Microdot Specimens $M-5$ and M-6, Series 2 


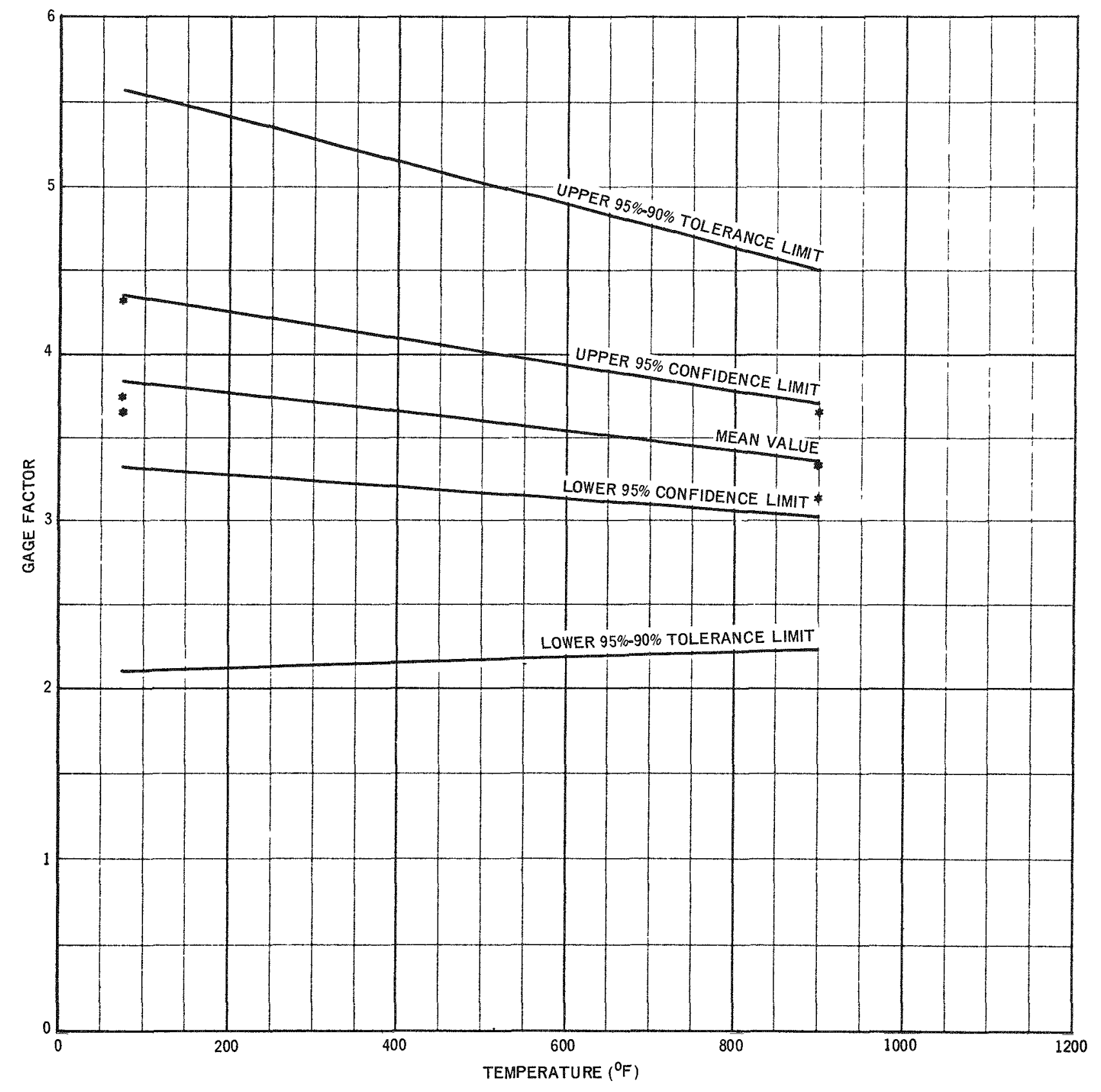

12.7.66 UNC

Figure 37. Gage Factor vs Temperature, With Confidence and Tolerance Limits, Microdot Specimens $M-5$ and M-6, Series 3 


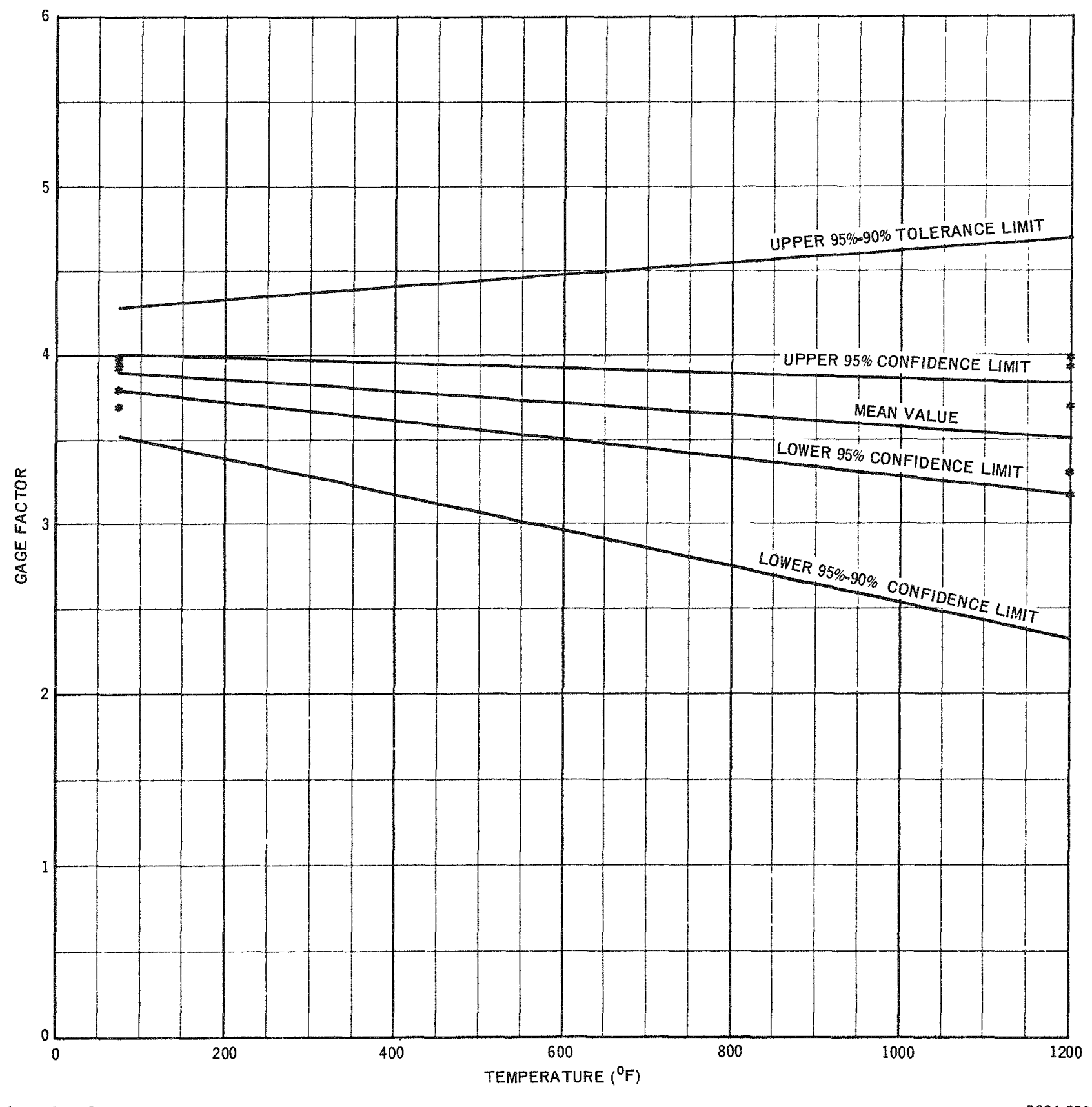

12-7-66 UNC

Figure 38. Gage Factor vs Temperature, With Confidence and Tolerance Limits, BLH Specimens B-1, B-2, and B-5 Through B-8, Series 1 
operating gages. All but one point fall within the confidence limits, and the spread between data points at $1200^{\circ} \mathrm{F}$ is $<5 \%$. Gage factor data beyond the first series are not presented, because no gages survived the first series.

\section{Drift Characteristics}

a. Microdot Gages

Figure 39 shows the drift data points, mean values, confidence limits, and tolerance limits for specimens $M-1$ through $M-3$. The drift, at any point in time, represents the total cumulative drift strain from the beginning of the Series 1 soak test. There was only $\sim 600 \mu \mathrm{\epsilon}$ of drift in $3000 \mathrm{hr}$, and the drift rate is essentially zero after the first $100 \mathrm{hr}$ of exposure. These excellent drift characteristics are attributed largely to stabilizing these gages at $1200^{\circ} \mathrm{F}$, which is $\sim 300^{\circ} \mathrm{F}$ higher than that used by the manufacturer. The maximum average drift rate for these gages was $<1 / 4 \mu \epsilon / \mathrm{hr}$. The majority of the data points fall within the confidence limits and all data points are well within the tolerance limits, again indicating that the tolerance limits are on the conservative side.

Figure 40 shows similar plots for Specimens $M-5$ and $M-6$. The drift characteristics of these gages which were stabilized at $900^{\circ} \mathrm{F}$, while satisfactory, are considerably more irregular than those which were stabilized at $1200^{\circ} \mathrm{F}$. The maximum average drift over the 2000-hr period is $<1 \mu \epsilon / h r$, which is about four times that observed for the gages stabilized at $1200^{\circ} \mathrm{F}$. All the data points are not only within the tolerance limits, but also within the confidence limits; this again indicates that the tolerance limits are on the conservative side.

\section{b. BLH Gages}

Figure 41 shows the drift data points, mean values, confidence limits, and tolerance limits for Specimens B-5 through B-8, which were the only specimens remaining with operating gages. During the first $70 \mathrm{hr}$, a substantial drift $(\sim 3100 \mu \epsilon)$ occurred. This is believed to be due to the greater instability of the gage alloy above $900^{\circ} \mathrm{F}$. After $70 \mathrm{hr}$, the drift decreased essentially in a linear manner, to $\sim 2000 \mu \epsilon$. The spread in the drift data points is $\sim 1500 \mu \epsilon$, with nearly all the data points falling within the confidence limits, and with all the points falling well within the tolerance limits. The drift data points in Figure 41 represent the total cumulative drift strain from the beginning of the Series 1 soak test.

$$
\text { NAA - SR - } 12118
$$




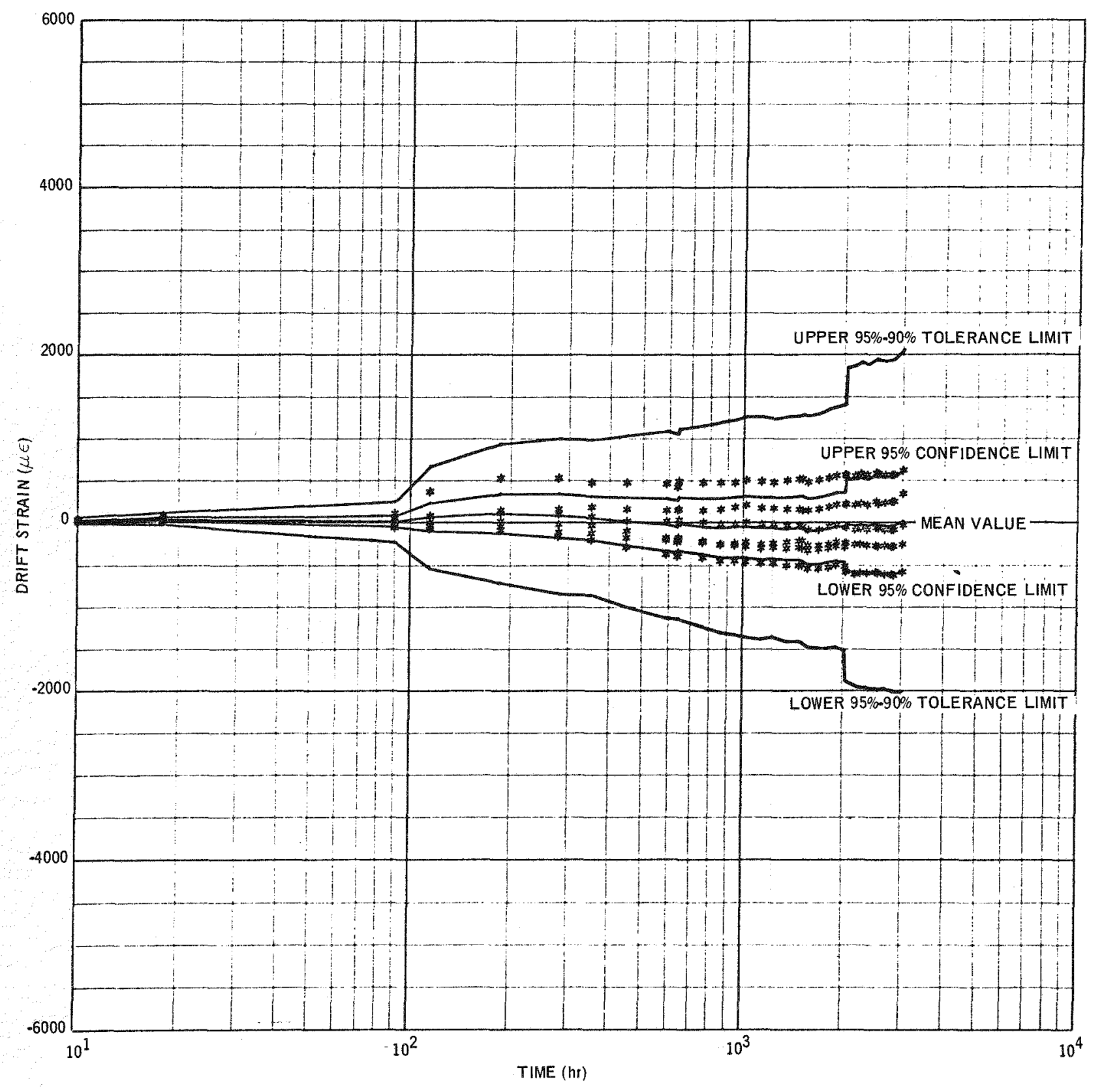

12-7.56 UNC

$7694-5537$

Figure 39. Drift vs Time, $900^{\circ} \mathrm{F}$, With Confidence and Tolerance Limits, Microdot Specimens $M-1$ Through M-3

NAA-SR- 12118 


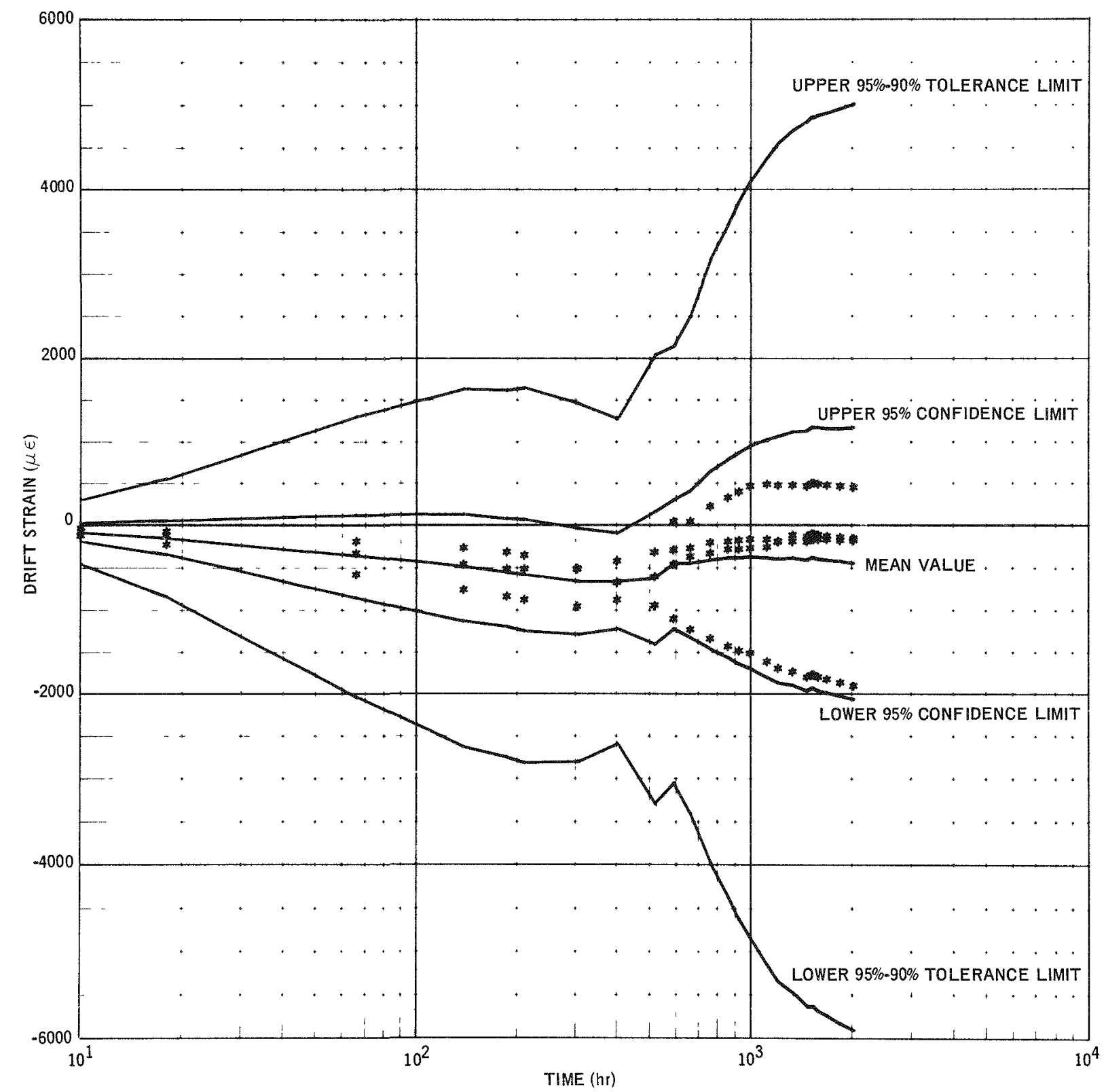

$12.7-66$ UNC

Figure 40. Drift vs Time, $900^{\circ} \mathrm{F}$, With Confidence and Tolerance Limits, Microdot Specimens $M-5$ and M-6 


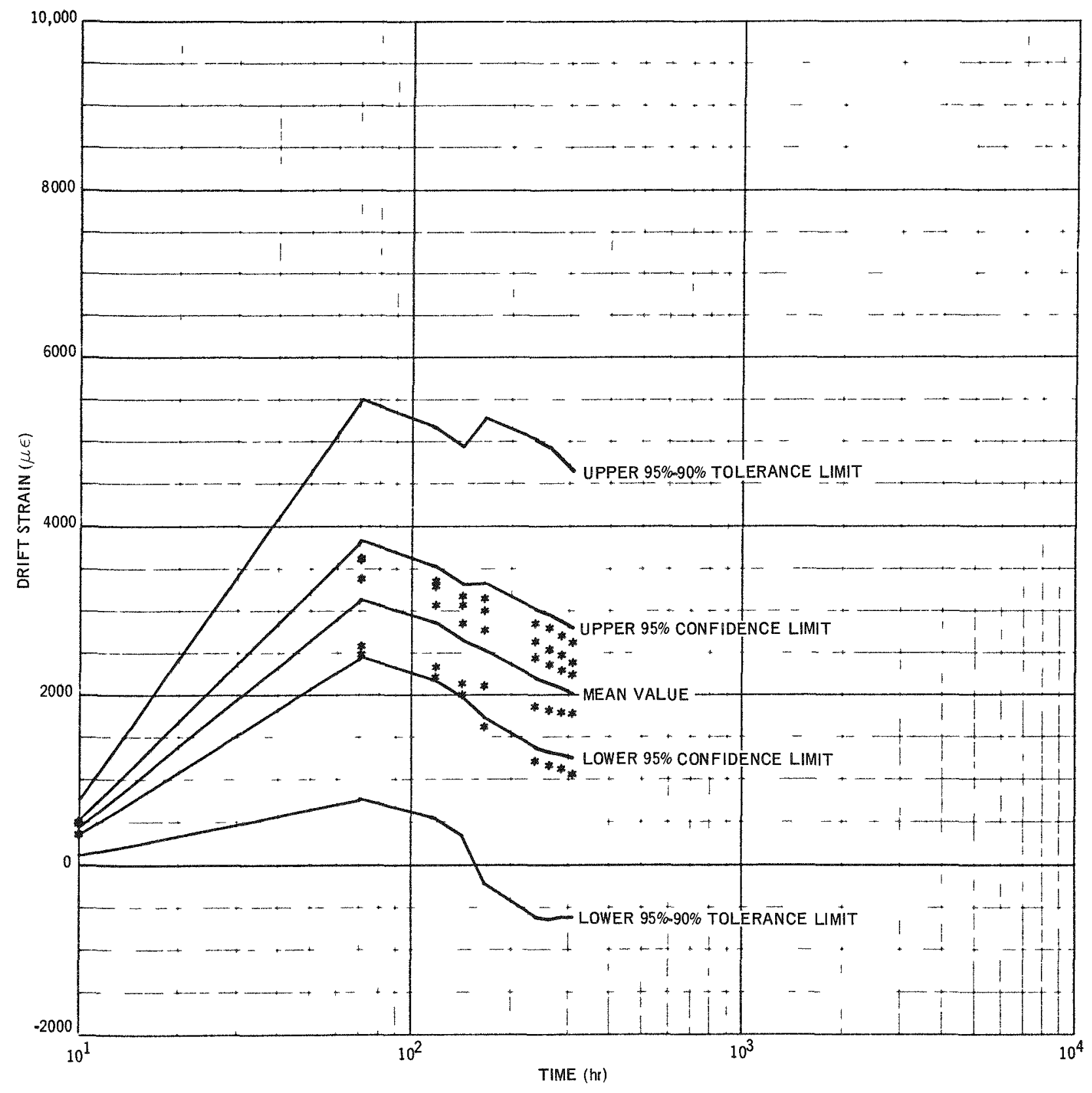

12-7-66 UNC

Figure 41. Druft vs Time, $1200^{\circ} \mathrm{F}$, With Confidence and Tolerance Limits, BLH Specimens B-5 Through B-8 


\section{Linearity and Repeatability Under Mechanical Strain}

a. Microdot Gage

Figure 42 is a plot of calculated vs average measured strains at ambient temperature, 500, and $900^{\circ} \mathrm{F}$, for Specimens $\mathrm{M}-1$ through $\mathrm{M}-3$. The ambient and $500^{\circ} \mathrm{F}$ curves are for Series 1 only; those at $900^{\circ} \mathrm{F}$ are for series 1 , 3, and 6 for the intermediate temperatures. The plots are quite linear; and there is a reduction in gage output with increasing temperature, due to an increase in gage resistivity or decreased gage factor. At $900^{\circ} \mathrm{F}$, the gage output changed little, from series to series, indicating very good repeatability. It should be pointed out that the gage factor setting on the strain indicator was 4.00 , during the entire linearity measurements were taken on all Microdot gages. The value of 4.00 is the manufacturer's nominal ambient (room temperature) gage factor. If the actual ambient gage factors of the gages tested had been precisely 4.00 , the slope of the ambient curve would have been $45^{\circ}$ (i.e., the calculated values would have been equal to the measured values at every point). Since this was not the case, the slopes of the curves were not $45^{\circ}$. In other words, the actual gage factors were somewhat less than 4.00. Using a gage factor setting of 4.00 did not introduce an error; since the gage factor curves, which were derived from these curves, were corrected for the gage factor setting.

Figure 43 shows similar information for Specimens $M-5$ and M-6, for Series 1, 2, and 3. The curves are quite linear, and similar in shape to those for Specimens $M-1$ through $M-3$, except for the fact that the measured strains are slightly higher. This difference is believed to be due to the difference in stabilization temperatures.

Figure 44 shows similar information for Specimen M-7 at ambient temperature and $1200^{\circ} \mathrm{F}$. Curves are shown for Series 1 and Series 2. Although the repeatability is excellent at ambient temperature, at $1200^{\circ} \mathrm{F}$ the curve for Series 2 is lower than the curve for Series 1 . This again points up the fact that the Microdot gage cannot be relied upon as a $1200^{\circ} \mathrm{F}$ gage under the test conditions used here.

b. BLH Gages

Figure 45 shows a similar plot for the BLH specimens at ambient temperature and $1200^{\circ} \mathrm{F}$. The plots are quite linear. They also show decrease in gage output

NAA-SR-12118 


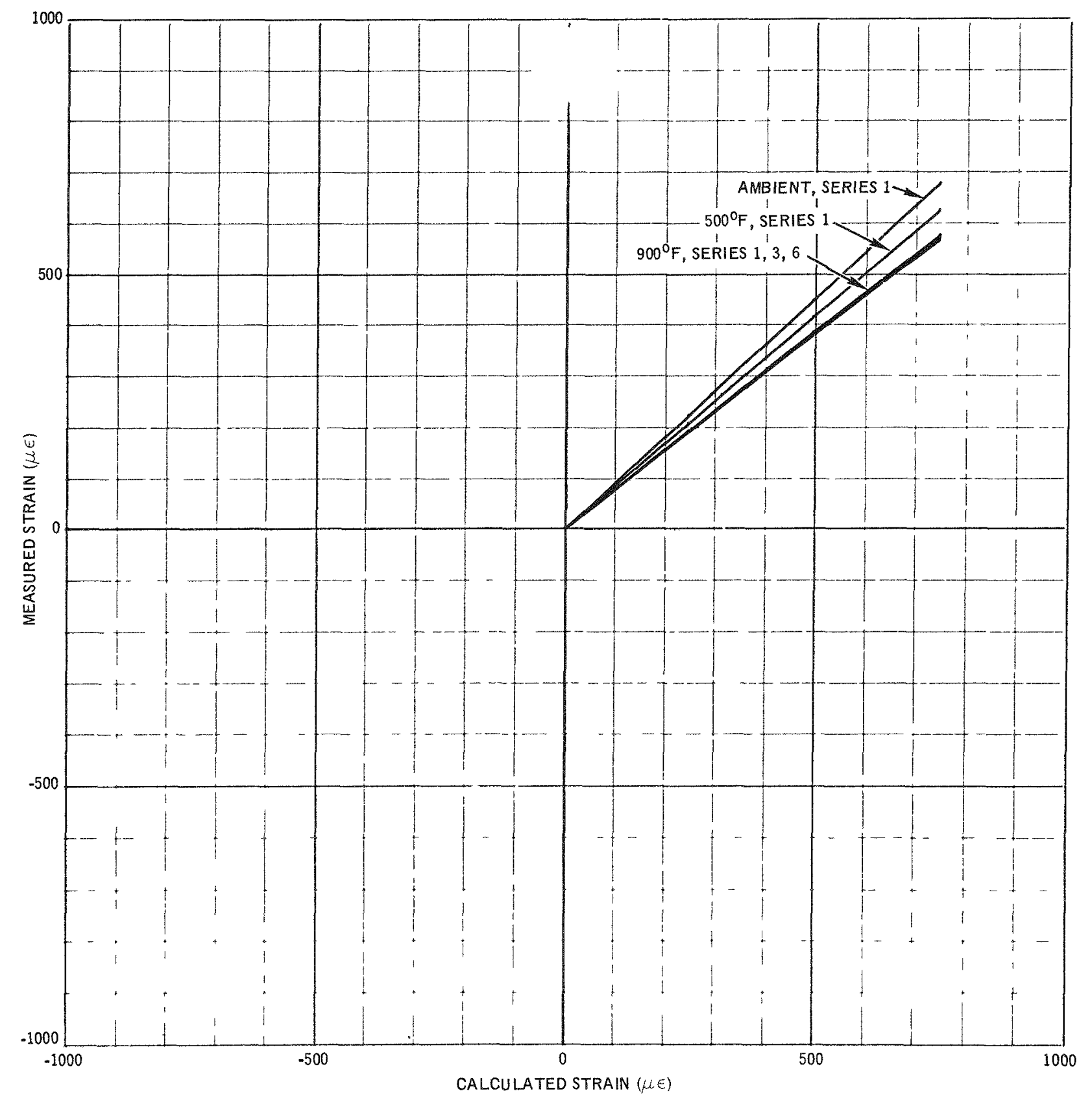

12-7-66 UNC

Figure 42. Measured Strain vs Calculated Strain, Microdot Specimens $\mathrm{M}-1$ Through $\mathrm{M}-3$ 


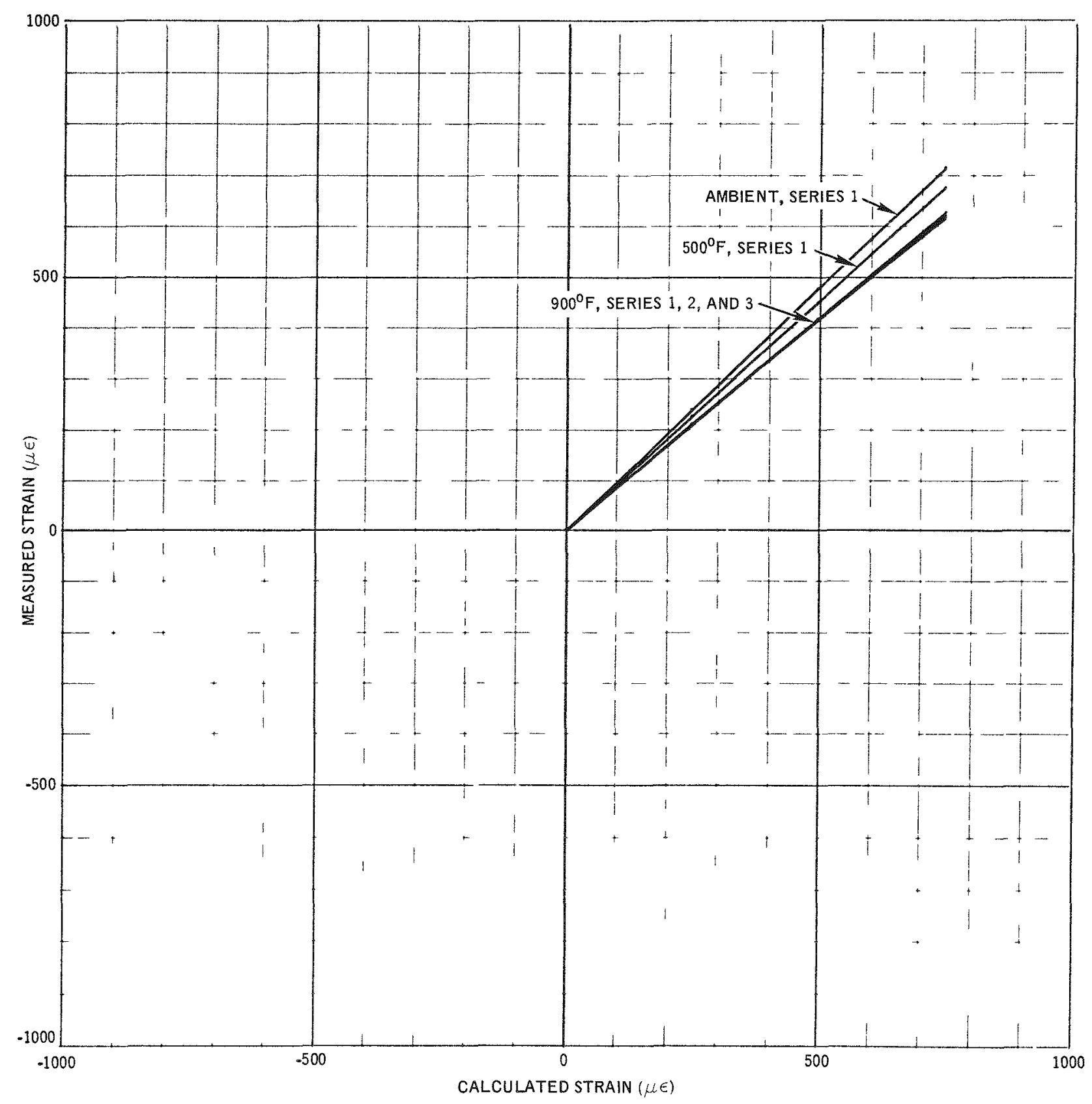

$12 \cdot 7-66$ UNC

Figure 43 Measured Strain vs Calculated Strain, Microdot Specimens M-5 and M-6 


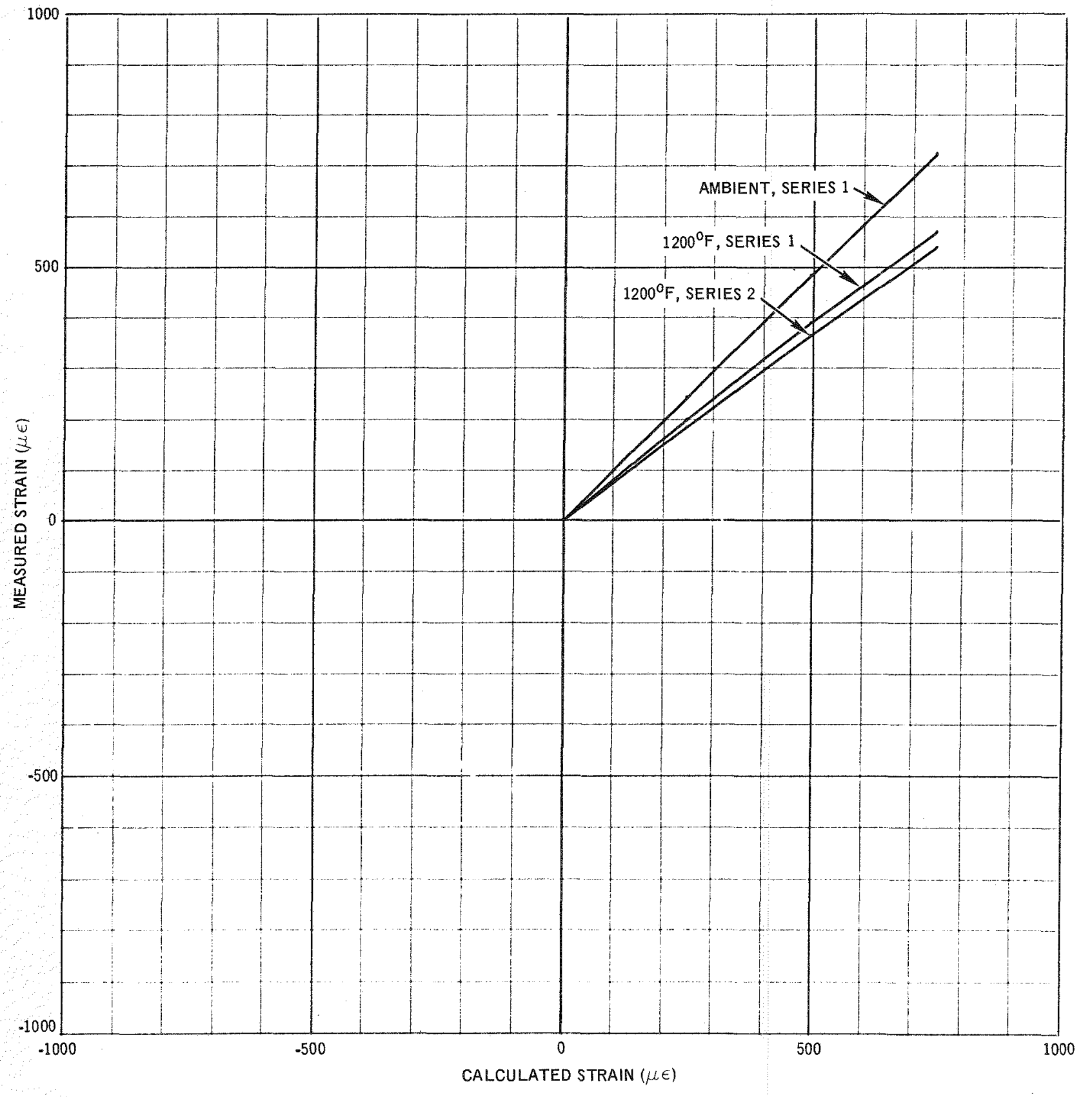

12-7-66 UNC

$7694-5542$

Figure 44. Measured Strain vs Calculated Strain, Microdot Specimen M-7

NAA-SR-12118 


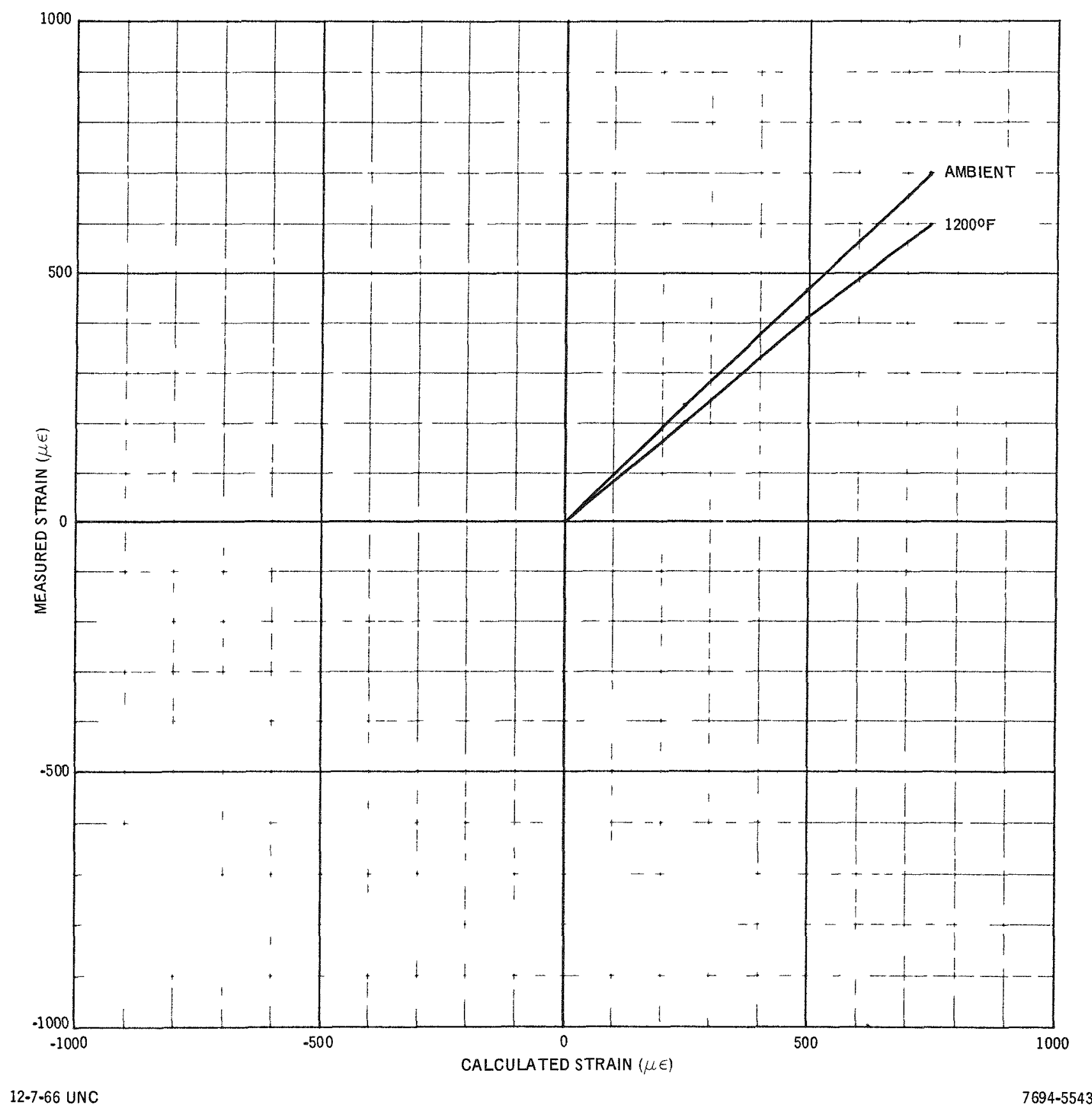

Figure 45. Measured Strain vs Calculated Straın, BLH Specimens

NAA-SR-12118 


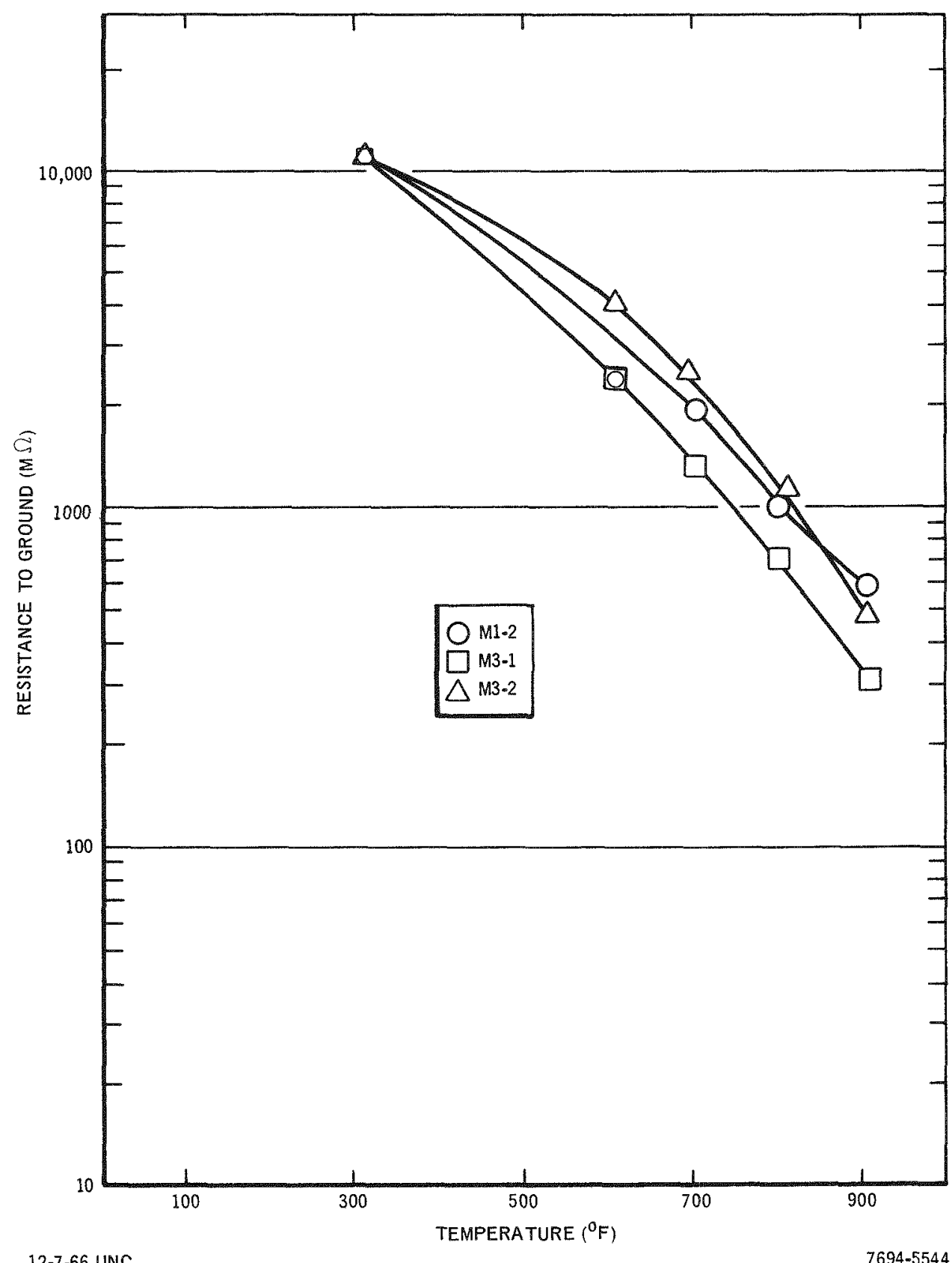

12.7-66 UNC

Figure 46. Resistance to Ground vs Temperature, Microdot Gages 
with increasing temperature. The effect of multiple series of tests cannot be shown, since the gages failed during the first series, as explained earlier.

\section{Resistance to Ground vs Temperature Characteristics}

\section{a. Microdot Gages}

Figure 46 shows the decrease in resistance to ground, as a function of temperature, for three different gages, up to $900^{\circ} \mathrm{F}$. This is a measure of the insulation resistance between the gage filament and the specimen to which the gage is attached. As the temperature increases, the ceramic insulation ( $\mathrm{MgO}$ ) becomes more conductive, electrically. This introduces a shunting effect across the gage which can produce a spurious gage output, if the resistance to ground drops below several megohms. These measurements were taken at $50-v \mathrm{dc}$ potential, with a General Radio Megger Model 1862C. All three gages follow the same trend, and the resistance to ground drops from 10,000 M $\Omega$ at ambient temperature to $\sim 500 \mathrm{M} \Omega$ at $900^{\circ} \mathrm{F}$. These resistance values remained fairly constant, from series to series. These values of resistance are high, and are considered quite acceptable, as explained in Section I-A.

\section{b. BLH Gages}

Figure 47 , shows similar curves, up to $1200^{\circ} \mathrm{F}$, which may be considered typical for the BLH gages evaluated in this program. Two of the curves for the BLH gages flame-spray bonded with Coors Rokide A 1/8-in.- diameter rod, and two of the curves are for BLH gages flame-spray bonded with the high-purity BLH Type H Rokide 1/4-in.-diameter rod. The substrate thickness was between 4 and 5 mils, in each case. Also shown in this figure are the manufacturer's curves. The shaded area represents the manufacturer's scatter band for resistance values. The high purity Type $H$ rod has a resistance to ground, at $1200^{\circ} \mathrm{F}$, which is about four times that of the Coors rod. However, the resistance does not approach that of the Microdot gage. Both the Coors and BLH Rokide were used to flame-spray bond the BLH gages to the test bars.

\section{Variations in Gage Resistance \\ a. Microdot Gages}

Figures 48 and 49 show, in histogram form, the variations in ambient gage resistance for Microdot Specimens $M-1, M-2, M-3, M-5$, and $M-6$ after:

$$
\text { NAA - SR - } 12118
$$




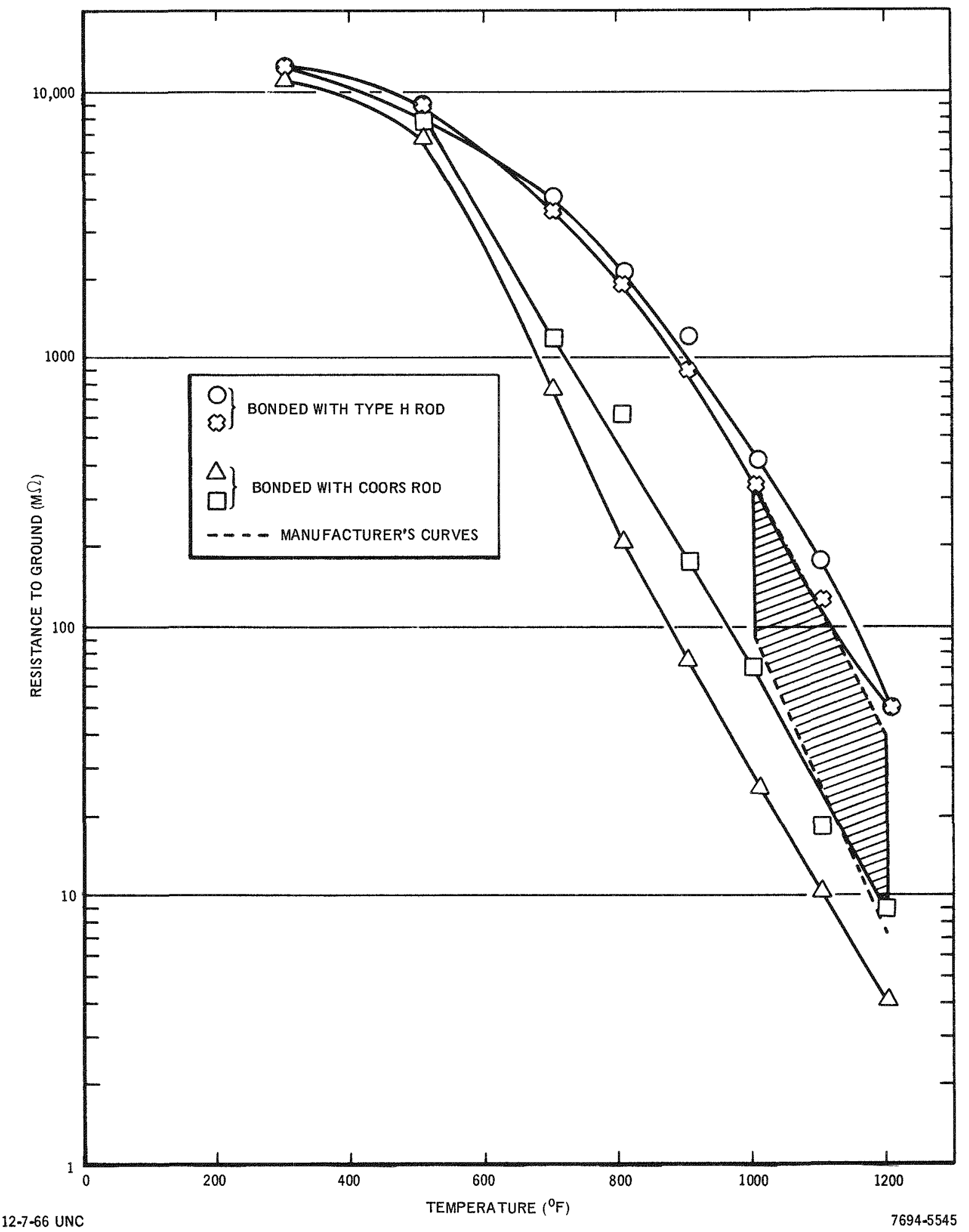

Figure 47. Resistance to Ground vs Temperature, BLH Gages 


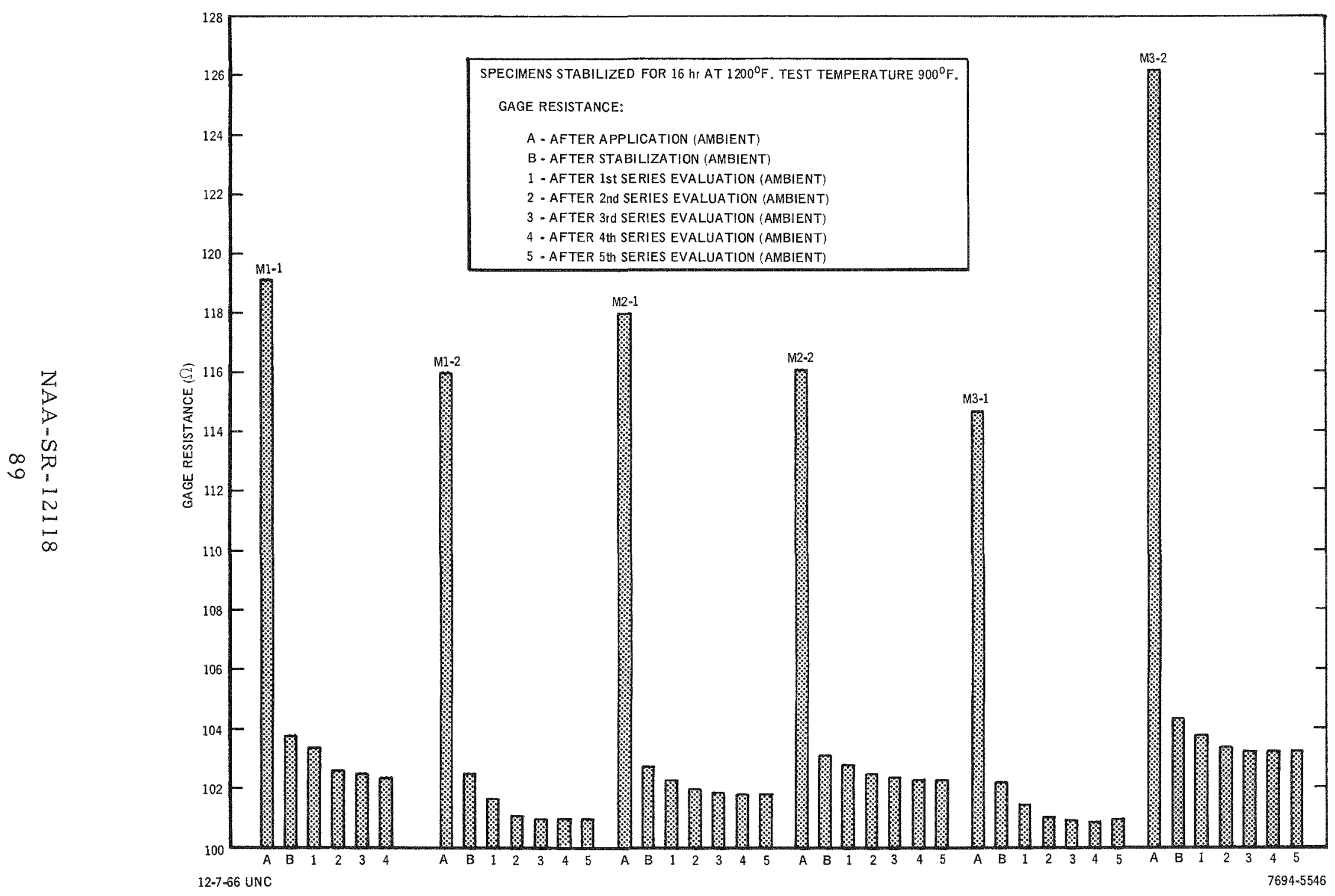

Figure 48. Variations in Gage Resistance, Microdot Specimens M-1 Through M-3 
2
3
3
1
0
0
0
0
1
$n$
5
5
5

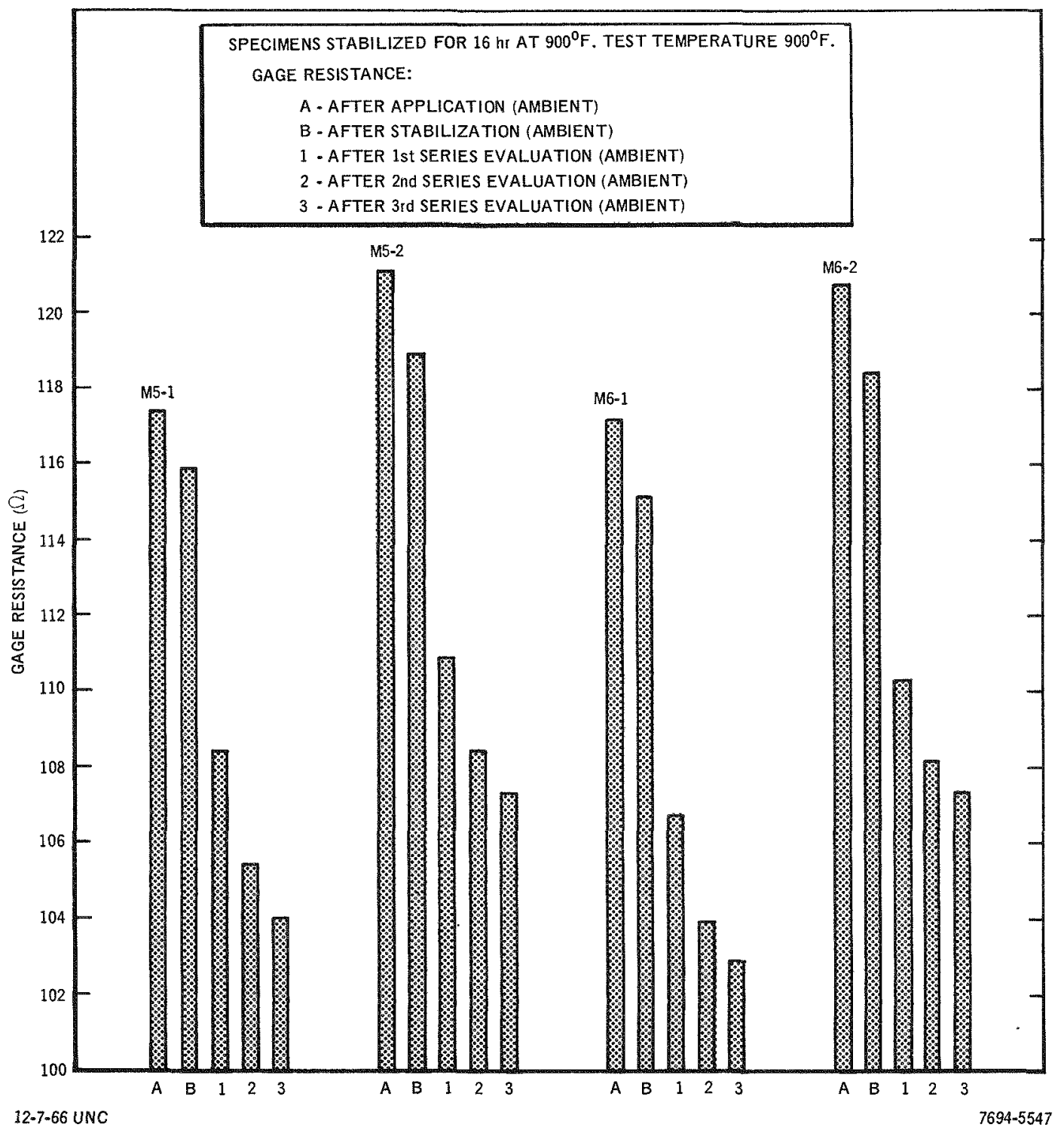

Figure 49. Variations in Gage Resistance, Microdot Specimens M-5 and M-6 
1) Installation of gage on the test bar

2) Stabilization

3) Each series of soaking and shocking.

The stabilization of the gages at $1200^{\circ} \mathrm{F}$ results in about a 12 to $15 \Omega$ drop in gage resistance, due to metallurgical changes in the gage alloy; whereas the $900^{\circ} \mathrm{F}$ stabilization results in a reduction of gage resistance of only a few ohms. To prevent the slight increase in heat generation $\left(I^{2} R\right)$ within the gage, the gages with the lower resistance would have to be excited with a correspondingly lower voltage. This would result in a small decrease in gage output which, in sodium component loop testing, is not considered objectionable, in terms of the marked improvement in gage stability resulting from a $1200^{\circ} \mathrm{F}$ stabilization. Even if the same excitation voltage were used, there should be little difference in gage performance. A close inspection of Figure 48 shows that there is very little change in gage resistance, after the first series. On the other hand, Figure 49 shows sizable changes in gage resistance with each series. In spite of these changes in gage resistance, their effect on gage factor (as noted from Figures 32 through 37) is small. Nevertheless, this change in resistance manifests itself in the form of drift, zero shift, etc. which must be accounted for when converting the indicated strains to true strains.

\section{b. BLH Gages}

Figure 50 shows similar histograms for Specimens B-1, B-2, and B-5 through B-8. A substantial reduction in gage resistance occurs during stabilization and after each series, resulting in the same kind of measurement errors characteristic of the Microdot gages stabilized at $900^{\circ} \mathrm{F}$.

\section{Overall Gage Performance}

a. Microdot Gages

Table 4 summarizes the overall gage performance of Specimens $M-1$ through M-3, and M-5 through M-8. All gages on Specimens $M-1$ through $M-3$, with the exception of Gage 1 on Specimen M-1, withstood all six series without a single gage failure in the form of an "open, "erratic behavior, or excessive drift, when subjected to the standard evaluation procedure (Figure 3), or to 

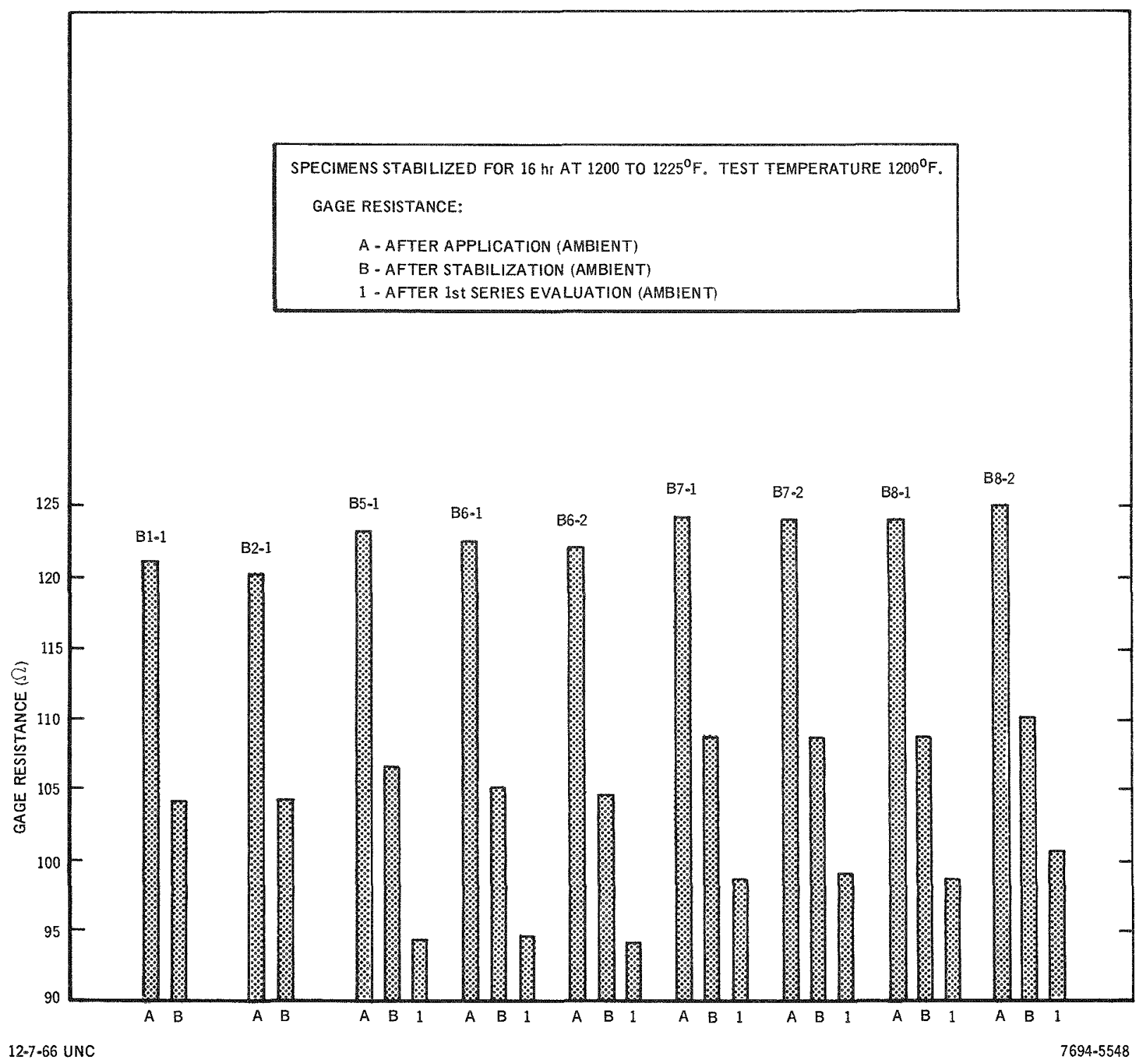

Figure 50. Variations in Gage Resistance, BLH Specimens 
TABLE 4

MICRODOT GAGE PERFORMANCE

\begin{tabular}{|c|c|c|}
\hline $\begin{array}{l}\text { Specimen } \\
\text { Number }\end{array}$ & $\begin{array}{c}\text { Gage } \\
\text { Number }\end{array}$ & Remarks on Performance \\
\hline \multirow[t]{2}{*}{$M-1$} & 1 & $\begin{array}{l}\text { Failed on first cycle at } 20^{\circ} \mathrm{F} / \mathrm{sec} \text { during fifth block of } \\
\text { thermal shocks. Total exposure at } 900^{\circ} \mathrm{F} \text { before fail- } \\
\text { ure, } 2032 \mathrm{hr} \text {. Total number of thermal shocks before } \\
\text { failure: } 50 \text { cycles at } 10^{\circ} \mathrm{F} / \mathrm{sec} \text {, plus } 41 \text { cycles at } \\
20^{\circ} \mathrm{F} / \mathrm{sec} \text {, plus } 40 \mathrm{cycles} \text { at } 30^{\circ} \mathrm{F} / \mathrm{sec} \text {. }\end{array}$ \\
\hline & 2 & $\begin{array}{l}\text { Withstood all six series without failure. Total ex- } \\
\text { posure before termination of test, } 3030 \mathrm{hr} \text { at } 900^{\circ} \mathrm{F} \text {. } \\
\text { Total number of thermal shocks before termination } \\
\text { of test: } 60 \text { cycles at } 10^{\circ} \mathrm{F} / \mathrm{sec} \text {, plus } 60 \text { cycles at } \\
20^{\circ} \mathrm{F} / \mathrm{sec} \text {, plus } 60 \text { cycles at } 30^{\circ} \mathrm{F} / \mathrm{sec} \text {. }\end{array}$ \\
\hline \multirow[t]{2}{*}{$M-2$} & 1 & (Same as for Specimen M-1, Gage 2) \\
\hline & 2 & (Same as for Specimen M-1, Gage 2) \\
\hline \multirow[t]{2}{*}{$M-3$} & 1 & (Same as for Specimen M-1, Gage 2) \\
\hline & 2 & (Same as for Specimen M-1, Gage 2) \\
\hline \multirow[t]{2}{*}{$M-5$} & 1 & $\begin{array}{l}\text { Withstood four series without failure. Total exposure } \\
\text { to date, } 2032 \mathrm{hr} \text { at } 900^{\circ} \mathrm{F} \text {. Total number of shocks } \\
\text { to date: } 40 \mathrm{cycles} \text { at } 10^{\circ} \mathrm{F} / \mathrm{sec} \text {, plus } 40 \text { cycles at } \\
20^{\circ} \mathrm{F} / \mathrm{sec} \text {, plus } 40 \mathrm{cycles} \text { at } 30^{\circ} \mathrm{F} / \mathrm{sec} \text {. }\end{array}$ \\
\hline & 2 & (Same as for Specimen M-5, Gage 1) \\
\hline \multirow[t]{2}{*}{$M-6$} & 1 & (Same as for Specimen M-5, Gage 1) \\
\hline & 2 & (Same as for Specimen M-5, Gage 1) \\
\hline \multirow[t]{2}{*}{$M-7$} & 1 & $\begin{array}{l}\text { Excessive drift noted during first } 22 \mathrm{hr} \text {. Test termi- } \\
\text { nated after } 300 \mathrm{hr} \text { at } 1200^{\circ} \mathrm{F} \text {. Total number of shocks } \\
\text { before termination of test: } 10 \text { cycles at } 10^{\circ} \mathrm{F} / \mathrm{sec} \text {, } \\
\text { plus } 10 \mathrm{cycles} \text { at } 20^{\circ} \mathrm{F} / \mathrm{sec} \text {, plus } 10 \mathrm{cycles} \text { at } 30^{\circ} \mathrm{F} / \mathrm{sec} \text {. }\end{array}$ \\
\hline & 2 & $\begin{array}{l}\text { Excessive drift noted during first } 22 \mathrm{hr} \text {. Test termi- } \\
\text { nated at end of } 400 \mathrm{hr} \text {. Total number of shocks before } \\
\text { termination of test: } 10 \text { cycles at } 10^{\circ} \mathrm{F} / \mathrm{sec} \text {, plus } 10 \\
\text { cycles at } 20^{\circ} \mathrm{F} / \mathrm{sec} \text {, plus } 10 \text { cycles at } 30^{\circ} \mathrm{F} / \mathrm{sec} \text {. }\end{array}$ \\
\hline$M-8$ & $\begin{array}{l}1 \\
\text { and } \\
2\end{array}$ & $\begin{array}{l}\text { Withstood } 3000 \mathrm{hr} \text { of exposure at } 900^{\circ} \mathrm{F} \text {, while sub- } \\
\text { jected to a mechanical strain of } 750 \mu \mathrm{\epsilon} \text {. Average } \\
\text { drift rate }<0.13 \mu \mathrm{G} / \mathrm{hr} \text {. }\end{array}$ \\
\hline
\end{tabular}

NAA-SR- 12118 
special tests to determine supplementary information on gage performance. This means that these gages were able to withstand $3000 \mathrm{hr}$ of soak at $900^{\circ} \mathrm{F}$, in addition to 60 shocks at $10^{\circ} \mathrm{F} / \mathrm{sec}$, plus 60 shocks at $20^{\circ} \mathrm{F} / \mathrm{sec}$, plus 60 shocks at $30^{\circ} \mathrm{F} / \mathrm{sec}$, without failure. Specimens $\mathrm{M}-5$ and $\mathrm{M}-6$ were subjected to four series, after which time it was well established that there was a marked difference in stability between gages stabilized at 900 and $1200^{\circ} \mathrm{F}$. The gages on these specimens withstood $2032 \mathrm{hr}$ of soak at $900^{\circ} \mathrm{F}$, in addition to 40 shocks at $10^{\circ} \mathrm{F} / \mathrm{sec}$, plus 40 shocks at $20^{\circ} \mathrm{F} / \mathrm{sec}$, plus 40 shocks at $30^{\circ} \mathrm{F} / \mathrm{sec}$, with no signs of failure.

Specimen M-7, which was tested at $1200^{\circ} \mathrm{F}$ instead of $900^{\circ} \mathrm{F}$, showed excessive drift on both Gages 1 and 2 after $22 \mathrm{hr}$. Measurements on Gage 1 terminated after $300 \mathrm{hr}$, after subjecting the gage to 10 shocks at $10^{\circ} \mathrm{F} / \mathrm{sec}$, plus 10 shocks at $20^{\circ} \mathrm{F} / \mathrm{sec}$, plus 10 shocks at $30^{\circ} \mathrm{F} / \mathrm{sec}$. Measurements on Gage 2 were terminated after $400 \mathrm{hr}$ of soaking, and after subjecting the gage to the same number of shocks as Gage 1 .

Specimen M-8 was subjected to a special test, to determine whether the presence of mechanical strain would affect overall gage performance or specific gage characteristics. The great bulk of the evaluation reported here was conducted on mechanically stress-free specimens. The question naturally arose as to what degree the presence of mechanically induced strains would affect the results. The results from this test indicated that the presence of $750 \mu \epsilon$ ( 19,000 psi mechanical stress) had little or no effect on the drift characteristics, even after $3000 \mathrm{hr}$ of exposure at $900^{\circ} \mathrm{F}$. The average drift rate was of the same general magnitude as that for the mechanically stress-free specimens, the average rate being $<0.13 \mu \epsilon / \mathrm{hr}$.

The Microdot gage is manufactured from an alloy having a coefficient of thermal expansion of $\sim 4 \mathrm{ppm} /{ }^{\circ} \mathrm{F}$ at $900^{\circ} \mathrm{F}$. The coefficient of thermal expansion of austenitic stainless steel at this temperature is $\sim 10 \mathrm{ppm} /{ }^{\circ} \mathrm{F}$.

During the evaluation, the gages are subjected to temperatures ranging from room temperature $\left(75^{\circ} \mathrm{F}\right)$ to $900^{\circ} \mathrm{F}$. This represents the extremes in temperature encountered in measurement of strain on most sodium components. Assuming full differential expansion between the test bar and the gage filament at $900^{\circ} \mathrm{F}$, the thermal stress in the filament $(\sigma)$, which has essentially the same effect on the

NAA-SR - 12118 
gage as a mechanical stress of equal magnitude, imposed on the gage and computed on an elastic basis, would be

$$
\sigma=\mathrm{E}_{\mathrm{g}}\left(\alpha_{\mathrm{m}}-\alpha_{\mathrm{g}}\right) \Delta \mathrm{T}
$$

where:

$$
\begin{aligned}
E_{\mathrm{g}}= & \text { average value of Young's modulus of elasticity of gage wire } \\
& \text { (assumed } \left.=23.5 \times 10^{6}\right) \\
\alpha_{\mathrm{g}}= & \text { coefficient of thermal expansion of gage wire }\left(4 \mathrm{ppm} /{ }^{\circ} \mathrm{F}\right) \\
\alpha_{\mathrm{m}}= & \text { coefficient of thermal expansion of Type } 304 \text { stainless steel test bar } \\
& \text { material (10 ppm } \left./{ }^{\circ} \mathrm{F}\right)
\end{aligned}
$$

$\Delta \mathrm{T}=$ change in metal temperature $\left({ }^{\circ} \mathrm{F}\right)$, positive for increasing temperature Inserting these values into Equation 7, we obtain:

$$
\sigma=\left(23.5 \times 10^{6}\right) \times\left(6.0 \times 10^{-6}\right) \times(825)=116,000 \mathrm{psi}, \text { tension. }
$$

Stresses of this magnitude are substantially higher than the mechanical stresses induced in a gage mounted on a sodium component designed to Section III of the ASME Code for Nuclear Vessels, or Section VIII of the Code for Unfired Pressure Vessels. Consequently, in the testing of code designed sodium components, one would not expect mechanical stresses in the gage wire of this magnitude. Since their magnitude would be a relatively small percentage of the total stress to which the gage is subjected, the effect of the mechanical stress on the gage would appear to be small. This assumes that the number of cycles to which the gage is subjected in service or loop testing is also small, so that failure of the gage due to mechanical low cycle fatigue $(<1000$ cycles $)$ is not likely. As a cons equence, it was decided that the gage evaluation could be satisfactorily performed, without the complication of having to subject the specimens to both mechanically and thermally induced stresses.

\section{b. BLH Gages}

Table 5 summarizes, in a manner similar to Table 4, the overall gage performance of Specimens B-1 through B-8. Unfortunately, these gages did not survive the first series. Their performance during the first series was not

NAA-SR -12118 
TABLE 5

BLH GAGE PERFORMANCE

\begin{tabular}{|c|c|c|}
\hline $\begin{array}{l}\text { Specimen } \\
\text { Number }\end{array}$ & $\begin{array}{l}\text { Gage } \\
\text { Number }\end{array}$ & Remarks on Gage Performance \\
\hline B- 1 & 4 & $\begin{array}{l}\text { Failed during fifth cycle at } 10^{\circ} \mathrm{F} / \mathrm{sec} \text { during first } \\
\text { series, with no soak }\end{array}$ \\
\hline$B-2$ & 1 & $\begin{array}{l}\text { Failed during first cycle at } 10^{\circ} \mathrm{F} / \mathrm{sec} \text { during first } \\
\text { series, after } 300-\mathrm{hr} \text { soak at } 1200^{\circ} \mathrm{F}\end{array}$ \\
\hline$B-3$ & 2 & $\begin{array}{l}\text { Failed during ninth cycle at } 10^{\circ} \mathrm{F} / \mathrm{sec} \text { during first } \\
\text { series, with no soak }\end{array}$ \\
\hline$B-4$ & 3 & $\begin{array}{l}\text { Failed during first cycle at } 10^{\circ} \mathrm{F} / \mathrm{sec} \text { during first } \\
\text { series, with no soak }\end{array}$ \\
\hline \multirow[t]{2}{*}{$B-5$} & 1 & $\begin{array}{l}\text { Failed during first cycle at } 10^{\circ} \mathrm{F} / \mathrm{sec} \text { during first } \\
\text { series, with no soak }\end{array}$ \\
\hline & 2 & Failed during stabilization soak \\
\hline \multirow[t]{2}{*}{$B-6$} & 1 & $\begin{array}{l}\text { Failed during first cycle at } 10^{\circ} \mathrm{F} / \mathrm{sec} \text { during first } \\
\text { series, after } 300-\mathrm{hr} \text { soak at } 1200^{\circ} \mathrm{F}\end{array}$ \\
\hline & 2 & $\begin{array}{l}\text { Failed during first cycle at } \sim 25^{\circ} \mathrm{F} / \mathrm{sec} \text { during first } \\
\text { series, after } 300-\mathrm{hr} \text { soak at } 1200^{\circ} \mathrm{F} \text { and } 10 \text { cycles } \\
\text { at } 10^{\circ} \mathrm{F} / \mathrm{sec} \text { plus } 10 \text { cycles at } 20^{\circ} \mathrm{F} / \mathrm{sec}\end{array}$ \\
\hline \multirow[t]{2}{*}{$B-7$} & 1 & $\begin{array}{l}\text { Failed during second cycle at } \sim 25^{\circ} \mathrm{F} / \mathrm{sec} \text { during } \\
\text { first series, after } 300-\mathrm{hr} \text { soak at } 1200^{\circ} \mathrm{F} \text { and } \\
10 \text { cycles at } 10^{\circ} \mathrm{F} / \mathrm{sec}\end{array}$ \\
\hline & 2 & $\begin{array}{l}\text { Failed during third cycle at } 10^{\circ} \mathrm{F} / \mathrm{sec} \text { during first } \\
\text { series, after } 300-\mathrm{hr} \text { soak at } 1200^{\circ} \mathrm{F}\end{array}$ \\
\hline \multirow[t]{2}{*}{$B-8$} & 1 & $\begin{array}{l}\text { Failed during fifth cycle at } 10^{\circ} \mathrm{F} / \mathrm{sec} \text { during first } \\
\text { series, after } 300-\mathrm{hr} \text { soak at } 1200^{\circ} \mathrm{F}\end{array}$ \\
\hline & 2 & $\begin{array}{l}\text { Failed during first series, at beginning of } 1200^{\circ} \mathrm{F} \\
\text { soak }\end{array}$ \\
\hline
\end{tabular}

NAA - SR - 12118 
uniform. Many of the gages failed during thermal shocking at the $10^{\circ} \mathrm{F}$ heating rate, and none of the gages withstood $300 \mathrm{hr}$ of soaking at $1200^{\circ} \mathrm{F}$.

\section{Accuracy}

Unfortunately, one cannot, in any simple manner, describe the accuracy of a high-temperature strain gage in the same way that one describes, for instance, a room-temperature pressure transducer, whose output is not time or temperature dependent. The output of such a transducer is purely a function of the pressure to which it is subjected. Its accuracy can therefore be determined by a relatively simple precalibration over its operating range, and described in terms of a percentage of the maximum operating pressure. In the case of high-temperature electric resistance strain gages, particularly those used for long-term measurements at temperatures of $900^{\circ} \mathrm{F}$ or greater, the output is not only a function of the parameter being measured (in this case, the strain in the metal to which the gage is bonded), but also the time at temperature.

Consequently, if one were required to make a general statement on the percent accuracy with which one can measure strain with, for example, the Microdot gage, one would have to select limits which were so broad as to be meaningless, or one would have to undertake the monumental task of conducting a parametric study of the variations in the gage parameters which would embrace every conceivable time-temperature combination anticipated in sodium component loop testing. This, of course, would not be practical. However, one can, in a specific case, make some statements on accuracy, on the basis of the available information on the gage's overall performance and the statistical data relating to the variations in the gage parameters, from gage to gage. Consider the following case: One wishes to know whether it is possible to determine stresses to $\pm 25 \%$ accuracy on a certain component fabricated from Type 304 stainless steel. The component is tested in a loop which requires $24 \mathrm{hr}$ for startup and achieving a steady-state metal temperature of $900^{\circ} \mathrm{F}$, and $1 \mathrm{hr}$ for taking the strain measurements. Assume that the gage is installed at a location where the magnitude of the strain generated in the metal during test is of the order of $1000 \mu \epsilon$. Also assume that a temperature compensation resistor has been used, and that its value is such that, theoretically, the apparent strain should be zero at $900^{\circ} \mathrm{F}$.

NAA-SR -12118 
To obtain the true metal strain from the measured "raw" strain, one must substract the apparent strain and, in long-term tests, also the drift strain. Further, one must multiply the indicated strain by the ratio of the gage factor setting on the strain indicator (which may or may not be set to the true gage factor) to the actual gage factor at the temperature in question.

Referring to Figure 18 we observe a width in the Tolerance Limit interval of $\sim 50 \mu \mathrm{\epsilon}$ which, in simple terms, means we can be $95 \%$ sure that $90 \%$ of the gages used will have an apparent strain value which will not deviate from the mean value in Figure 18 by more than $\pm 25 \mu \epsilon$. Thus, after the correction to the "raw" or indicated strain is made, the true strain should not be in error by more than $\pm 25 \mu \epsilon$, due to any error stemming from gage-to-gage variations in apparent strain, within the stated probability.

Referring to Figure 39, the width of the tolerance interval for drift strain at the end of $25 \mathrm{hr}(24+1)$ of exposure is $\sim 200 \mu \epsilon$. This means that the maximum error (for a 95\%-90\% probability) due to gage-to-gage variations in drift strain would not exceed $\pm 100 \mu \mathrm{\epsilon}$. (Actually, it would be less than this, since the mean temperature over the $25-\mathrm{hr}$ interval would be substantially $<900^{\circ} \mathrm{F}$, and hence, there would be smaller tolerance interval.) Thus, after correcting the indicated strain for drift, the true strain should not be in error by more than $\pm 100 \mu \epsilon$, due to any error stemming from gage-to-gage variations in drift characteristics, within the stated probability.

Referring to Figure 32, the tolerance interval for gage factor at $900^{\circ} \mathrm{F}$ is $\sim 1.3$, with a mean value for gage factor of $\sim 3$. This means that the maximum probable error (for $95 \%-90 \%$ probability), due to gage-to-gage variations in gage factor, would not exceed $\pm 0.65 \times 3.0 \times 1000= \pm 195 \mu \epsilon$, for a $1000-\mu \epsilon$ level in the metal of the test component.

Summing of these maximum probable errors, we obtain a total maximum error of $\pm 25 \pm 100 \pm 195= \pm 320 \mu \epsilon$, assuming all errors are additive, which is a "worst case" assumption. Thus, the 95\%-90\% maximum total error in measurement of the true strain, after the corrections for apparent strain, drift, and gage factor have been made, is $\pm 320 \div 1000$ or $\pm 32 \%$. Since the $95 \%-90 \%$ tolerance limits bracketed the actual scatter, from gage to gage, with a considerable margin to spare, it would appear justifiable to accept less stringent tolerance

$$
\text { NAA-SR - } 12118
$$


limits (e.g., 90\%-90\% or even less), in which case the maximum probable error in strain could be shown to be less that $\pm 25 \%$. In a uniaxial field, this means that the error in stress measurement should not exceed $\pm 25 \%$.

If it is felt that this statistical sampling approach, which is based on testing only a limited percentage of the gages, is not reliable enough to achieve the accuracy required for a specified test, then the only alternatives are to:

1) Use gages in replication

2) Precalibrate each and every gage for the actual time-temperature history that it will see in service.

The latter alternative may be costly and time consuming. However, if the utmost accuracy and reliability is required, this may be the only alternative. 


\section{CONCLUSIONS AND RECOMMENDATIONS}

On the basis of the information obtained during this evaluation, the following conclusions for the Microdot Type SG-420 gage and the BLH Type HT-12125A gage were reached.

The Microdot gage should be suitable for sodium component loop testing, under steady-state and transient heating conditions, at temperatures not exceeding $900^{\circ} \mathrm{F}$ and heating rates not greater than $30^{\circ} \mathrm{F} / \mathrm{sec}$. While the evaluation indicated satisfactory performance up to $3000 \mathrm{hr}$, under laboratory conditions without the use of integral leads, use of this gage without integral leads is not recommended for those field applications where there are prolonged down periods or where humidity can cause corrosion or otherwise affect the gage in a deleterious manner. To achieve a degree of accuracy from which meaningful strain measurements can be obtained from these gages, a temperature compensation resistor should be used in the bridge completion network. The temperature compensation resistor should be of such a value as to produce a minimum apparent strain over the temperature range of primary interest. In most instances, this will be in the vicinity of the maximum temperature. The statistical information included in this report may be used to obtain an estimate of the gage-to-gage variations in apparent strain, gage factor, and drift, on the basis of the confidence and tolerance limits. In the absence of any other information, the mean value curves may be used as a basis for correcting the "raw" measured strains. However, it is recommended, prior to commencement of a test program of any magnitude, that all the gages be procured well in advance of the time the test is to get underway, and that a sufficient number of samples be taken from that lot of gages and evaluated to determine the strain gage parameters for the particular time-temperature histories in question. This will require evaluating a minimum sample of $10 \%$ of the gages required for the test, but in no case less than 4 to 6 gages. The evaluation should, of course, be performed with gages attached to test bars of material similar to that of the test article.

Because of the relatively long gage length of this gage, the gage should not be used in locations having sharp gradients, unless "averaged" strain values are acceptable. Otherwise, a gage of shorter gage length will have to be used in

NAA-SR - 12118 
conjunction with the Microdot gage, to determine the extent of averaging over the gage length. This shorter gage need not necessarily have a service life comparable to that of the Microdot gage. It is further recommended that, whenever possible, the test be planned so that the important strain measurements be taken as soon as possible, to insure maximum accuracy and reliable gage performance. If this is not possible, gages should be used in replica at all critical locations, space permitting.

The Microdot gage is not suitable for strain measurements at $1200^{\circ} \mathrm{F}$, except for very brief periods of less than 10 to $15 \mathrm{hr}$ duration.

Best performance of the Microdot gage can be achieved by stabilizing the gages at $1200^{\circ} \mathrm{F}$ for a period of time not less than $16 \mathrm{hr}$. For gages with integral leads, the user should consult the manufacturer for the optimum stabilization temperature. The user should also require the manufacturer to provide integrally leaded gages that have a minimum resistance to ground at $900^{\circ} \mathrm{F}$ of at least $5 \mathrm{M} \Omega$, to insure reliable gage performance.

The BLH gage, while having a short gage length and other advantages, is not recommended for applications where it is bonded to austenitic stainless steels or materials having a coefficient of expansion comparable to that of stainless steel, if the heating rate is in excess of $5^{\circ} \mathrm{F} / \mathrm{sec}$ and the temperatures as high as $1200^{\circ} \mathrm{F}$. Whether this gage is satisfactory below $1200^{\circ} \mathrm{F}$, when bonded to stainless steel, is not known at this time. If pilot tests, which are in progress, show the gage to have promise as a $900^{\circ} \mathrm{F}$ gage, a detailed evaluation of this gage for sodium component loop testing would appear justified, since the gage is less expensive and has a much shorter gage length than the Microdot gage.

When the corrections for apparent strain, drift, and gage factor, obtained from the mean values and tolerance limits, on the basis of evaluating a given percentage of the gages of the entire batch, are not considered accurate enough to suit the requirements of a particular test, the use of gages in replication or precalibration of each gage may be necessary. For a further discussion on this point, see Section III-C-9.

If the precalibration approach is used, the precalibration must be carried out for a period of time at temperature corresponding to the service conditions. For example, an inspection of the drift curves in Figures 39,40 , and 41 shows that

NAA-SR - 12118 
the drift rate is not constant and that, in particular, the drift rate over the first 50 to $100 \mathrm{hr}$ is by no means representative of the drift rate for periods of time in excess of $100 \mathrm{hr}$. An inspection of the information contained in this report for the other gage parameters also indicates that one cannot, in general, reliably extrapolate gage parameter information to 1000 to $3000 \mathrm{hr}$, on the basis of data obtained over much shorter periods of time. This means that, to perform a reliable gage evaluation or calibration, one must perform the evaluation or calibration over a time span corresponding to that which the gage will be subjected to in service.

There is no commercially available $1200^{\circ} \mathrm{F}$ strain gage on the market which is suitable for sodium component loop testing. Gages for use at $1200^{\circ} \mathrm{F}$ must be developed. 


\section{REFERENCES}

1. J. W. Dally and W. F. Riley, Experimental Stress Analysis, (McGraw-Hill Book Co., Inc., New York, 1965)

2. "Weldable Strain Gage Manual," Microdot Industries, Pasadena, California

3. "Wire Strain Gage Specifications," Bulletin 100-2, BLH Electronics, Waltham, Massachusetts

4. B. Ostle, Statistics in Research, (Iowa State University Press, Ames, Iowa, 1963) 